\title{
Energy metabolism during long-term storage and subsequent thermal stress in liquid preserved boar spermatozoa
}

\author{
Dissertation \\ to obtain the Ph. D. degree \\ in the International Ph. D. Program for Agricultural Sciences in Goettingen (IPAG) \\ at the Faculty of Agricultural Sciences, \\ Georg-August-University Göttingen, Germany
}

Presented by

Nguyen Thu Quynh

Born in Hanoi, Vietnam

Göttingen, September 2015 
1. Name of supervisor: Prof. Dr. Dr. Matthias Gauly

2. Name of co-supervisor: Prof. PhD. Wolfgang Holtz

Prof.Dr. Dagmar Waberski

Date of dissertation: $18^{\text {th }}$ November 2015 


\section{Table of contents}

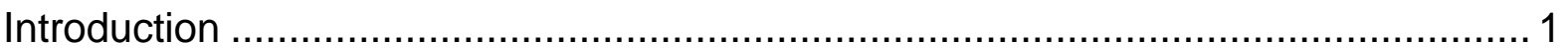

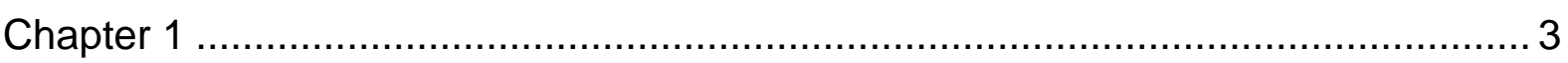

A revised protocol for efficient extraction of ATP from boar spermatozoa ................... 3

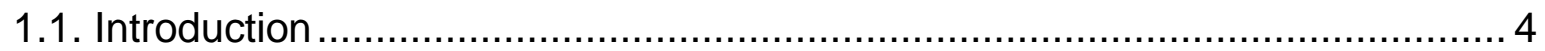

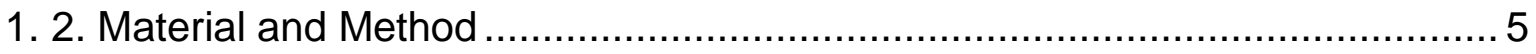

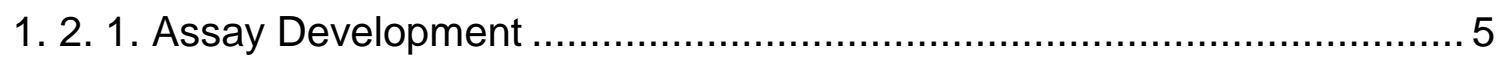

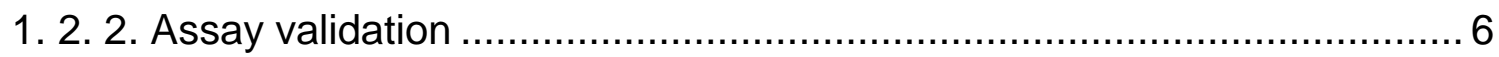

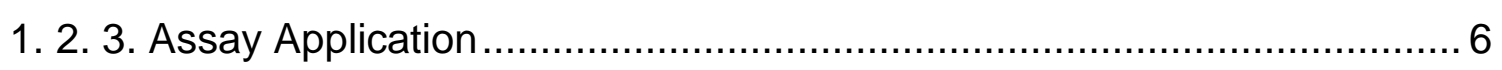

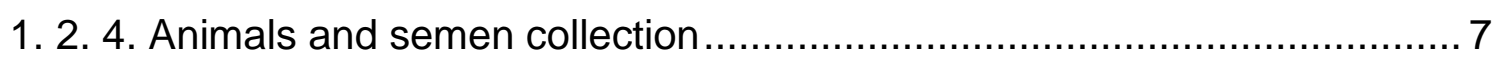

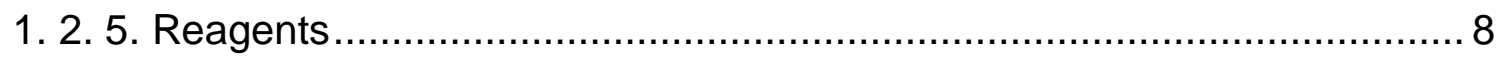

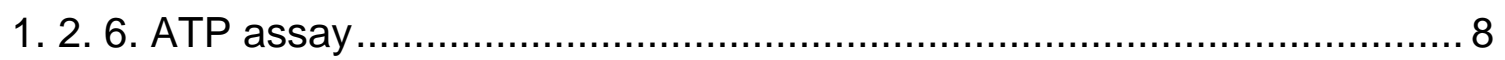

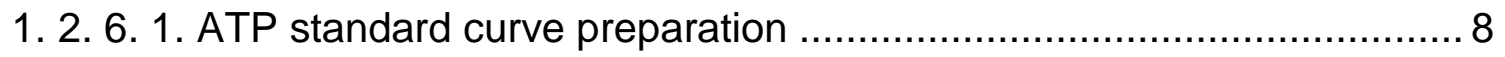

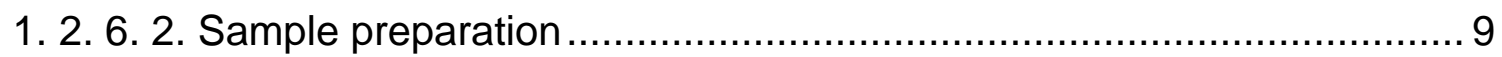

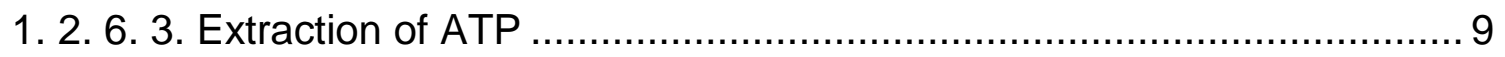

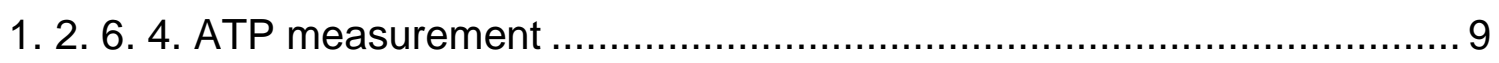

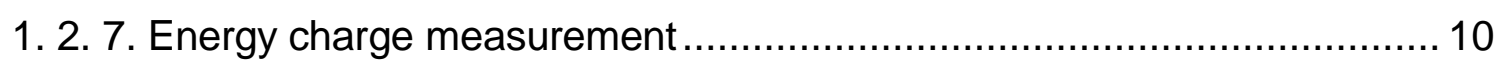

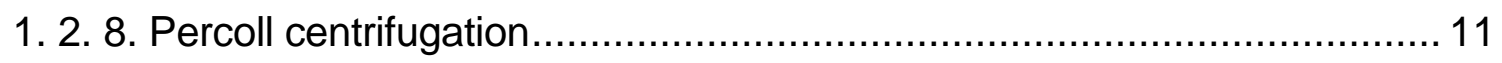

1. 2. 9. Assessment of plasma and acrosome membrane integrity.................... 11

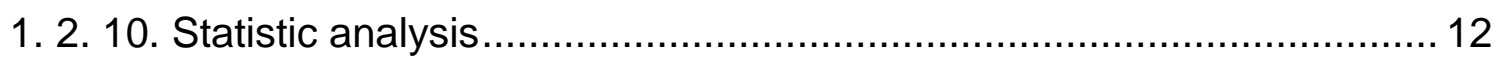

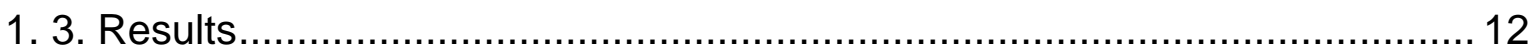

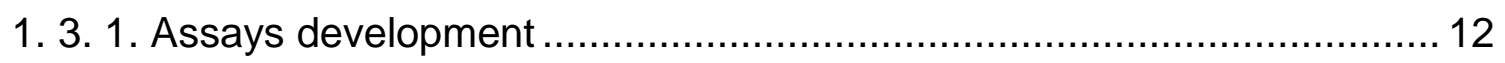

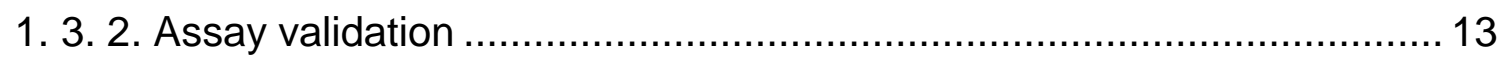

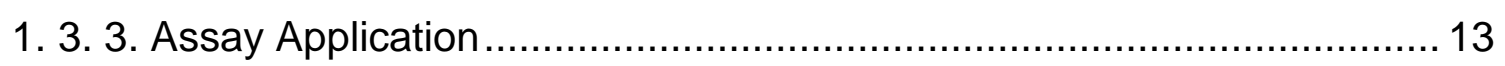

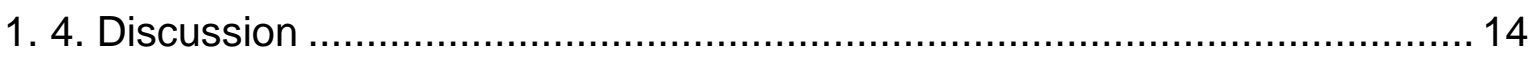

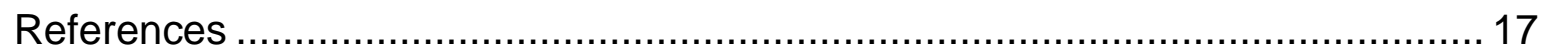

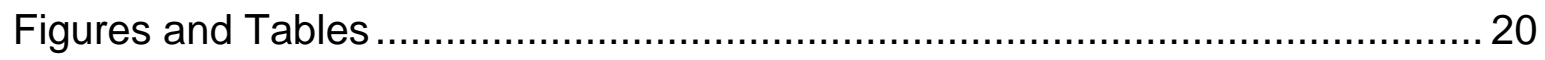

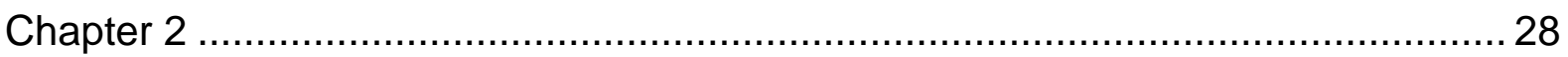

The energy status of thermically stressed boar spermatozoa after long-term storage in vitro is not dependent on high mitochondrial membrane potential...................... 28

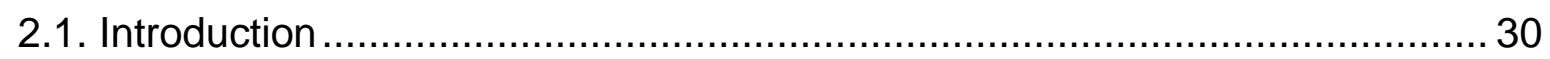

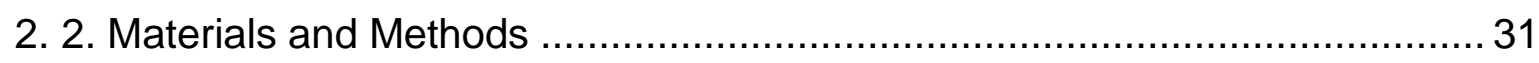

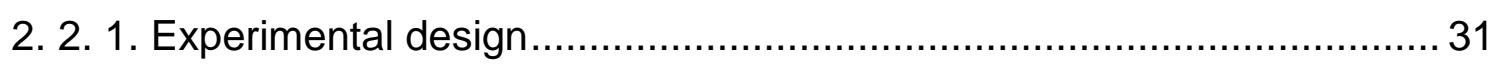

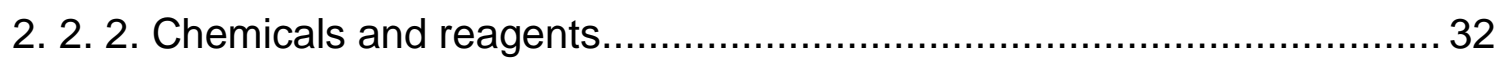

2. 2. 3. Animals, semen collection and dilution ………................................ 32 


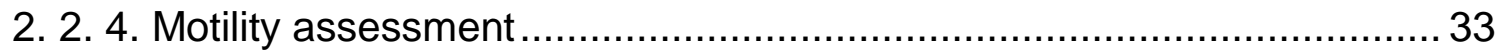

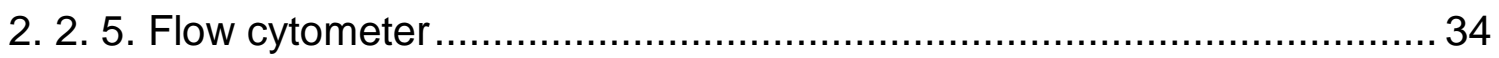

2. 2. 6. Assessment of mitochondrial transmembrane potential in live

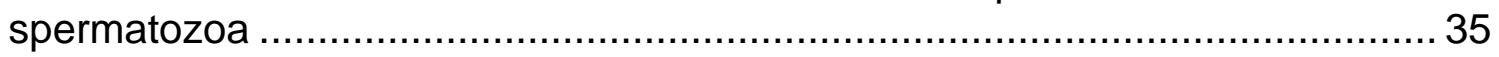

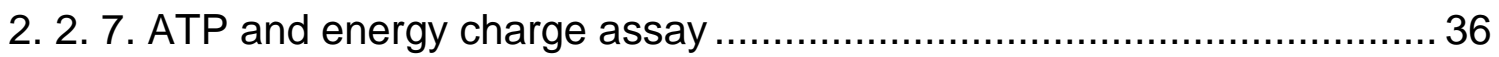

2. 2. 7. 1. Sample preparation and nucleotide extraction ............................... 36

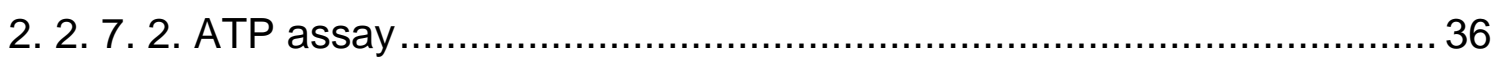

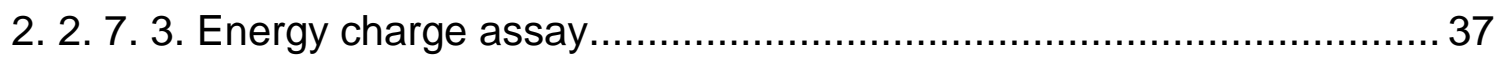

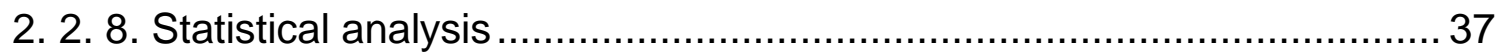

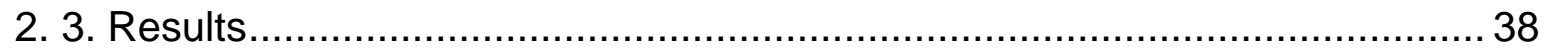

2. 3. 1. Membrane integrity, ATP content and energy charge of samples stored

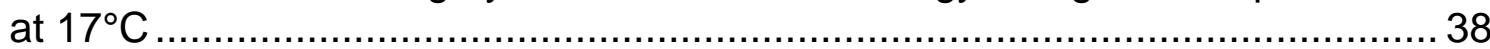

2. 3. 2. Motility parameters, membrane integrity and mitochondrial membrane

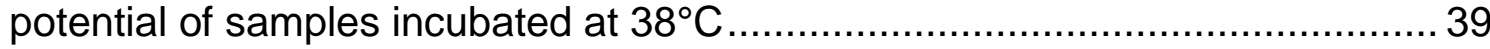

2. 3. 3. ATP content and energy charge of samples incubated at $38^{\circ} \mathrm{C}$............ 40

2. 3. 4. Relation of ATP content and energy charge in samples stored at $17^{\circ} \mathrm{C}$ with mitochondrial activity and sperm motility after incubation at $38^{\circ} \mathrm{C}$.

2. 3. 5. Relation of ATP content and energy charge in samples incubated at $38^{\circ} \mathrm{C}$ with mitochondrial activity and sperm motility .......................................... 41

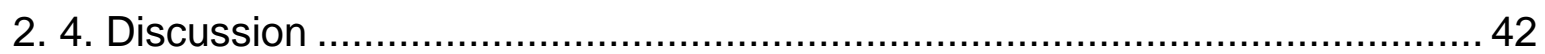

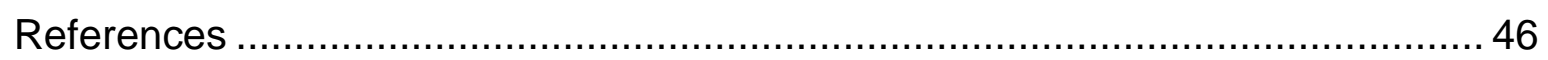

Figures and Tables

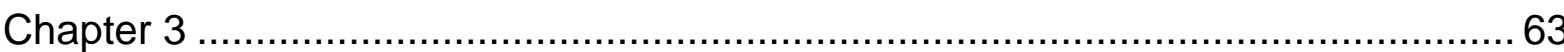

Revisiting storage temperature for liquid preserved boar semen from the perspective

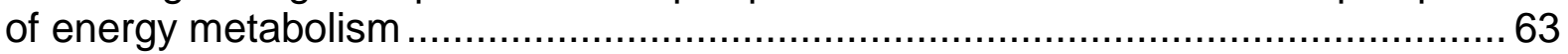

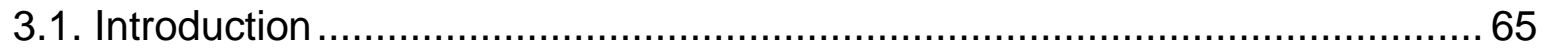

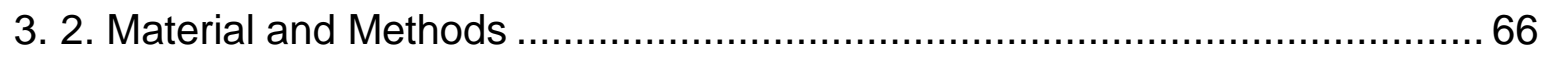

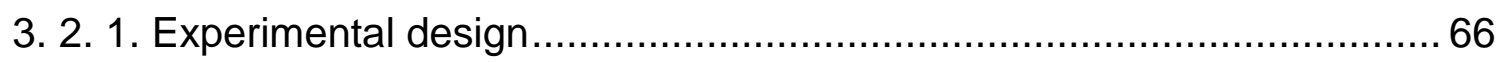

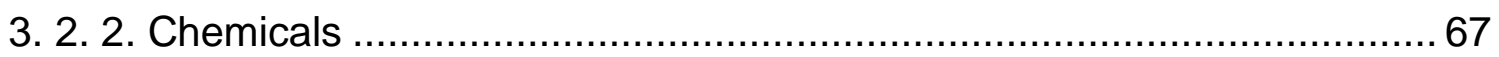

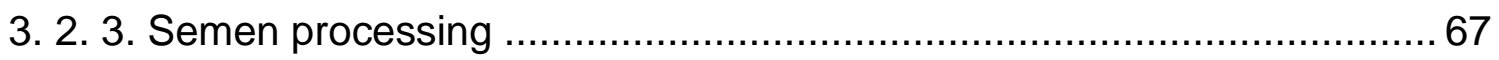

3. 2. 4. Computer-assisted semen analysis (CASA) .................................... 68

3. 2. 5. Assessment of viability and acrosome integrity ................................. 68

3. 2. 6. Assessment of mitochondrial transmembrane potential in live

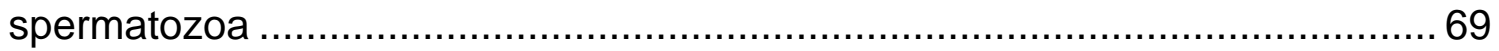

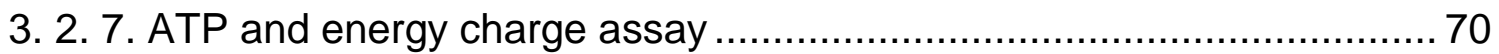

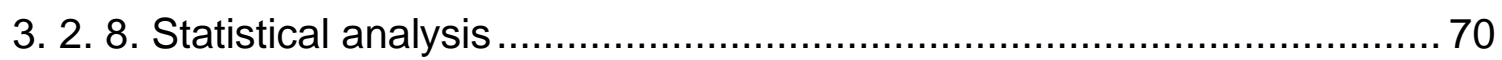

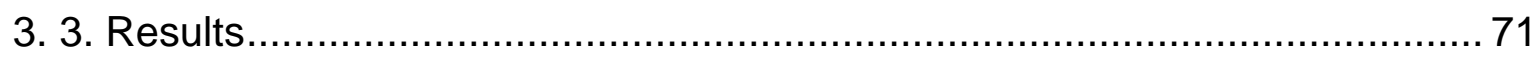

3. 3. 1. ATP content, energy charge, and membrane integrity of boar sperm at different storage temperatures 
3. 3. 2. ATP content, energy charge, mitochondrial transmembrane potential and

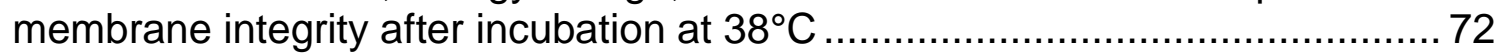

3. 3. 3. Motility of samples stored at different temperatures .......................... 74

3. 3. 4. Correlation of energy metabolism with sperm function and integrity ..... 76

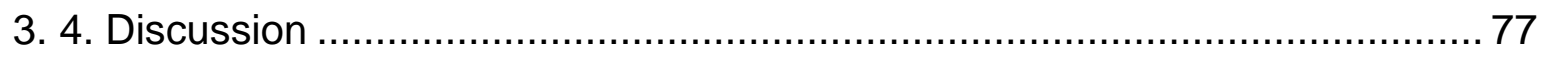

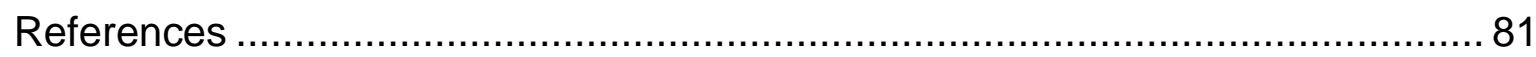

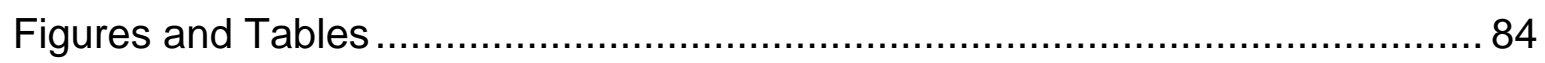

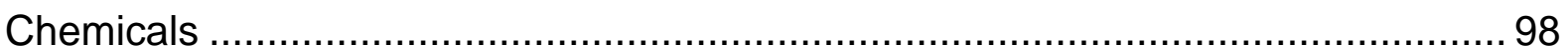

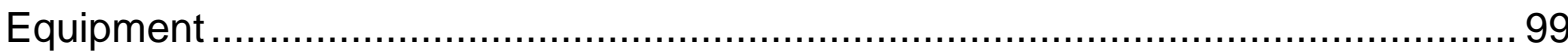

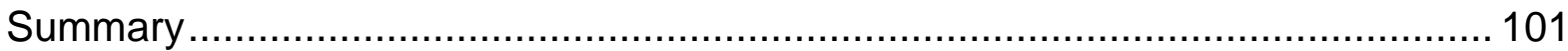

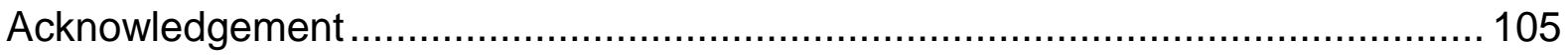

Curriculum vitae of Nguyen Thu Quynh...............Fehler! Textmarke nicht definiert. 


\section{Abbreviations}

ADP Adenosine diphosphate

AMP Adenosine monophosphate

ALH Amplitude of Lateral Head Displacement

ATP Adenosine-5'-triphosphate

BCF Beat Cross Frequency

BSA Bovine Serum Albumin

${ }^{\circ} \mathrm{C} \quad$ Grad Celsius

CASA Computer Assisted Semen Analysis

DMSO Dimethylsulfoxide

et al. et alli

EC Energy charge

EDTA Ethylendiaminetetraacetate

FITC Fluorescein isothiocyanate

Fig Figure

FL 1-3 Filter Number 1 to 3

FSC Forward scatter

g Gravitational acceleration

h Hour

HBS Hepes buffered saline 


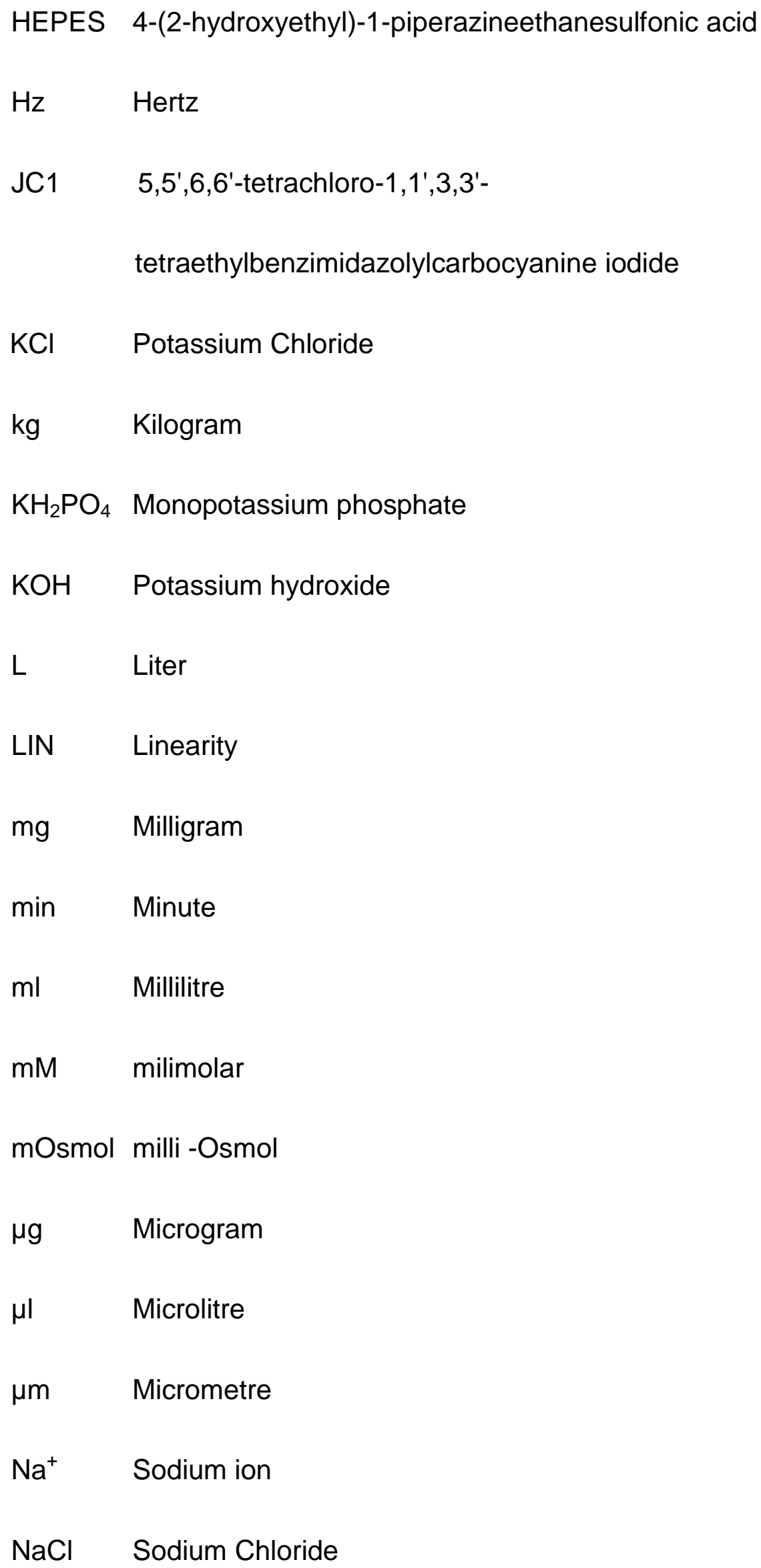


$\mathrm{NaOH}$ Sodium hydroxide

p Significance level

PI Propidium iodide

PNA Peanut agglutinin

SSC Side scatter

STR Straightness

SD Standard deviation

Tab Table

VAP Average path velocity

VCL Curvilinear velocity

VSL Straight line velocity

WOB Wobble 


\section{Introduction}

In major pork producing countries, artificial insemination is used in more than $90 \%$ of breeding sows. Maintenance of good sperm quality during semen preservation is mandatory to ensure high fertility. Boar spermatozoa are highly sensitive to cold shock, and therefore are stored in unfrozen stage. With currently marketed extenders, the ideal temperature to store liquid preserved boar semen for up to five days is between 16 and $18^{\circ} \mathrm{C}$ (Johnson et al. 2000, Riesenbeck 2011). Storage at lower temperature would be advantageous for prolonging semen shelf live, decreasing bacterial growth and slow- down of chemical reactions (Johnson et al. 2000, Schmid et al. 2013).

During hypothermic storage, sperm metabolism is suppressed to save energy for essential sperm functions on the route of fertilization. Spermatozoa specifically utilize ATP as the energy source for cellular activities such as motility, capacitation and acrosome reaction (du Plessis et al. 2015). Similarly to the situation in somatic cells, sperm function relies on a balanced level between ATP, ADP and AMP, which is expressed in the adenylate energy charge (Ford and Leach 1998). Spermatozoa are able to generate ATP through mitochondrial respiration and through glycolysis in the fibrous sheet and in the sperm head. The relevance of mitochondrial activity for ATP-production and sperm function is controversially debated and seems to vary between species (Rodriguez-Gil 2013). Depending on storage length and temperature, preservation of boar semen may cause deficits in energy metabolism and thereby affect sperm function. In the presence of metabolic substrates, activation of in hypothermically stored spermatozoa by re-warming to body temperature might partially or fully restore the energy metabolism. However, under the condition of both natural and artificial insemination, sperm need to survive in the female reproductive tract for up to $24 \mathrm{~h}$ until oocytes are released into the oviduct. It is well known that motility decreases when spermatozoa are exposed to prolonged thermal stress in vitro, particularly with a preceding longer preservation period. Whether in vitro storage and subsequent thermal stress leads to exhaustion of sperm energy metabolism and whether this is causative for the loss of motility is yet not clear. 
The aim of the present study was to examine the effect of prolonged storage at different temperatures and subsequent thermal stress on the energy metabolism and sperm quality in liquid preserved boar spermatozoa. Therefore, protocols for ATP extraction were revised to ensure sensitive and precise measurements of adenine nucleotides by the luciferin-luciferase reaction. The role of mitochondrial membrane potential for ATP production and adenylate energy charge as well as the relation between motility and energy measures were elucidated. 


\section{Chapter 1}

\section{A revised protocol for efficient extraction of ATP from boar spermatozoa}

\section{Abstract}

Mammalian spermatozoa utilize adenosine triphosphate (ATP) as energy source for key functions on the route to fertilization. ATP and its precursor nucleotides ADP and AMP are determined in many sperm physiology studies by the luciferin-luciferase reaction. Assay reliability strongly depends on the efficiency of ATP extraction and prevention of enzymatic degradation of adenine nucleotides. The aim of the present study was to develop a revised protocol for efficient ATP extraction and measurement of energy charge from diluted boar spermatozoa which yields consistently high ATP concentrations and energy charge in fresh and frozen samples. Boar semen samples diluted in BTS $(n=6)$ were incubated with phosphatase inhibitor cocktail at room temperature or on ice. Boiling for ATP extraction with or without boiling buffer, centrifugation, and subsequent ATP assessment from the supernatant was done either directly after the inhibition step (fresh) or after freezing of subsamples at $-20^{\circ} \mathrm{C}$. Both inhibition on ice and the use of a boiling buffer increased the amount of extracted ATP $(p<0.05)$. Combination of both steps resulted in the highest efficiency of ATP extraction. In fresh samples, measured ATP concentration was approximately tenfold higher when both steps were combined $(p<0.05)$. Freezing had no impact on ATP concentration compared to freshly analyzed samples when phosphatase inhibition was done on ice and a boiling buffer was used ( $p>0.05)$. ATP content of fresh and frozen samples correlated best for this treatment $(r=0.83 ; p<0.05)$. In conclusion, using a protocol with phosphatase inhibitor treatment on ice and a boiling buffer increases the efficiency of ATP extraction. Moreover, after treatment with inhibitors on ice samples can be frozen at $20^{\circ} \mathrm{C}$ for later assessment without affecting ATP content.

Keywords : ATP, energy charge, boar spermatozoa 


\subsection{Introduction}

Adenosine triphosphate (ATP) is the energy source for key functions of spermatozoa on the route to fertilization. Spermatozoa specifically utilize ATP in energy dependent cellular activities such as motility (Mukai and Okumo 2004), capacitation (Travis et al. 2001), hyperactivation, and acrosome reaction (reviewed in Du Plessis et al., 2015). Due to the essential functions for maintenance and regulation of cellular function, the determination of ATP concentration is included in many sperm physiology studies. ATP content in spermatozoa is commonly determined by bioluminescence using the firefly luciferin-luciferase assay in a wide variety of species including fish (Perchec et al. 1995), boar (Long \& Guthrie 2006), bull (Guminska 1997), domestic poultry (Wishart 1982), human (Blerkom et al. 1995). Protocols vary widely between reports and evidence for assay accuracy is often lacking. Long-term preservation experiments for several days require storing of semen samples in a frozen state for later assessment, ideally without changing the measured ATP content. In addition, the assay must allow maximum detection of intracellular ATP. Maximal detection of ATP depends on efficient phosphatase inhibition to prevent ATP degradation and an effective ATP extraction step. The immediate use of a phosphatase inhibitor cocktail containing acidic and alkaline phosphatases as well as tyrosine protein phosphatases in aqueous solution prior to ATP release was found to increase the amount of detectable ATP in sperm samples of turkey, rooster and boar (Long \& Guthrie 2006). A simple method for extraction of ATP and other nucleotides is the boiling water method. In several studies, boiling buffers were used to support lysing the cell membrane for releasing intracellular ATP and to prevent the action of ATPase or other energy-expending enzymes without interfering with the luciferin-luciferase system (Ford \& Leach 1998; Yang et al., 2002). Studies on fresh and stored boar semen using variants of the bioluminescence method report variable ATP contents ranging between 5 and 152 pmol/106 sperm (Long \& Guthrie 2006; Dziekońska \& Strzeżek 2011; Dziekońska et al. 2013) and only few studies consider the concentration of the ATP pre courser nucleotides ADP and AMP. The relative available concentrations of ATP, ADP and AMP allow the calculation of energy charge (EC) as first defined by Atkinson and Walter (1967). Surprisingly, only few information is available in literature about the EC of spermatozoa, although the EC is regarded as a more distinct indicator of the 
metabolic energy status of living cells than ATP concentrations alone (Du Toit et al. 1993).

The objective of the present study was to develop a revised protocol for efficient ATP extraction and measurement of energy charge from diluted boar spermatozoa which yields consistently high ATP concentrations and energy charge in fresh and frozen samples. Protocol revision was based on the ATP and adenylate energy charge assay from Ford and Leach (1998) and key features of the ATP quantification assay for spermatozoa of Long and Guthrie (2006). The revised bioluminescence assay was then applied to determine ATP content and energy charge in chilled boar spermatozoa with consideration of the nucleotide concentration in semen extender media.

\section{2. Material and Method}

\section{2. 1. Assay Development}

\section{Experiment 1}

Experiment 1 was based on the protocol of Long and Guthrie (2006) and had the aim to repeat two methods which have been suggested as optimal processing steps to store samples in a frozen state for later ATP assessment without affecting the ATP content. In the control procedure, diluted semen samples were treated with a phosphatase inhibitor cocktail at room temperature (RT). Thereafter, ATP was extracted from the samples and subsequently analysed with a commercial firefly luciferin-luciferase assay. In the two test treatments, either the supernatant after ATP extraction was stored for three days at $-20^{\circ} \mathrm{C}$ before thawing and use in the ATP assay; or the semen sample was frozen after treatment with phosphatase inhibitor cocktail and extraction of ATP was done post thaw. The overview on processing steps is as follows:

a. Fresh semen $->$ Inhibitor treatment at RT $\rightarrow$ ATP extraction $\rightarrow$ ATP assay (control)

b. Fresh semen $->$ Inhibitor treatment at RT $\rightarrow$ ATP extraction $->-20^{\circ} \mathrm{C}$ storage - Thawing at RT -> ATP assay 
C. Fresh semen $->$ Inhibitor treatment at RT $->-20^{\circ} \mathrm{C}$ storage $->$ ATP extraction >ATP assay

\section{Experiment 2}

Results from Experiment 1 indicated that a) ATP extraction from samples treated with inhibitor at room temperature seems to be suboptimal and that b) a small volume of the supernatant after ATP extraction is inconvenient for further processing. Therefore, the next experiment focussed on optimizing the ATP extraction procedure. A $2 \times 2$ factorial design was used to evaluate how the temperature during phosphatase inhibitor treatment (room temperature or on ice) and the use of a boiling buffer during ATP extraction a) would affect the amount of extractable ATP and b) whether the amount of extractable ATP from directly processed samples or frozen/thawed aliquots after three days storage at $-20^{\circ} \mathrm{C}$ differ.

\section{2. 2. Assay validation}

\section{Intra-day and Inter-day variation for ATP assay and Energy charge assay}

After determining optimum conditions for effective ATP extraction from boar spermatozoa, the repeatability (intra-day variation) for ATP assessments and energy charge assessments was determined. Intra-day variation was assessed by calculating the coefficient of variation for 6 different assay runs from aliquots of the same diluted semen samples. Inter-day variation was determined by comparing results of aliquots from frozen/thawed samples at different days.

\section{2. 3. Assay Application}

\section{ATP and Energy charge in spermatozoa of hypothermic stored semen samples}

Boar spermatozoa are usually preserved in the liquid state at $17^{\circ} \mathrm{C}$. During processing and storage, molecules from membrane-damaged spermatozoa may diffuse from the intracellular compartment to the medium. The presence of nucleotides in the liquid phase may be a confounding factor for the determination of ATP content and Energy charge in diluted spermatozoa. Diluted semen samples $(\mathrm{n}=6)$ were stored at $17^{\circ} \mathrm{C}$ and $5^{\circ} \mathrm{C}$ for $24 \mathrm{~h}$ and $72 \mathrm{~h}$. At each time of storage, 
extender and spermatozoa were separated by centrifugation of samples through a discontinuous Percoll ${ }^{\circledR}$ gradient with layers of $70 \%$ and $35 \%$ Percoll® working solution. While spermatozoa are enriched in the pellet of the tube, semen extender stays on top of the $35 \%$ Percoll layer. The concentration of nucleotides for calculation of the adenylate energy charge (ATP, ADP and AMP) determined from pelleted spermatozoa and from the extender. In addition, the amount of sperm with intact plasma and acrosome membrane was determined from the pellet.

After ejaculation, spermatozoa are mixed with the secretion of the accessory sex glands. For three out of six boars, also the nucleotide concentrations in semen and seminal plasma after isothermic $\left(36^{\circ} \mathrm{C}\right)$ separation on a discontinuous Percoll $\circledast$ were determined.

\section{2. 4. Animals and semen collection}

Semen was collected from a total of six healthy, mature boars (Pietrain, Germany Large White and crossbred animals) housed at Unit for Reproductive Medicine of Clinics, University of Veterinary Medicine Hannover. The ejaculates were collected by gloved hand method into disposable semen collection bags with integrated filter (Minitube, Tiefenbach, Germany), which were enclosed in insulated plastic thermos cups pre-heated to $38^{\circ} \mathrm{C}$. Immediately after collection, semen was transferred to the laboratory and isothermically $\left(33^{\circ} \mathrm{C}\right)$ diluted with Beltsville Thawing solution (BTS; Minitube). Sperm concentration was assessed by the "Thoma neu" counting chamber with phase-contrast microscope (Zeiss, Jena, Germany) at 400x magnification (ocular 10x, objective 40x, phase 2). Only normospermic ejaculates were used for the experiments i.e. ejaculates with $\geq 100 \mathrm{ml}$ volume, $\geq 160 \times 10^{6}$ sperm $/ \mathrm{ml}$ concentration, $\geq 70 \%$ motile spermatozoa, $\leq 25 \%$ morphological abnormal sperm. Diluted semen with a final concentration of $20 \times 10^{6} \mathrm{sperm} / \mathrm{ml}$ was kept at room temperature and used at the day of collection to develop and validate the ATP and EC assay. In case diluted semen was stored, samples (100 ml) were kept for $90 \mathrm{~min}$ at room temperature. Then, samples were transferred to a storage unit $\left(17^{\circ} \mathrm{C}\right)$. Cooling to $5^{\circ} \mathrm{C}$ was achieved by holding semen for $60 \mathrm{~min}$ at $17^{\circ} \mathrm{C}$, followed by $60 \mathrm{~min}$ at $10^{\circ} \mathrm{C}$ before samples were stored at $5^{\circ} \mathrm{C}$. 


\section{2. 5. Reagents}

Unless otherwise stated, chemicals were obtained from Sigma-Aldrich (Steinheim, Germany), Merck (Darmstadt, Germany), and Roth (Karlsruhe, Germany)

\section{2. 6. ATP assay}

The ATP assay can be divided into the following steps:

1) Preparation of an ATP standard curve

2) Sample preparation

3) ATP extraction

4) ATP detection with luciferin/luciferase reaction

Variations of the single steps are described in the respective sub-chapters.

\section{2. 6. 1. ATP standard curve preparation}

An ATP standard solution was prepared by dissolving the content $(1 \mathrm{mg})$ of one vial $\left(2 \times 10^{6} \mu \mathrm{mol}\right)$ of ATP standard (FLAAS, Sigma Aldrich, St.Louis, MO, USA) with 1 ml AMPUWA water (Fresenius Kabi, Bad Homburg, Germany). From this stock solution a serial dilution with concentrations of 62.5, 125, 250, 500, 1000, 2000 $\mathrm{pmol} / \mathrm{ml}$ was prepared. A standard dilution series was prepared for each day. Aliquots of the stock solution were stored at $-20^{\circ} \mathrm{C}$ until use.

A volume of $25 \mu \mathrm{l}$ of ATP standard concentrations $(62.5,125,250,500,1000$, and $2000 \mathrm{pmol}$ ATP/ml) and a blank sample (AMPUWA water) were added to the wells of a 96 wells microliter plate with white wall and clear bottom, (Greiner Bio-One, Frickenhausen, Germany). Then, the ATP assay mix solution (FLAAM, SigmaAldrich, St.Louis, MO, USA) was diluted 1:25 with dilution buffer (FLAAB, SigmaAldrich, St.Louis, MO, USA). A volume of $100 \mu$ of the diluted ATP assay mix were added to each well by using an automatic pipette (Biohit eLine E 1000, Biohit, Rosbach, Germany). The plate was briskly swirled and the amount of produced_light immediately measured with a Tecan GENios Pro plate reader (Tecan Group Ltd., Männedorf, Switzerland) controlled by "Magellan" software (Version V5.03, Tecan 
Group Ltd., Männedorf, Switzerland). All standards and blank samples were prepared and measured in duplicate.

The relative light units $(R L U)$ measured for each ATP standard concentration were subtracted from the light units obtained from the blank sample. The corrected values for the RLU are proportional to the amount of ATP in the standard samples. A linear regression between RLU and ATP concentrations was established (c.f. Figure 1 A).

\section{2. 6. 2. Sample preparation}

The effectiveness of phosphatase inhibitor cocktail in preventing ATP degradation was evaluated using whole semen (Long and Guthrie 2006). $100 \mu \mathrm{l}$ of diluted boar semen were incubated with $1 \mu \mathrm{l}$ phosphatase inhibitor cocktail (P5726, SigmaAldrich, Steinheim, Germany) at room temperature or on ice for 30 minutes. Inhibitor treatment was followed by ATP extraction, and ATP and energy charge assessment or freezing of subsamples at $-20^{\circ} \mathrm{C}$.

\section{2. 6. 3. Extraction of ATP}

After inhibitor treatment, fresh or frozen samples were boiled either with or without a boiling buffer solution (50 mM Tricine, $10 \mathrm{mM} \mathrm{MgSO}_{4}, 2 \mathrm{mM}$ EDTA, pH =7.8) for nucleotide extraction. Samples without addition of boiling buffer were directly heated for $10 \mathrm{~min}$ in a Thermomixer 5436 (Eppendorf, Hamburg, Germany). When a boiling was used, tubes containing $900 \mu \mathrm{l}$ boiling buffer were heated for $5 \mathrm{~min}$ at $95^{\circ} \mathrm{C}$ before the samples were added. After addition of samples, the mixture was heated for $10 \mathrm{~min}$ to reach $95-96^{\circ} \mathrm{C}$. After that, the tubes were chilled on ice for $10 \mathrm{~min}$ and then centrifuging at $5000 \times \mathrm{g}$ for $30 \mathrm{~min}$ at $4^{\circ} \mathrm{C}$ (Universal $30 \mathrm{RF}$, Hettich, Tuttlingen, Germany). The supernatant was used for determination of ATP and EC.

\section{2. 6. 4. ATP measurement}

A volume of $25 \mu \mathrm{l}$ of each sample was added to a well of a 96 well microliter plate. Then, $100 \mu \mathrm{l}$ of the diluted ATP reaction mix were added by an automatic pipette. The plate was swirled briskly and the amount of light produced was immediately measured. Each run of samples was accompanied by a blank sample and a standard ATP sample. All samples were prepared and analysed in duplicate. After 
correction of all RLU values for background light_as assessed by the blank sample, the standard sample was used to calculate a correction factor for each run. Light production in samples and ATP standards increases over time and any delay between start of the reaction and reading the emitted light may lead to a bias in the data (Figure $1 \mathrm{~B}$ and $1 \mathrm{C})$. The correction factor for each run was calculated by dividing the light units for the standard sample in a given run by the light units obtained during preparation of the standard curve for a given ATP concentration. The correction factor was applied to calculate the corrected value of relative light units for each sample. Relative light units were averaged for each sample and the ATP concentration determined by using the linear equation of the ATP standard curve $\left(y=a^{*} x+b\right)$, where relative light units are " $y$ " and the ATP concentration is " $x$ ".

\section{2. 7. Energy charge measurement}

The energy charge was determined by modification of procedures described by Ford and Leach (1998). The modifications are described below. Three aliquots (each 100 $\mu l)$ of the samples to be analyzed for nucleotides were incubated each with $25 \mu \mathrm{l}$ of one of three different buffers_(buffer A, buffer B, buffer $C$ ). Reaction buffer $A$ was used for determination of ATP and contained $75 \mathrm{mM}$ Tricine, $5 \mathrm{mM} \mathrm{MgCl}_{2}$ and $0.0125 \mathrm{mM} \mathrm{KCl}, \mathrm{pH}$ 7.5. Reaction buffer $\mathrm{B}$ was used for determining the combined amount of ATP and ADP. In addition to reaction buffer $A$, buffer $B$ contained $0.1 \mathrm{mM}$ phosphoenolpyruvate (P7002, Sigma-Aldrich) and $0.08 \mu \mathrm{g} / \mu \mathrm{l}$ of pyruvate kinase (Sigma P1506). Phosphoenolpyruvate and pyruvate kinase stock solutions were centrifuged for $5 \mathrm{~min}$ at $10000 \times \mathrm{g}$, the pellet diluted 1: 3 in $20 \mathrm{Mm}$ Tris and $0.1 \%$ bovine serum albumin (Sigma $\mathrm{A} 2153 \mathrm{pH}=7.5$ ) before addition to buffer $\mathrm{B}$

Phosphoenolpyruvat (PEP) reacts with ADP to form ATP. The reaction is catalysed by pyruvate kinase:

$$
\mathrm{ADP}+\mathrm{PEP} \stackrel{\text { Pyruvate kinase }}{\longrightarrow} \mathrm{ATP}+\text { Pyruvate }
$$

Tubes containing reaction mix $A$ and $B$ were incubated at $30^{\circ} \mathrm{C}$ for 30 min.

Reaction buffer $C$ was used for determining the combined amount of ATP, ADP, and AMP. In addition to reaction buffer $B$, buffer $C$ contained $0.1 \mu \mathrm{g} / \mu \mathrm{l}$ of adenylate (myo) 
kinase (Sigma M 3003). The adenylate (myo) kinase stock solution was centrifuged for $5 \mathrm{~min}$ at $10000 \times \mathrm{g}$, the pellet diluted 1: $12 \mathrm{in} 20 \mathrm{Mm}$ Tris and $0.1 \%$ bovine serum albumin, $\mathrm{pH}=7.5$ ) before addition to buffer $\mathrm{C}$. The adenylate kinase converts AMP in the sample to ADP and subsequently phosphoenolpyruvate and pyruvate kinase convert ADP to ATP.

$$
\mathrm{AMP}+\mathrm{ATP} \stackrel{\text { adenylate kinase }}{\longrightarrow} 2 \mathrm{ADP}
$$

Tubes containing reaction mix $\mathrm{C}$ were incubated at $30^{\circ} \mathrm{C}$ for $90 \mathrm{~min}$. All three tubes were boiled at $95^{\circ} \mathrm{C}$ for 3 min to stop reactions and then chilled on ice until assayed for ATP content. Measurement and calculation of the ATP content was similar to the procedure described for the ATP assay. Concentrations of ADP and AMP were obtained by subtracting the results from the appropriate measurements. The energy charge was calculated as described by Ball and Atkinson (1975) by the following formula:

$$
\text { Adenylate energy charge }(\mathrm{EC})=\frac{[\mathrm{ATP}]+0.5[\mathrm{ADP}]}{[\mathrm{ATP}]+[\mathrm{ADP}]+[\mathrm{AMP}]}
$$

\section{2. 8. Percoll centrifugation}

Aliquots of $4 \mathrm{~mL}$ extended semen stored at 5 and $17^{\circ} \mathrm{C}$ or after iso-thermic at $38^{\circ} \mathrm{C}$ for 30 min were carefully layered over the two step Percoll ${ }^{\circledR}$ gradient (35 and 70\%), and tubes were centrifuged at $300 \times g$ for $10 \mathrm{~min}$ followed by $15 \mathrm{~min}$ at $750 \times \mathrm{g}$ without stopping the centrifuge. After centrifugation, the supernatant were checked on microscope and collected for ATP and energy charge measurement. The pellet spermatozoa were gently re-suspended in BTS extender to final concentration $20 \mathrm{x}$ $10^{6} \mathrm{sperm} / \mathrm{ml}$ for determination of intact plasma and acrosome membrane, and measurement of ATP/ energy charge.

\section{2. 9. Assessment of plasma and acrosome membrane integrity}

Integrity of plasma and acrosomal membranes was assessed using a mix propidium iodide (PI)/FITC-PNA/ Hoechst staining. Briefly, aliquots of $5 \mu \mathrm{l}$ sample of diluted semen after storage at 5 an $17^{\circ} \mathrm{C}$ or from pellet after Percoll centrifugation was mixed with $980 \mu \mathrm{HBS}$ pre-incubated at $38^{\circ} \mathrm{C}$ in the incubator $(137 \mathrm{mM} \mathrm{NaCl}, 20$ 
$\mathrm{mM}$ HEPES, $10 \mathrm{mM}$ glucose, $2.5 \mathrm{mM} \mathrm{KOH}, 1 \mathrm{mg} / \mathrm{ml} \mathrm{BSA}, \mathrm{pH} 7.4$ at $20^{\circ} \mathrm{C}, 300 \pm 5$ $\mathrm{mOsmol} / \mathrm{kg}), 5 \mu \mathrm{l} \mathrm{Pl}$ stock solution $(1 \mathrm{mg} / \mathrm{ml}), 5 \mu \mathrm{FITC}-P N A$ stock solution $(600$ $\mu \mathrm{g} / \mathrm{ml}$ ) and $5 \mu \mathrm{l}$ Hoechst 33342 stock solution $(150 \mu \mathrm{g} / \mathrm{ml})$ and incubated for 5 minutes at $38^{\circ} \mathrm{C}$ in an incubator. Flow cytometric analysis of stained samples was performed on a DAKO Galaxy flow cytometer (Dako Cytomation GmbH, Hamburg, Germany), equipped with a 488-nm blue argon laser and BP 537.5/22.5, BP 590/25, LP 630-nm and BP465- nm filters for green, orange, red and blue fluorescence, respectively. The sperm population was identified by characteristic forward and side scatter distribution patterns, and fluorescence intensities (in logarithmic mode) were collected for 10,000 events per sample, at a rate of 400 to 800 events/s. Data were analyzed using FloMax software (Partec $\mathrm{GmbH}$, Münster, Germany). Correction of data for non-DNA particles was performed as proposed by Petrunkina et al. (2010).

\section{2. 10. Statistic analysis}

Analysis of data was performed using Excel (Microsoft Office 2007, Microsoft Corporation, Washington, United States) and the Statistic Analysis Software (SAS, Version 9.2, Cary, NC, USA). Data were tested for normal distribution with a Shapiro-Wilk test. In case of normal distribution data from different treatments were compared with Student's t-test. If no normal distribution could be achieved by data transformation, comparisons were done with Wilcoxon's signed-rank test. Data were correlated with Pearson correlation coefficient. All data in this study are reported as mean \pm standard deviation (SD). The significance level was set at $\mathrm{P}<0.05$.

\section{3. Results}

\section{3. 1. Assays development}

\section{Experiment 1.}

Levels of ATP in boar sperm were similar when ATP was measured of fresh samples (treatment a, 2240 pmol ATP/ $10^{6}$ spermatozoa) was the frozen-stored supernatant after ATP (treatment b, 2035 pmol ATP/ $10^{6}$ spermatozoa; Figure 2). Surprisingly, when ATP was extracted from samples that were only treated with phosphatase inhibitor before freezing (treatment $\mathrm{c}, 3185$ pmol ATP/ $10^{6}$ spermatozoa), a sharp increase in ATP levels was noted $(P<0.05)$. 
Experiment 2.

Both, inhibition on ice and the use of a boiling buffer increased the amount of extracted ATP from fresh samples ( $p<0.05$, Figure 3). A higher ATP content in both fresh and frozen samples was detected when inhibitor treatment took place on ice $(P<0.05)$. No difference in fresh analysed and frozen samples was detected when either inhibitor treatment on ice or a boiling buffer or both were used for samples preparation and ATP extraction $(P>0.05)$. The combined use of phosphatase inhibitor treatment on ice and use of a boiling buffer resulted in the highest values of detectable ATP $(P<0.05)$. ATP content of fresh and frozen samples correlated significantly $(r=0.94, P<0.01$; Figure 4).

\section{3. 2. Assay validation}

\section{Intra-day and Inter-day variation for ATP assay and Energy charge assay}

After determining optimum conditions for effective ATP extraction from boar spermatozoa, the procedure was tested for repeatability. Table 1 shows the repeatability (intra-day variation) for ATP assessments and energy charge assessments. The coefficients of variation for intra-day variation were below $10 \%$ for both, ATP assay (average: $5.7 \%$; range: 3.0 - $9.1 \%$; Table $1 \mathrm{~A}$ ) and adenylate energy charge assay (average: $4.5 \%$; range: 2.4 - 7.0\%; Table 1B). The inter-day variation for the ATP assay (average: $8.0 \%$; range: $3.6-12.3 \%$;Table 2A) and adenylate energy charge assay (average: $3.4 \%$; range: 1.7 - $4.9 \%$;Table 2B) Freezing of the samples had no impact on ATP content and results of the adenylate energy charge assay (Table $2 \mathrm{~A}$ and $2 \mathrm{~B}$ ).

\section{3. 3. Assay Application}

\section{ATP and Energy charge in spermatozoa of hypothermic stored semen samples}

The ATP concentration was higher in sperm stored at $17^{\circ} \mathrm{C}$ compared to $5^{\circ} \mathrm{C}$ $(P<0.05$; Figure 5A). Storage had no impact on the ATP and ADP concentration. The AMP concentration increased from $24 \mathrm{~h}$ until $72 \mathrm{~h}$ storage in samples held at $5^{\circ} \mathrm{C}$. The ATP concentration and energy charge, but not ADP and AMP concentration, in 
sperm were highly correlated with the percentage of sperm with intact plasma and acrosomal membrane (Table 3).

The ATP content of the isolated semen extender was negligible irrespective of storage time and temperature (Figure 5B). Almost no ADP and AMP were detectable in the supernatant of samples stored at $17^{\circ} \mathrm{C}$. On the contrary, a considerable amount of ADP (58\% of amount found in spermatozoa) was detected in the supernatant for samples stored for $24 \mathrm{~h}$ at $5^{\circ} \mathrm{C}$. The ADP concentration decreased until $72 \mathrm{~h}$ storage. The AMP concentration in the supernatant of samples at $5^{\circ} \mathrm{C}$ was more than threefold higher than the AMP concentration in sperm at $24 \mathrm{~h}$ and more than twofold higher at $72 \mathrm{~h}$ storage. The concentration of AMP in the supernatant was inversely correlated with the percentage of sperm with intact plasma and acrosomal membrane (Table 3).

There was no ATP and almost no ADP and AMP found in seminal plasma directly after collection (Table 4). The energy charge of spermatozoa ranged between 0.85 and 0.92 .

\section{4. Discussion}

A reliable method for extraction of adenine nucleotide from cells is determined by complete release of intracellular adenine nucleotides from intact cells, complete and irreversible inactivation of all adenine nucleotide converting enzymes, and no interference with enzymes used in the luciferin-luciferase assay (Lundin \& Thore 1975). In this study, a revised protocol for efficient extraction of ATP for subsequent measurement of cellular ATP and energy charge using the luciferin-luciferase reagent is presented. Modifications were based on assay protocols described by Long \& Guthrie (2006) and Ford \& Leach (1998). Key feature of the revised assay was an improved method for ATP extraction by phosphatase inhibition on ice and use of a boiling buffer. Efficient and consistent ATP extraction is considered as the most critical step for intracellular ATP measure. With the method reported here 10 to 20-fold higher ATP concentrations in boar spermatozoa were measured compared to previous reports (Long \& Guthrie 2006, Dziekońska \& Strzeżek 2011, Dziekońska et al. 2013). The improved method therefore enhanced sensitivity and could be used for samples where only smaller numbers of spermatozoa are available. Attempts to 
modify ATP extraction were triggered by the observation that freezing of samples before ATP extraction revealed higher ATP concentrations compared to fresh semen or samples frozen after ATP extraction (Exp. 1). It was assumed that freezing induced membrane disruption and thereby gave access to previously not released ATP residues. We then found that phosphate inhibition on ice as described by Guthrie et al. (2011) in striped bass spermatozoa and the use of a Tricine boiling buffer (Ford \& Leach 1998) yielded highest ATP concentration without detectable difference between fresh and frozen-stored boar semen samples (Exp. 2). Therefore, ice conditions effectively prevented ATP degradation during phosphatase inhibitor treatment. In absence of ice, degradation processes lead to at a loss of $40 \%$ detectable ATP within 15 min (Long \& Guthrie 2006). After the inhibition step, heating the sample in presence of a boiling buffer was performed to extract ATP. Previously, the tricine buffer as used in the present study was found to be the most effective buffer among the ten tested for ATP extraction and does not interfere with the luciferin-luciferase system (Webster et al. 1980). Since then the tricine buffer was used in many sperm ATP-assays of different species (Leach 1988; Ford \& Leach 1998; Ho \&Suarez 2003; Yi et al. 2008).

The present assay revealed a linear relationship between ATP standard concentration and RLU from 31 to 2000 pmol ATP (Fig 1). This contrasts with the report of Long and Guthrie (2006) that values higher than 160 pmol ATP required a $\log / \log$ transformation to achieve linearity. It is important to note that sensitivity and precision of the luciferin-luciferase assay is high (Holm-Hansen, 1978, Long \& Guthrie 2006). Consequently, sources of variation rather lay in the efficiency of ATP extraction and prevention of ATP degradation than in the luciferin-luciferase reaction. High correlations between ATP concentration of fresh and frozen-stored samples together with low intra-assay variation for both ATP and EC values (Exp. 2) demonstrate that the present method is suitable for routine assessment of cellular energy metabolism in stored samples. Application of this assay for measurement of ATP concentrations and energy charge in fresh and frozen-thawed boar semen was highly repeatable with low intra- and inter-assay variation. EC in fresh boar semen was on high level (0.9) and corresponds to EC measured in freshly ejaculated boar spermatozoa after determination of adenine nucleotides by a fluorometric enzymatic assay (Kamp et al. 2003). Similarly high EC levels (0.8-0.9) are considered as 
physiological in freshly ejaculated human spermatozoa (Chulavatnatol et al. 1977). It is important to note, that the presence of membrane defect sperm may influence ATP and EC values in semen samples. Leakage of adenine nucleotide through disrupted membranes in the surrounding medium may result in low ATP/ADP/AMP concentration in a membrane-defect subpopulation of cells. In fact, the present study revealed a high positive correlation between the proportion of membrane intact sperm and ATP and EC levels, respectively, whereas AMP in the supernatant was negatively correlated to the energy measures. Consequently, in samples with distinct amounts of membrane damaged cells obtained ATP and EC values will rather reflect the proportion of viable (membrane intact) cells in the sample rather than the energy status of living cells. Any determination of energy status of cells therefore should include information on the integrity of the plasma membranes. In accordance with observations of Long \&Guthrie (2006), the ATP content of seminal plasma was negligible in fresh semen samples. In the present study membrane disruption was induced by lowering the semen storage to temperature to $5^{\circ} \mathrm{C}$ (Exp.3). Under these conditions when boar spermatozoa were cooled below lipid phase transistion temperature $\left(30^{\circ}\right.$ to $10^{\circ}$, Drobnis et al., 1993, Schmid et al., 2013), increased ADP and AMP concentration were found in the extender medium regardless of the storage period. The hypothesis that cooling-induced rearrangement of lipids domains increases membrane permeability (Drobnis et al. 1993) and thus leads to leakage of intracellular nucleotids through disintegrated membranes was confirmed. The lower intracellular ATP concentrations in samples stored at $5^{\circ} \mathrm{C}$ may partially result from loss of precursor nucleotides AMP and ADP and partially from impaired activity of ATP generating enzymes. Noteworthy, cooled semen samples were incubated at $38^{\circ}$ for $15 \mathrm{~min}$ to reactivate temperature-dependent enzyme activity before samples for adenine nucleotides were taken. Thus additionally other, temperature-independent anabolic energy metabolic pathways may got affected by cooling-induced rearrangement of lipids domains.

In conclusion, a revised protocol for efficient and highly repeatable ATP extraction in boar spermatozoa is presented which allows freezing of samples at $-20^{\circ} \mathrm{C}$ prior to the luciferin-luciferase reaction without affecting the ATP content and energy charge. The application of the revised ATP assay is recommended to study energy metabolism in boar spermatozoa, particularly when only low sperm number are 
available or samples need to be stored for later assessment. In any case cell membrane integrity of the original semen sample should be considered to avoid misleading data interpretation.

\section{References}

1. Atkinson DE, Walton GM (1967) Adenosine triphosphate conservation in metabolic regulation. Rat liver citrate cleavage enzyme. J. Biol. Chem. 242: 3239-3241.

2. Blerkom JV, Davis PW, and John L (1995). ATP content of human oocytes and developmental potential and outcome after in-vitro fertilization and embryo transfer. Human Reproduction 10: 415- 424.

3. Chulavatnatol M, Haesungchatern A (1977) Stabilization of adenylate energy charge and its relation to human sperm motility. J Bio Chemistry 252: 8088- 8091

4. Drobnis EZ, Crowe LM, Berger T, Anchordoguy TJ, Overstreet JW, Crowe JH. (1993) Cold shock damage is due to lipid phase transitions in cell membranes: a demonstration using sperm as a model. J Exp Zool 265, 432-437.

5. Du Plessis SS, Agarwal A, Mohanty G, Van Der Linde M (2015) Oxidative phosphorylation versus glycolysis: what fuel do spermatozoa use?Asian J Androl 17(2):230- 235

6. Du Toit D, Bornman MS, Van Der Merwe MP. , Du Plessis DJ, Oosthuizen JM (1993) Differential sperm motility scoring and sperm ATP concentrations. Andrology 30: 69- 71.

7. Dziekońska A, Fraser L, Strzeżek J (2009) Effect of different storage temperatures on the metabolic activity of spermatozoa following liquid storage of boar semen. J. Anim Feed Sci 18: 638- 649.

8. Dziekońska A, Strzeżek J (2011) Boar variability affects sperm metabolism activity in liquid stored semen at 5०. Pol J Vet Sci 14:21- 27.

9. Dziekońska A, Fraser L, Majewska A, Lecewicz M, Zasiadczyk L, Kordan W (2013) Effect of commercial long- term extenders on metabolic activity and membrane integrity of boar spermatozoa stored at $17^{\circ} \mathrm{C}$. Pol J Vet Sci 16: 517525.

10. Ford SR, Leach FR (1998). Bioluminescent assay of the adenylate energy charge. Method Mol Biol 102: 69- 81. 
11. Guminska M, Kedryna T, Laszczka A, Godlewski M, Slawinski J, Fabianczyk B S, Kwiecinska T, Rajfur Z, Wierzuchowska D (1977) Changes ATP level and ironinduced ultra- weak photon emission in bull spermatozoa, caused by membrane peroxidation during thermal stress. Quaterly 44: 131- 138.

12. Ho H C, Suarez S S (2003) Characterization of the intracellular calcium store at the base of the sperm flagellum that regulates hyperactivated motility. Bio Repro 68: 1590- 1596.

13. Holm- Hansen O, Karl D M (1978) Biomass and adenylate energy charge determination in microbial cell extracts and environmental samples. Methods Enzymol 57: 73- 85.

14.Kamp G, Busselmann G, Jones,B.Wiesner N, Lauterwein J (2003) Energy metabolism and intracellular $\mathrm{pH}$ in boar spermatozoa. Reproduction 126: 517525.

15. Long J. A, Guthrie H.D (2006) Validation of a rapid, large-scale assay to quantify ATP concentration in spermatozoa. Theriogenology 65: 1620- 1630.

16. Mukai C, Okumo M (2004) Glycolysis plays a major role for adenosine triphosphate supplementation in mouse sperm flagellar movement. Biol Reprod 71: $540-547$.

17. Parks JE, Lynch DV. (1992) Lipid composition and thermotropic phase behavior of boar, bull, stallion, and rooster sperm membranes. Cryobiology 29, 255-266.

18. Perchec G, Jeulin C, Cosson J, Andre F, Billard R (1995) Relationship between sperm ATP content and motility of carp spermatozoa. Cell Science 108: 747-753.

19. Schmid S., H. Henning, H. Oldenhof, W. F. Wolkers, A. Petrunkina, and D. Waberski (2013). The specific response to capacitating stimuli is a sensitive indicator of chilling injury in hypothermically stored boar spermatozoa. Andrology $1: 376-386$

20. Travis AJ, Jorgez CJ, Merdiushew T, Jones BH, Dess DM, Diaz- Cueto L, Storey BT, Kopf GS, Moss SB (2001) Functional relationships between capacitation dependent cell signalling and compart-metitalized metabolic pathways in murine spermatozoa. J Bio Chem 276: 7630-7636

21. Webster JJ, Chang J, Manley ER, Spivey HO, Leach FR (1980) Buffer effects on ATP analysis by firefly luciferase. Analytical Biochemistry 106: 7- 11 
22. Wishar G J (1982) Maintenance of ATP concentrations in and of fertilizing ability of fowl and turkey spermatozoa in vitro. J. Reprod. Fert 66: 457- 462

23. Yang NC, Ho WM, Chen YH, Hu ML (2002) A convenient one step extraction of cellular ATP using boiling water for luciferin- luciferase assay of ATP. Analytical Bio Chem 306: 323- 327.

24. Yi YJ, Li ZH, Kim ES, Song ES, Kim HB, Cong PQ, Lee JM, Park CS (2008) Comparision of motility, acrosome, viability and ATP of boar sperm with or without cold shock, resistance in liquid semen at $17^{\circ} \mathrm{C}$ and $4^{\circ} \mathrm{C}$, and frozenthawed semen. Asian- Aust. J. Anim. Sci 21: 190- 197. 
Figures and Tables
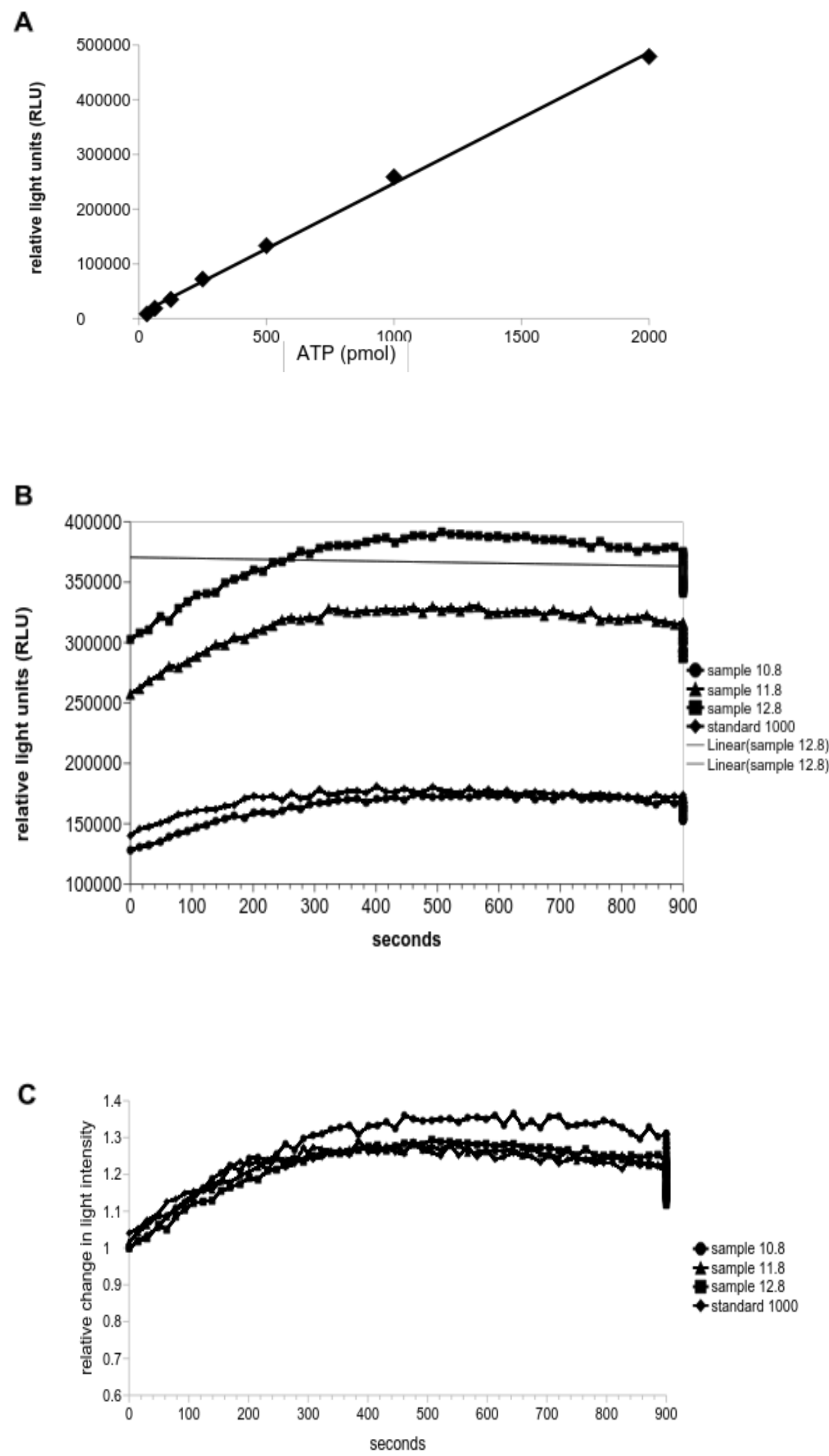
Figure 1. Example of linearity of standard curves with the linear range from 31.25 pmol to 2000 pmol ATP (A). Relative light emission of samples or standard solutions increases over a time irrespective of the initial starting values (B). Relative changes in light intensity over time are similar for samples $(10.8,11.8,12.8)$ or standard solutions (C; e.g. 1000 pmol ATP).

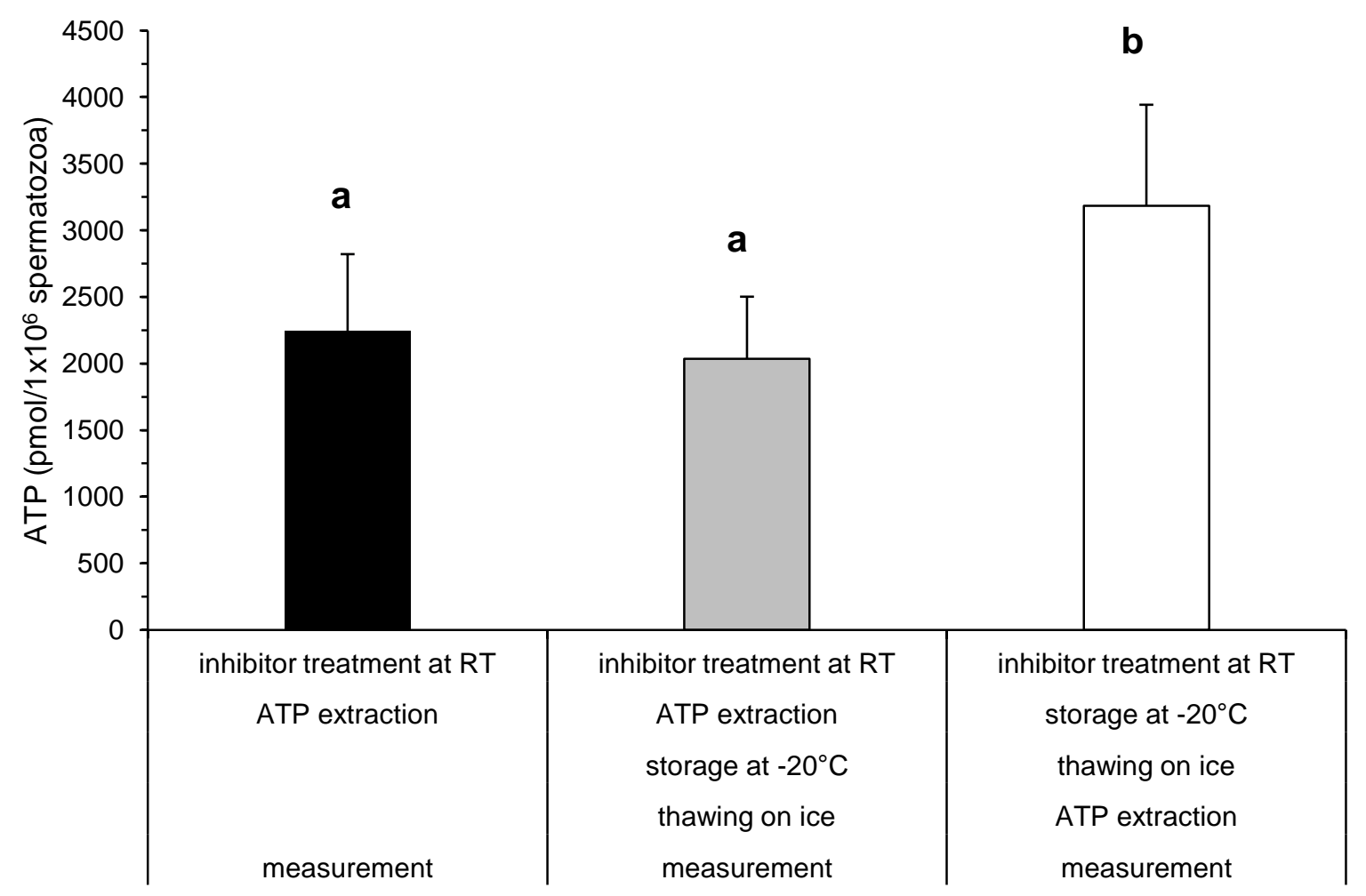

Figure 2 . Evaluation of processing variants for storing samples frozen at $-20^{\circ} \mathrm{C}$ prior to the ATP assay. Fresh semen samples was diluted in BTS extender $\left(20 \times 10^{6}\right.$ sperm/ml). Immediate processing and ATP determination (control) was compared with two different ways of processing:

(a) Inhibitor treatment at room temperature - ATP extraction - measurement (control)

(b) Inhibitor treatment at room temperature - ATP extraction - storage at $-20^{\circ} \mathrm{C}-$ thawing on ice - measurement

(c) Inhibitor treatment at room temperature - storage at $-20^{\circ} \mathrm{C}-$ thawing on ice ATP extraction - measurement

All values are mean $\pm S D(n=11)$. Different letters indicate significant differences between processing variants ( $p<0.05$, Wilcoxon signed-rank test). 


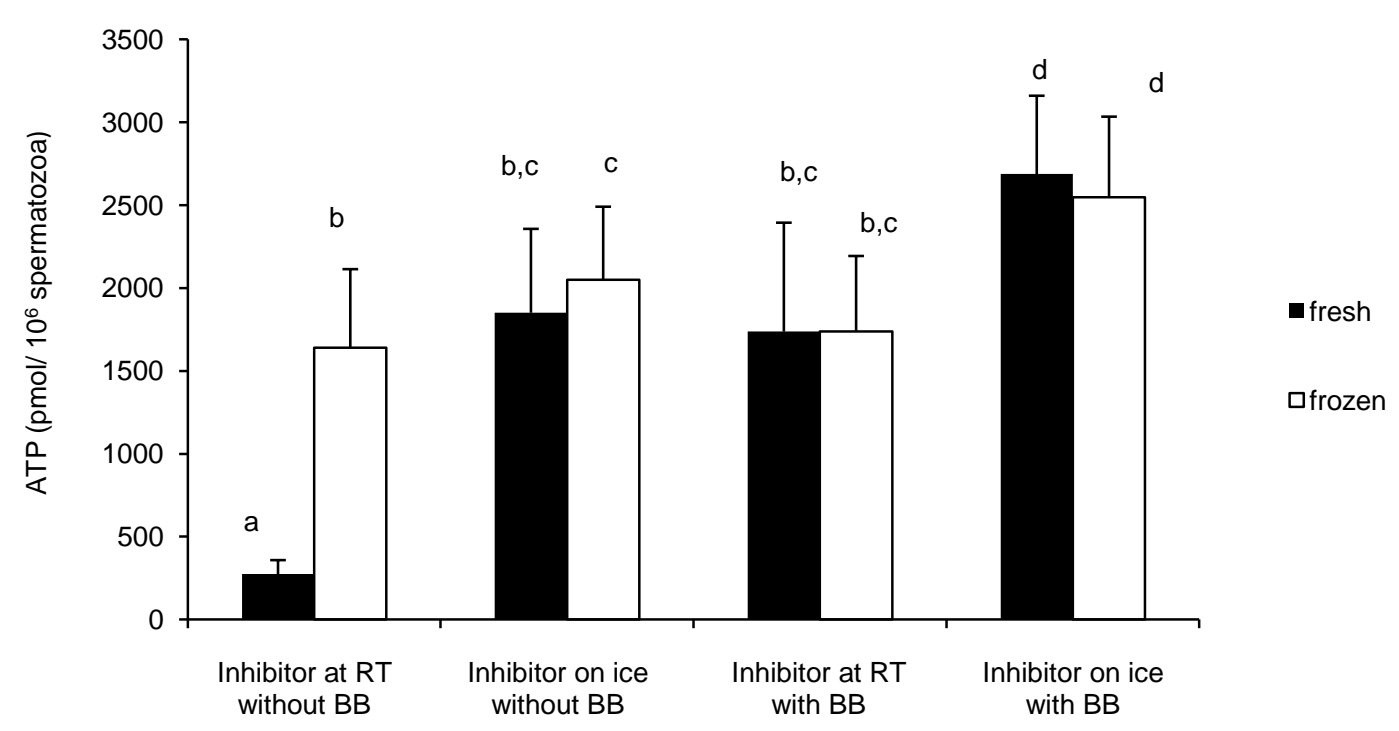

Figure 3. Comparison of different processing conditions for determination of ATP concentration in diluted boar semen samples $(n=6)$. Inhibitor treatment was either performed at room temperature or on ice. An aliquot of each sample was stored at $20^{\circ} \mathrm{C}$ (frozen) while the other part was further processed and analysed (fresh). ATP extraction in samples was performed with or without a boiling buffer. Different superscripts indicate significant differences $(p<0.05$; Student's $t$-test for paired observations).

$\mathrm{BB}=$ boiling buffer, $\mathrm{RT}=$ room temperature 


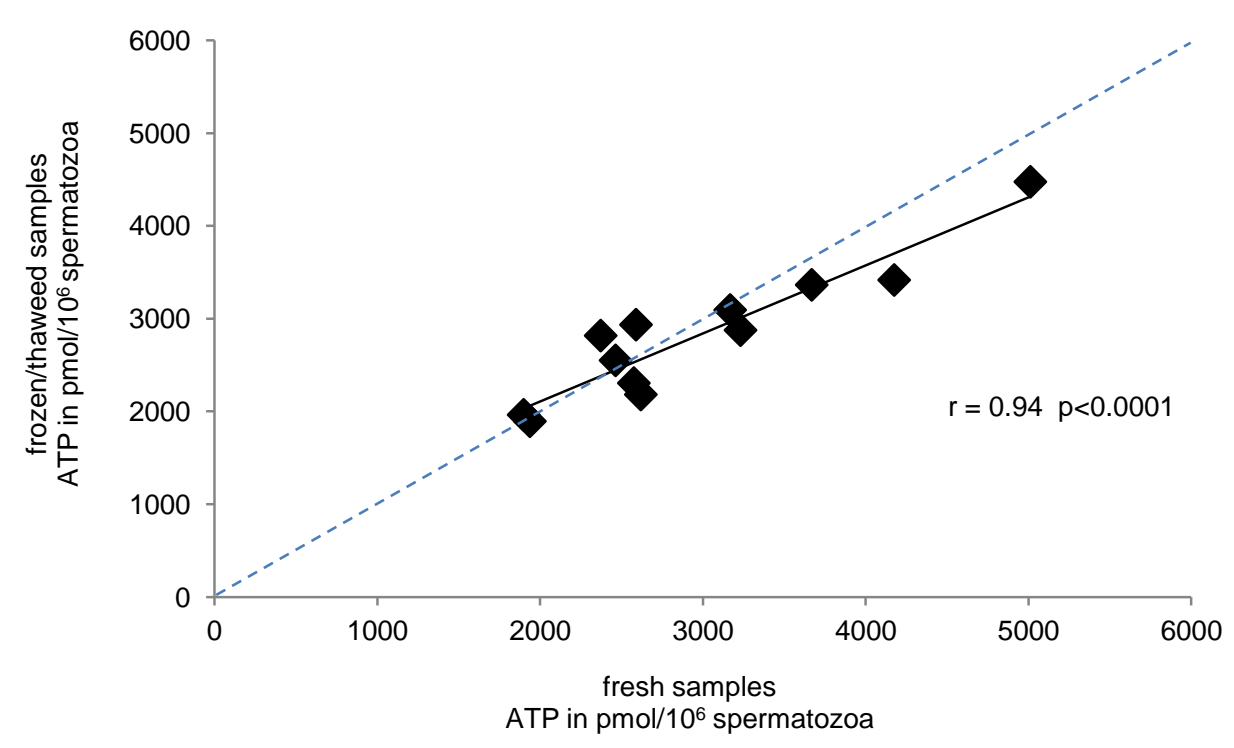

Figure 4. Correlation between the ATP concentration in directly analysed subsamples (fresh) and subsamples assessed after storage at $-20^{\circ} \mathrm{C}$ (frozen) using both inhibition on ice and boiling buffer treatment $(n=12$; Pearson's correlation coefficient). The dashed lined indicates the equation where $\mathrm{x}=\mathrm{y}$. 

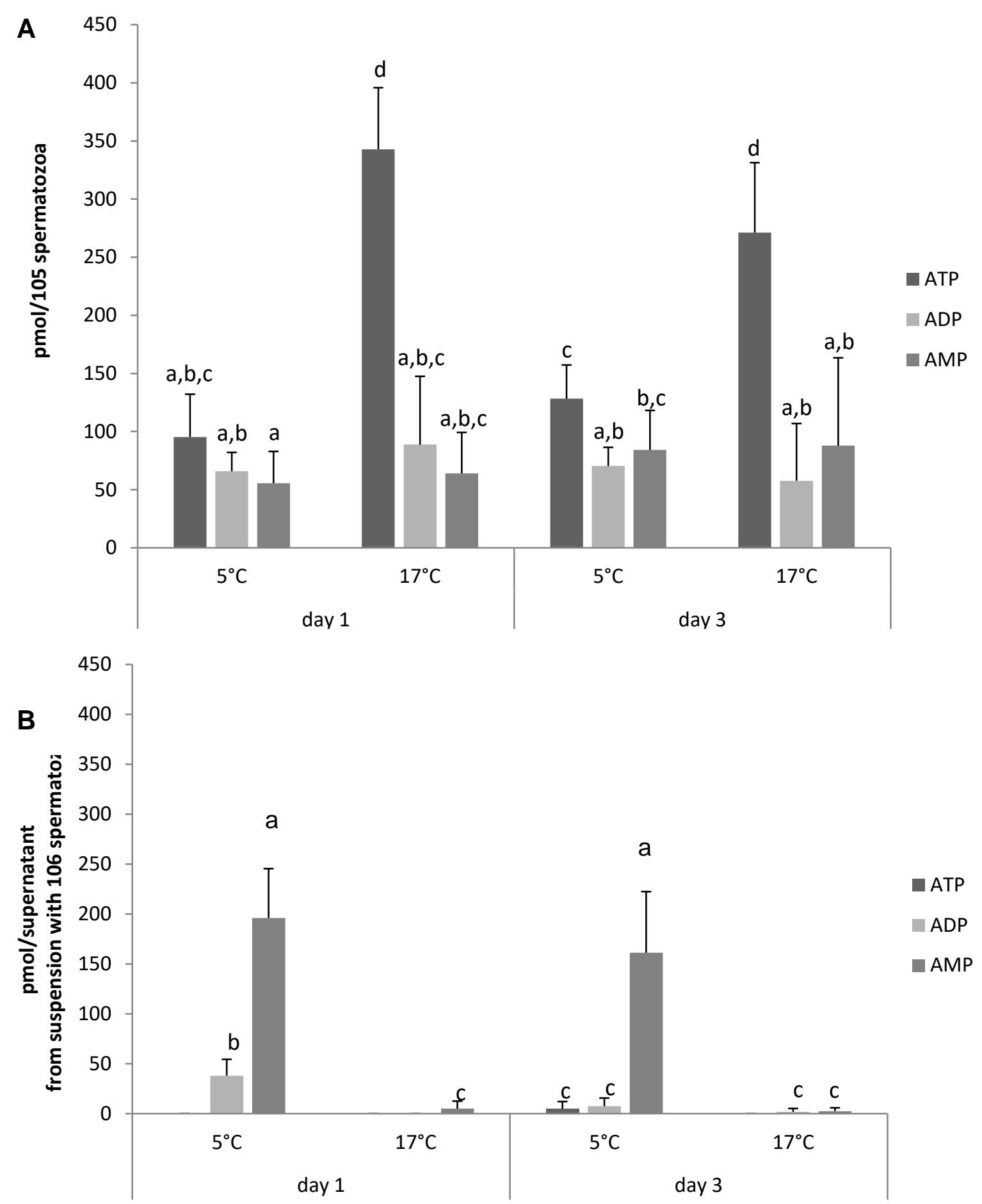

Figure 5. ATP, ADP and AMP content of boar spermatozoa (A) and medium (B) after storage at $5^{\circ} \mathrm{C}$ and $17^{\circ} \mathrm{C}(n=6)$. Boar semen was diluted in BTS extender to $20 \times 10^{6}$ sperm $/ \mathrm{ml}$ (day of dilution =day 0 ). Supernatant and spermatozoa were separated by centrifugation through a discontinuous Percoll ${ }^{\circledR}$ gradient before assessment of nucleotides. All values are mean \pm SD $(p<0.05)$. 
Table 1 Intra-Assay variation for assessment of ATP and EC in boar semen samples.

A ATP concentration ( $\mathrm{pMol} / 10^{6}$ spermatozoa)

Measurement

$\begin{array}{llllllllll}\text { Sample } & 1 & 2 & 3 & 4 & 5 & 6 & \text { Mean } & \text { SD } & \text { CV }\end{array}$

$\begin{array}{llllllllll}1 & 3630 & 3907 & 3983 & 3865 & 3931 & 4071 & 3898 & 149 & 3.8\end{array}$

$\begin{array}{llllllllll}2 & 3211 & 2885 & 3118 & 2786 & 3082 & 3151 & 3039 & 166 & 5.5\end{array}$

$\begin{array}{llllllllll}3 & 3058 & 2974 & 3143 & 3118 & 2902 & 3026 & 3037 & 90 & 3.0\end{array}$

$\begin{array}{llllllllll}4 & 2476 & 2643 & 2669 & 2743 & 3060 & 2630 & 2704 & 195 & 7.2\end{array}$

$\begin{array}{llllllllll}5 & 3983 & 3211 & 3316 & 3365 & 3230 & 3143 & 3375 & 308 & 9.1\end{array}$

Mean CV: $\quad 5.7$

B

Energy charge (EC)

Measurement

$\begin{array}{llllllllll}\text { Sample } & 1 & 2 & 3 & 4 & 5 & 6 & \text { Mean } & \text { SD } & \text { CV }\end{array}$

$\begin{array}{llllllllll}1 & 0.74 & 0.68 & 0.72 & 0.67 & 0.70 & 0.66 & 0.70 & 0.03 & 4.4\end{array}$

$\begin{array}{llllllllll}2 & 0.65 & 0.66 & 0.71 & 0.65 & 0.72 & 0.77 & 0.69 & 0.05 & 7.0\end{array}$

$\begin{array}{llllllllll}3 & 0.65 & 0.68 & 0.68 & 0.71 & 0.69 & 0.66 & 0.68 & 0.02 & 3.2\end{array}$

$\begin{array}{llllllllll}4 & 0.68 & 0.65 & 0.69 & 0.67 & 0.66 & 0.69 & 0.67 & 0.02 & 2.4\end{array}$

$\begin{array}{llllllllll}5 & 0.74 & 0.69 & 0.66 & 0.67 & 0.63 & 0.68 & 0.68 & 0.04 & 5.4\end{array}$

Mean CV: $\quad 4.5$ 
Table 2 Inter-Assay Variation in assessment of ATP and EC in fresh processed and frozen thawed boar semen samples.

$$
\text { ATP concentration (pMol/10 } 6 \text { spermatozoa) }
$$

\begin{tabular}{|c|c|c|c|c|c|c|}
\hline \multirow[b]{2}{*}{ Sample } & \multirow[b]{2}{*}{ fresh } & \multicolumn{2}{|c|}{ Frozen/thawed } & \multirow[b]{2}{*}{ mean } & \multirow[b]{2}{*}{ SD } & \multirow[b]{2}{*}{$\mathrm{CV}$} \\
\hline & & same day & 3 days later & & & \\
\hline 1 & 3988 & 3676 & 3219 & 3628 & 387 & 10.7 \\
\hline 2 & 3038 & 2894 & 2833 & 2922 & 105 & 3.6 \\
\hline 3 & 3037 & 3275 & 3566 & 3293 & 265 & 8.0 \\
\hline 4 & 2704 & 3171 & 2947 & 2941 & 234 & 8.0 \\
\hline 5 & 3375 & 2923 & 2651 & 2983 & 366 & 12.3 \\
\hline \multirow[t]{3}{*}{6} & 3143 & 2872 & 3152 & 3056 & 159 & 5.2 \\
\hline & & & & & Mean CV: & 8.0 \\
\hline & \multicolumn{3}{|c|}{ Energy charge (EC) } & & & \\
\hline
\end{tabular}

\begin{tabular}{|c|c|c|c|c|c|c|}
\hline \multirow[b]{2}{*}{ Sample } & \multirow[b]{2}{*}{ fresh } & \multicolumn{2}{|c|}{ Frozen/thawed } & \multirow[b]{2}{*}{ mean } & \multirow[b]{2}{*}{$\mathrm{SD}$} & \multirow[b]{2}{*}{ CV } \\
\hline & & same day & 3 days later & & & \\
\hline 1 & 0.70 & 0.77 & 0.72 & 0.73 & 0.04 & 4.9 \\
\hline 2 & 0.69 & 0.65 & 0.64 & 0.66 & 0.03 & 0 \\
\hline 3 & 0.68 & 0.64 & 0.68 & 0.67 & 0.02 & 5 \\
\hline 4 & 0.67 & 0.67 & 0.65 & 0.66 & 0.01 & .7 \\
\hline 5 & 0.68 & 0.64 & 0.66 & 0.66 & 0.02 & 3.0 \\
\hline 6 & 0.68 & 0.69 & 0.65 & 0.67 & 0.02 & \\
\hline
\end{tabular}

Mean CV: $\quad 3.4$ 
Table 3 Pearson correlation coefficients between the percentage of sperm with intact plasma and acrosomal membrane and the amount of ATP, ADP and AMP per $10^{6}$ sperm. Values were determined from the sperm pellet after Percoll centrifugation. Data are combined values of samples after storage at $5^{\circ} \mathrm{C}$ and $17^{\circ} \mathrm{C}$ for $24 \mathrm{~h}$ and 72 $h$, respectively $(n=24)$.

\begin{tabular}{|c|l|l|l|l|l|l|}
\hline Storage temperature & $\begin{array}{c}\text { ATP } \\
\text { pmol/10 } \\
\text { sperm }\end{array}$ & $\begin{array}{c}\text { ADP } \\
\text { pmol/10 } \\
\text { sperm }\end{array}$ & $\begin{array}{c}\text { AMP } \\
\text { pmol/10 } \\
\text { sperm }\end{array}$ & $\begin{array}{c}\text { Energy } \\
\text { charge }\end{array}$ & $\begin{array}{c}\text { AMP** } \\
\text { pmol } / 10^{6} \\
\text { sperm }\end{array}$ \\
\hline $\begin{array}{c}\% \text { PI \& PNA-FITC } \\
\text { negative }\end{array}$ & $0.90^{*}$ & 0.02 & -0.05 & $0.70^{*}$ & $-0.82^{*}$ \\
\hline
\end{tabular}

${ }^{*} p<0.001$

${ }^{* *} \mathrm{AMP}$ in supernatant 
Table 4 Nucleotide content of sperm and seminal plasma directly after collection.

\begin{tabular}{|c|c|c|c|c|c|c|}
\hline & & $\begin{array}{c}\text { ATP } \\
\text { pmol/10 } 6 \\
\text { sperm }\end{array}$ & $\begin{array}{c}\text { ADP } \\
\text { pmol/10 } \\
\text { sperm }\end{array}$ & $\begin{array}{c}\text { AMP } \\
\text { pmol/10 } 6 \\
\text { sperm }\end{array}$ & $\begin{array}{c}\text { Total } \\
\text { nucleotide } \\
\text { content } \\
\text { pmol } / 10^{6} \\
\text { sperm }\end{array}$ & $\begin{array}{l}\text { Energy } \\
\text { charge }\end{array}$ \\
\hline \multirow{3}{*}{$\begin{array}{l}\text { Seminal } \\
\text { plasma }\end{array}$} & Boar 1 & 0 & 0 & 20.9 & 20.9 & \\
\hline & Boar 2 & 0 & 0 & 0.0 & 0 & \\
\hline & Boar 3 & 0 & 4.3 & 37.2 & 41.5 & \\
\hline \multirow[t]{3}{*}{ Sperm } & Boar 1 & 938.5 & 112.6 & 34.8 & 1086.0 & 0.92 \\
\hline & Boar 2 & 952.7 & 180.4 & 45.7 & 1178.9 & 0.88 \\
\hline & Boar 3 & 625.2 & 20.9 & 98.1 & 744.3 & 0.85 \\
\hline
\end{tabular}




\section{Chapter 2}

\section{The energy status of thermically stressed boar spermatozoa after long-term storage in vitro is not dependent on high mitochondrial membrane potential}

\section{Abstract}

A variety of ATP dependent processes are required to maintain the functional integrity of spermatozoa. The aim of the present study was to investigate the impact of a long-term storage and subsequent thermal stress on the cellular ATP level and adenylate energy charge (AEC) of extended boar spermatozoa. Metabolic energy data were related to mitochondrial membrane potential (MMP) of live sperm as assessed by flow cytometry using the JC-1/PI assay and to sperm kinematics evaluated by computer-assisted semen analysis (CASA). Ejaculates of seven boars were diluted in Beltsville Thawing Solution, cooled to $17^{\circ} \mathrm{C}$ and stored for 24,72 , 120 , and $168 \mathrm{~h}$. At each time point, samples were analyzed before and after 15, 30, 60,120 , and $180 \mathrm{~min}$ incubation at $38^{\circ} \mathrm{C}$. High levels of motile and membrane intact sperm, ATP content and EC were maintained throughout semen storage. ATP levels and $A E C$ of spermatozoa during incubation at $38^{\circ} \mathrm{C}$ were significantly affected by storage length and incubation time $(\mathrm{P}<0.05)$. ATP content and total motility of sperm declined moderately and earliest after 60 min incubation $(P<0.05)$, while the percentage of live sperm with high MMP decreased dramatically already after $30 \mathrm{~min}$ of incubation at $38^{\circ} \mathrm{C}(\mathrm{P}<0.05)$. Concomitantly with the decrease of MMP, motility patterns changed from an activated to a steady state pattern. ATP values of samples stored at $17^{\circ} \mathrm{C}$ decreased during incubation for $15 \mathrm{~min}$ at $38^{\circ} \mathrm{C}(\mathrm{P}<0.05)$. With ongoing storage time the relative difference between ATP levels before and after incubation increased (day 0: 7.1, day 5: $24.2 \mathrm{pmol} / 10^{5}$ sperm, $\mathrm{P}<0.05$ ) indicating an increasing relative expense of ATP to regain a functional (motile) state during rewarming. Total motility correlated moderately with the ATP content $(r=0.48, P<0.05)$ and low to moderate to \% live sperm with high MMP $(r=0.38, P<0.05)$. In conclusion, energy reserves in liquid preserved boar spermatozoa remain stable during prolonged storage at $17^{\circ} \mathrm{C}$, though the contribution of oxidative phosphorylation in mitochondria seems to be rapid and only short-term compared to 
glycolysis. The transitory increase in ATP levels yield by mitochondrial activity is associated with motility activation. Moreover, the storage-associated increase of the ATP expense of energy for reactivation of motility indicates that ATP dependent cell functions become increasingly vulnerable during semen storage.

Keywords: energy metabolism, boar spermatozoa, semen storage 


\subsection{Introduction}

The storage of boar spermatozoa in the liquid state at temperatures between $+15^{\circ} \mathrm{C}$ and $+18^{\circ} \mathrm{C}$ is the most common way to preserve the male gametes from this species (Johnson et al. 2000). Semen samples can be stored more than three days with none or only a minor reduction of motility and plasma membrane integrity (Henning et al 2012; Schmid et al. 2013). However, data from insemination trials in vivo suggest that the fertilizing ability is already reduced within 48 of storage (Waberski et al. 1994, Haugan et al. 2005). Elucidating the underlying cause for a reduced fertility already in the first days of storage although standard parameters are indicating high quality has been as consistent challenge. The assessment of dynamic regulatory processes such as calcium influx under capacitating conditions has indicated that the cellular function is gradually impaired the longer samples are stored (Henning et al. 2012). Many complex regulated cell functions, such as calcium homeostasis, capacitation, hyper-activation or volume regulation, are partly dependent ATP processes (reviewed by Miki 2007, Suarez 2008). Therefore, deficits in ATP levels or energy charge may at least be co-factors that contribute to an impaired sperm function.

Somatic cells and spermatozoa rely on balanced levels of ATP, ADP and AMP which is expressed in the adenylate energy charge (Ford and Leach 1998). Chilling of cells or spermatozoa below body temperature reduces all metabolic activities, and consequently, also the generation and consumption of ATP decline. Whether this leads to imbalances in the energy charge of the spermatozoa is not clear. Earlier studies report conflicting results on ATP levels in stored boar semen. While ATP levels of density gradient selected spermatozoa did not change during storage over five days (Long \& Guthrie 2006), other studies found that storage at $17^{\circ} \mathrm{C}$ leads to a decrease in ATP values over time (Fraser et al. 2002, Yi et al. 2008, Gogol et al. 2009, Dziekonska et al. 2013). It is yet unknown to which extent rewarming to body temperature and ongoing thermal stress affect energy metabolism of sperm following long-term storage. The relevance of mitochondrial activity for ATP levels and sperm function is controversially debated. Spermatozoa are able to generate ATP through oxidative phosphorylation in the mitochondria and through glycolysis at the fibrous sheath and in the sperm head (Rodriguez-Gil 2013). Positive 
correlations between motility, mitochondrial function and ATP levels in fresh boar spermatozoa suggest a certain dependency on mitochondrial activity (Fraser et al. 2002). On the other hand, results from mouse models suggest that glycolysis and not oxidative phosphorylation is the major source of ATP production and indispensable for sperm motility (Miki et al. 2004).

By employing recently refined protocols for assessment of ATP levels and EC in pig spermatozoa (Nguyen et al., unpublished) we sought to shed new light on the relation of mitochondrial activity, energy balance and sperm function, i.e. motility, during liquid preservation and subsequent thermal stress. The aim was to test whether prolonged storage of liquid preserved semen leads to deficits in energy metabolism of boar spermatozoa already at storage temperature or after subsequent rewarming to body temperature for up to three hours. Effects of storage at $17^{\circ} \mathrm{C}$ and subsequent incubation at $38^{\circ} \mathrm{C}$ on mitochondrial membrane potential, ATP levels and energy charge were evaluated. Changes in overall motility and sperm movement patterns were assessed as these parameters may be impaired by deficits in available ATP or a decrease in energy charge.

\section{2. Materials and Methods}

\section{2. 1. Experimental design}

Boar semen samples $(n=7)$ were diluted to a sperm concentration of $20 \times 10^{6}$ sperm/ml in Beltsville Thawing Solution (BTS, Minitube, Tiefenbach, Germany) and stored at $17^{\circ} \mathrm{C}$. Day of semen collection and dilution was designated day 0 . Samples were evaluated on day $0,1,3,5$, and 7 of storage, respectively. ATP concentration, adenylate energy charge (EC), and the amount of sperm with intact plasma and acrosome membrane were assessed in stored samples and after 15, 30, 60, 120, and $180 \mathrm{~min}$ incubation at $38^{\circ} \mathrm{C}$. The percentage of live sperm with high mitochondrial transmembrane potential and motility parameters as assessed by computer assisted semen analysis (CASA) were determined only in samples incubated at $38^{\circ} \mathrm{C}$. 


\section{2. 2. Chemicals and reagents}

All chemicals were of analytical grade. Propidium iodide (PI) was from Sigma Aldrich (Steinheim, Germany), peanut agglutinin conjugated to fluorescein-isothiocyanate (PNA-FITC) and 5,5',6,6'-tetrachloro-1,1',3,3'-tetraethylbenzimidazolylcarbocyanine iodide (JC-1) was obtained from Enzo Life Sciences (Lörrach, Germany). Hoechst 33342 (H342) was purchased from life technologies (Darmstadt, Germany).

\section{2. 3. Animals, semen collection and dilution}

Semen was obtained from seven mature, clinically healthy boars (Pietrain, German Large White and crossbred animal) housed at the Unit for Reproductive Medicine of Clinics, University of Veterinary Medicine Hannover.

One full ejaculate from each boar was collected by the 'gloved hand' method into disposable semen collection bags with an integrated filter (Minitube, Tiefenbach, Germany) to remove the gel fraction. Collection bags were enclosed in insulated plastic thermos cups pre-heated to $38^{\circ} \mathrm{C}$. Immediately after collection, semen was transported to the laboratory in Styrofoam boxes. Sperm concentration was assessed with a hemocytometer chamber ('Thoma neu'). Motility of raw semen was estimated with a phase-contrast microscope (Zeiss, Jena, Germany) at 160x magnification (ocular 10x, objective 16x, phase 1). The morphology of 200 spermatozoa was assessed after liquid fixation of $50 \mu \mathrm{l}$ raw semen in $300 \mu \mathrm{l}$ fixation buffer (10 mM citric acid in aqua dest. with $4 \%$ formalin $(\mathrm{v} / \mathrm{v})$ ) using phase contrast microscopy (x1000, oil immersion). Spermatozoa were classified according to a simplified scheme based on morphology classifications proposed by Waberski et al 1990. In case of multiple defects per cell only the most severe abnormality was considered. The hierarchy for severity of sperm defects was: 1) Duplicate sperm parts (e.g. two tails), 2) loose heads, 3) acrosome abnormalities (e.g. detached acrosome), 4) head abnormalities (e.g. tapered head), 5) abnormalities in the neck, mid-piece, principal and end piece (e.g. bent tails), and 6) cytoplasmic droplets. Only spermatozoa whose entire outline was visible were considered in the assessment.

Only normospermic ejaculates were used for the experiments, i.e. ejaculates with $\geq$ $100 \mathrm{ml}$ volume, $\geq 160 \times 10^{6}$ sperm $/ \mathrm{ml}$ concentration, $\geq 70 \%$ motile spermatozoa, $\leq 25$ 
$\%$ morphological abnormal sperm. Semen was diluted isothermically $\left(33^{\circ} \mathrm{C}\right)$ in a onestep procedure with Beltsville Thawing Solution (BTS; Minitube, Germany) to a final concentration of $20 \times 10^{6}$ cells per $\mathrm{mL}$. After dilution, semen samples were kept at room temperature for $1.5 \mathrm{~h}$ and subsequently stored at $17^{\circ} \mathrm{C}$.

\section{2. 4. Motility assessment}

An aliquot of $2 \mathrm{ml}$ diluted semen was transferred into a $10 \mathrm{ml}$ tube and incubated in a water bath at $38^{\circ} \mathrm{C}$. After 15, 30, 60, 120 and $180 \mathrm{~min}$, respectively, an aliquot (3 $\left.\mu \mathrm{l}\right)$ was loaded into one chamber of a pre-warmed $\left(38^{\circ} \mathrm{C}\right)$ four-chamber slide (Leja, Nieuw Vennep, The Netherlands) with a chamber depth of $20 \mu \mathrm{m}$ for analysis. At the same time, an aliquot of each semen sample $(100 \mu \mathrm{l})$ was processed for assessment of ATP concentration and energy charge.

The sperm motility parameters were determined by a computer-assisted semen analysis (CASA) system (SpermVision ${ }^{\circledR}$, Minitube, Tiefenbach, Germany). The microscope (BX41TF, Olympus, Hamburg, Germany) was equipped with a 20 fold objective, a camera adapter (U-TV0,63XC, Olympus, Hamburg, Germany), and a camera with a resolution of $648 \times 484$ pixels (Accu Pixel TM 6760CL, JAI A/S Glostrup, Denmark). The system was operated by Sperm Vision ${ }^{\circledR}$ software (Version 3.7, Minitube, Tiefenbach, Germany). For each sample, 10 successive fields in the central axis of a chamber were recorded at a rate of 30 pictures per 0.5 second per field.

The following parameters were considered: total motility (TM; \%), progressive motility (PM; \%), average path velocity (VAP, $\mu \mathrm{m} / \mathrm{s})$, curvilinear velocity $(\mathrm{VCL}, \mu \mathrm{m} / \mathrm{s})$, straight-line velocity $(\mathrm{VSL} ; \mu \mathrm{m} / \mathrm{s})$, straightness $(\mathrm{STR}=\mathrm{VSL} / \mathrm{VAP})$, linearity $(\mathrm{LIN}=$ VSL/VCL), wobble (WOB = VAP/VCL), amplitude of lateral head-displacement $(A L H$; $\mu \mathrm{m})$, and beat cross frequency (BCF; Hz). Spermatozoa were defined by a head area between $23 \mu \mathrm{m}^{2}$ and $120 \mu \mathrm{m}^{2}$. A spermatozoon was considered to be motile when its average head orientation change (AOC) was higher than $2.5^{\circ}$, and considered to be progressively motile when the distance moved from $A$ to $B$ in $a$ straight line (VSL) exceeded $4.5 \mu \mathrm{m}$. 


\section{2. 5. Flow cytometer}

All measurements were performed on a DAKO "Galaxy" flow cytometer (DAKO, Hamburg, Germany) controlled by "FloMax ${ }^{\circledR "}$ software (version 2.8, Partec, Münster, Germany). It was equipped with an argon ion laser (488 nm, $20 \mathrm{~mW}$ ) and an HBOlamp for excitation of the dyes. HBO excitation spectrum was restricted with filters to wavelengths between $270 \mathrm{~nm}$ and $405 \mathrm{~nm}$ (main peak: $365 \mathrm{~nm}$ ). Filters for detection of emitted fluorescent light were FL-1 $(537.5 / 22.5 \mathrm{~nm})$ for green, FL-2 $(590 / 25 \mathrm{~nm})$ for orange, FL-3 (630 nm LP) for red and FL-4 (465 nm BP) for blue fluorescent light. A HEPES-buffered saline solution (HBS; $137 \mathrm{mM} \mathrm{NaCl}, 20 \mathrm{mM}$ HEPES, $10 \mathrm{mM}$ glucose, $2.5 \mathrm{mM} \mathrm{KOH}, 1 \mathrm{mg} / \mathrm{ml} \mathrm{BSA}, \mathrm{pH} 7.40 \pm 0.05,300 \pm 5 \mathrm{mOsmol} / \mathrm{kg}$ ) was used as sheath buffer.

\section{Integrity of the plasma and acrosome membrane}

In parallel to motility assessments, another aliquot of $2 \mathrm{ml}$ diluted semen was incubated in a water bath at $38^{\circ} \mathrm{C}$. After $10,25,55,115$ and $175 \mathrm{~min}$, an aliquot of diluted semen $(5 \mu \mathrm{l})$ was mixed with $980 \mu \mathrm{l}$ pre-warmed HBS $\left(38^{\circ} \mathrm{C}\right), 5 \mu \mathrm{l} \mathrm{PI}$ stock solution $(1 \mathrm{mg} / \mathrm{ml}), 5 \mu \mathrm{l}$ PNA-FITC stock solution $(600 \mu \mathrm{g} / \mathrm{ml}), 5 \mu \mathrm{l}$ Hoechst 33342 stock solution $(150 \mu \mathrm{g} / \mathrm{ml})$, and incubated for further 5 minutes at $38^{\circ} \mathrm{C}$ before assessment on the flow cytometer. For assessment of stored samples, an aliquot of semen was directly transferred to the pre-warmed HBS, stained, and analysed after 5 min incubation at $38^{\circ} \mathrm{C}$. Data from 10,000 events were collected for each samples. The overlap of the emission spectra from PI and PNA-FITC was mathematical compensated post acquisition.

Hoechst 33342 was used to the stain the chromatin of all DNA-containing particles in the samples. This enabled the distinction between cellular debris (H342 negative) and the DNA-containing cells (H342 positive), i.e. predominantly spermatozoa as verified by microscopy in channel FL-4. For data evaluation, a logical gate defined the DNA containing events (H342 positive) with a forward scatter signal in the size range of a single spermatozoon. Events fitting in this gate were considered for further evaluation. Propidium iodide, detected in FL-3, was used to differentiate between spermatozoa with intact plasma membrane ( $\mathrm{PI}$ negative) and damaged plasma membrane (PI positive). Peanut agglutinin conjugated to fluorescein 
isothiocyanate (PNA-FITC) is a peanut lectin which has high specificity for binding to Gal- $\beta(1-3)$-GalNAc structures. In boar spermatozoa, it binds to the inner leaflet of the outer acrosomal membrane (Flesch et al. 1998). The emitted green fluorescence (channel FL-1) allowed to distinguish between sperm with intact (PNA-FITC negative) and defective outer acrosomal membrane (PNA-FITC positive). For statistical evaluation, the percentage of spermatozoa with intact plasma and acrosome membrane was determined (PI \& PNA-FITC negative).

\section{2. 6. Assessment of mitochondrial transmembrane potential in live spermatozoa}

The principle of this measurement is based on the properties of the dye 5,5',6,6'tetrachloro-1,1',3,3'-tetraethylbenzimidazolylcarbocyanine iodide (JC-1). Depending on the electrochemical gradient of the mitochondrial membrane, JC-1 reversibly transforms from a green fluorescent monomer (low transmembrane potential; emission peak approx. $529 \mathrm{~nm}$ ) to an aggregated form emitting orange to red fluorescence (high transmembrane potential; emission peak approx. $590 \mathrm{~nm}$ ). An additional staining with $\mathrm{PI}$ allowed differentiation of live and dead spermatozoa.

Five sub-samples of semen from each boar $\left(1 \mathrm{ml}\right.$ each) were incubated at $38^{\circ} \mathrm{C}$ in a water bath for 15, 30, 60, 120, and $180 \mathrm{~min}$, respectively. Fifteen minutes before assessment, $1 \mu \mathrm{l} \mathrm{JC-1}$ stock solution (1.53 mM), $10 \mu \mathrm{l}$ Hoechst 33342 stock solution $(150 \mu \mathrm{g} / \mathrm{ml})$, and $20 \mu \mathrm{l} \mathrm{Pl}$ stock solution $(1 \mathrm{mg} / \mathrm{ml})$ were added to $1 \mathrm{ml}$ diluted semen. For assessment, $5 \mu \mathrm{l}$ of the stained sample were transferred to $995 \mu \mathrm{l}$ pre-warmed HBS $\left(38^{\circ} \mathrm{C}\right)$. In each measurement, 10,000 events were collected.

Spermatozoa were defined as Hoechst 33342 positive in the size range of single spermatozoa. Analysis was further restricted to live, i.e. PI-negative, spermatozoa. The percentage of live spermatozoa with high mitochondrial membrane potential was estimated by plotting signals from channel FL-1 (green) vs channel FL-2 (orange). The threshold between high and low mitochondrial membrane potential was defined for samples after 15 min incubation time (day 0) and kept constant throughout the experiment. The average fluorescence intensity for JC-1 aggregates (arithmetic mean) in live sperm was calculated from data in the FL-2 channel. Compensation 
between $\mathrm{PI}$ and JC-1 spectral overlap was adjusted at the beginning of the experiment.

\section{2. 7. ATP and energy charge assay}

\section{2. 7. 1. Sample preparation and nucleotide extraction}

ATP content and adenylate energy charge (EC) in spermatozoa were determined by recently described methods from Nguyen et al. (unpublished). The protocols are based on modifications of assays described by Ford and Leach (1998) and Long and Guthrie (2006). In short, $100 \mu \mathrm{l}$ of a diluted boar semen sample (stored at $17^{\circ} \mathrm{C}$ or incubated for $15,30,60,120$ and $180 \mathrm{~min}$ at $38^{\circ} \mathrm{C}$ ) were incubated with $1 \mu \mathrm{l}$ phosphatase inhibitor cocktail (P5726, Sigma-Aldrich, Steinheim, Germany) on ice for 30 minutes. After inhibitor treatment samples were stored at $-20^{\circ} \mathrm{C}$ for later ATP and EC assessment.

Extraction of sperm adenylate nucleotides (ATP, ADP, AMP) was achieved by treating the frozen samples with $900 \mu \mathrm{l}$ pre-heated boiling buffer solution $(50 \mathrm{mM}$ Tricine, $10 \mathrm{mM} \mathrm{MgSO}_{4}$ and $2 \mathrm{mM}$ EDTA, $\mathrm{pH}$ 7.80) and boiling for 10 minutes at $95^{\circ} \mathrm{C}$. Subsequently, samples were chilled on ice for 10 minutes and centrifuged at $5,000 \mathrm{~g}$ for 30 minutes at $4^{\circ} \mathrm{C}$. The supernatant was used for determination of ATP, ADP, and AMP.

\section{2. 7. 2. ATP assay}

ATP was determined using a luciferase reaction kit according to the manufacturer's protocol (FL-AA kit, Sigma-Aldrich, Steinheim, Germany). Bioluminescence was measured with Tecan GENios Pro plate reader (Tecan Group Ltd., Männedorf, Switzerland) controlled by "Magellan" software (Version V5.03, Tecan Group Ltd., Männedorf, Switzerland). Light emission was calibrated using standard solution of ATP and ATP content in spermatozoa was calculated from an ATP standard curve (Nguyen et al., unpublished). 


\section{2. 7. 3. Energy charge assay}

Aliquots $100 \mu \mathrm{l}$ of the samples to be analyzed or nucleotides was incubated with 25 $\mu \mathrm{l}$ of three different buffers. Buffer A contained $75 \mathrm{mM}$ Tricine, $5 \mathrm{mM} \mathrm{MgCl} 2$ and $0.0125 \mathrm{mM} \mathrm{KCl}(\mathrm{pH}$ 7.5) for determination of ATP. Buffer $B$ contained in addition to buffer A, $0.1 \mathrm{mM}$ phosphoenolpyruvate (P7002, Sigma- Aldrich, Steinheim, Germany) and $0.08 \mu \mathrm{g} / \mu \mathrm{l}$ of pyruvate kinase. Buffer $B$ was used for conversion of $A D P$ to ATP. Tubes containing buffer $A$ and $B$ were incubated at $30^{\circ} \mathrm{C}$ for $30 \mathrm{~min}$. Buffer $C$, contained in addition to buffer $B, 0.1 \mu \mathrm{g} / \mu \mathrm{l}$ of adenylate (myo) kinase (M3003, Sigma-Aldrich, Steinheim, Germany). Adenylate (myo) kinase converts AMP to ADP. Samples incubated with buffer $C$ were used for combined assessment of ATP, ADP, and AMP, respectively. Tubes containing buffer $C$ were incubated at $30^{\circ} \mathrm{C}$ for $90 \mathrm{~min}$. Pre-heated boiling buffer was added to all tubes at $95^{\circ} \mathrm{C}$ for $3 \mathrm{~min}$ to stop the enzymatic reactions. Samples were then chilled on ice and processed for assessment of the total amount of ATP. The energy charge was calculated as describe by Ball and Atkinson (1975); c.f. Nguyen et al. (unpublished).

\section{2. 8. Statistical analysis}

Data were analyzed with using Excel (Microsoft Office 2010, Microsoft Corporation, Washington, USA) and Statistical Analysis Software (SAS, version 9.3, Cary, NC, USA). Data from all parameters were assumed to be normal distributed. Data after incubation of samples for $15 \mathrm{~min}$ to $180 \mathrm{~min}$ at $38^{\circ} \mathrm{C}$ were analyzed with a twofactorial analysis of variance (ANOVA) for repeated measurements to estimate the influence of storage time at $17^{\circ} \mathrm{C}$ and incubation time at $38^{\circ} \mathrm{C}$. Pair-wise comparisons were done with Student's t-test for paired samples. Data that were directly obtained from samples stored at $17^{\circ} \mathrm{C}$ (ATP content, EC and amount of live, acrosome intact sperm) were compared between different days of storage with Student's t-test for paired samples. Pearson correlation coefficients were calculated for selected parameters. The significance level was set at $P<0.05$. 


\section{3. Results}

\section{3. 1. Membrane integrity, ATP content and energy charge of samples stored at $17^{\circ} \mathrm{C}$}

The amount of sperm with intact plasma and acrosomal membrane was at day 5 $(90.7 \pm 2.35 \%)$ and day $7(89.0 \pm 3.11 \%)$ marginally, but significantly lower when compared to day 0 or day 1 (Table $1 ; \mathrm{P}<0.05$ ). A drop in ATP levels and EC was detectable between day of dilution (day $0 ; 438.5 \pm 21.4 \mathrm{pMol} / 105 \mathrm{sperm}$ ) and day 1 $\left(384.52 \pm 14.0 \mathrm{pMol} / 10^{5}\right.$ sperm; $\left.\mathrm{P}<0.05\right)$. However, the ATP concentration on day 3 to day 7 was similar to day 0 (Table 1). Concomitant with the ATP concentration, the EC was also lower on day $1(0.70 \pm 0.07)$ when compared to day $0(0.78 \pm 0.05)$. The EC remained on the same level as on day 1 throughout the storage period (Table 1).

In general, ATP levels in semen samples held at $17^{\circ} \mathrm{C}$ were higher when compared to ATP levels after incubation at $38^{\circ} \mathrm{C}(P<0.05)$. Only exceptions were at the day of dilution (day 0 ) after $15 \mathrm{~min}$ incubation and at day 7 after $30 \mathrm{~min}$ incubation. At both times, ATP concentrations in semen at $17^{\circ} \mathrm{C}$ and at $38^{\circ} \mathrm{C}$ did not differ $(P>0.05)$.

The difference (delta) in ATP levels between stored samples and those incubated for $15 \mathrm{~min}$ at $38^{\circ} \mathrm{C}$ increased with storage length (Supplemental Figure $2 \mathrm{~A}$ ). On day 0 , the average delta was lowest $(32.3 \pm 49.3 \mathrm{pMol})$ while on day 5 it reached its maximum (112.9 $\pm 57.5 \mathrm{pMol} ; \mathrm{P}<0.05)$. For a standardized comparison, the decrease in ATP within 15 min incubation was expressed as relative change with respect to ATP concentrations in samples at $17^{\circ} \mathrm{C}$ (Supplemental Table 2B). The relative decrease in ATP demonstrates that the with prolonged storage an increasing amount of the initially available ATP is converted within the first 15 min of incubation at $38^{\circ} \mathrm{C}$ (day 0: $7.1 \pm 10.96 \%$; day 5: $24.2 \pm 10.31 \%$; $\mathrm{P}<0.05$; Supplemental Figure 2B).

Comparable to the situation for ATP levels, a higher EC was present on day 0 , day 3 , and day 7 in samples at $17^{\circ} \mathrm{C}$ than in samples after incubation at $38^{\circ} \mathrm{C}$. On day 1 and day $5, \mathrm{EC}$ at $38^{\circ} \mathrm{C}$ was similar to that of samples at $17^{\circ} \mathrm{C}$ until $60 \mathrm{~min}$ and $30 \mathrm{~min}$ 
incubation, respectively $(p>0.05)$. Thereafter, $E C$ in samples at $38^{\circ} \mathrm{C}$ was again lower when compared to samples at storage temperature $(P<0.05)$.

\section{3. 2. Motility parameters, membrane integrity and mitochondrial membrane potential of samples incubated at $38^{\circ} \mathrm{C}$}

Total motility and progressive motility were both significantly influenced by storage length and incubation time at $38^{\circ} \mathrm{C}$ (Figure 1 , Table 2). On day 0 and day 1 , incubation at $38^{\circ} \mathrm{C}$ had no significant effect on progressive motility when compared to values after 15 min incubation. A gradual decrease in progressive motility was noted on day 3 , day 5 , and day 7 , respectively, when samples were incubated for 60 to 180 minutes (Figure $1 \mathrm{~A} ; \mathrm{P}<0.05$ ). Average progressive motility was above $70 \%$ until samples were incubated on day 5 for 180 minutes. The most pronounced decrease in progressive motility occurred on day 7. Motility significantly decreased from $80.4 \pm 3.6$ (15 $\mathrm{min}$ ) to $74.0 \pm 4.0$ (60 $\mathrm{min}$ ) and finally $54.2 \pm 20.0$ (180 min; figure $1 \mathrm{~A}$; all $\mathrm{P}<0.05)$. Notably, average total motility and percentage of sperm with intact plasma and acrosome membrane (PI \& PNA-FITC negative) never dropped below $70 \%$ throughout the experiment (Table 2 and Table 3).

The average motility parameters of progressive motile spermatozoa were influenced by incubation time (except VSL) or an interaction of incubation time and storage (except VSL and BCF). Only VSL and STR were influenced by storage length. Velocity curved line (VCL), linearity (LIN) and amplitude of lateral head-displacement $(\mathrm{ALH})$ were chosen as representative parameters to illustrate the influence of prolonged incubation at body temperature on sperm motility. An overview on all parameters is given in Table 1. Changes of motility parameters after prolonged storage for 5 to 7 days became for most parameters only evident after 60 to $180 \mathrm{~min}$ incubation at $38^{\circ} \mathrm{C}$ (Table 1$)$.

On each day of storage VCL was highest after 15 min incubation (Figure 2A). On day 0 , day 1 and day 3 , VCL was lower between 30 min to $180 \mathrm{~min}$ incubation when compared to 15 min incubated samples $(P<0.05$; Figure $2 A)$. Values between 30 min and 180 min showed no consistent differences. On day 5 and day 7, as similar drop in VCL was present between 15 min and 30 min incubated samples $(P<0.05)$, but it was less prominent. Linearity (VSL/VCL) of the sperm track increased between 15 
min and 30 min incubation irrespective of previous storage length $(P<0.05$; Figure 2B). On day 1 , day 3 , and day 5 , a second rise in linearity was present between 30 $\min$ and $60 \mathrm{~min}$ of incubation (Figure 2B). Thereafter, linearity remained constant. The amplitude of lateral head-displacement (ALH) decreased step-wise during incubation on day 0 (Figure 2C). A similar decrease in ALH between 15 min (3.1 \pm $0.4 \mu \mathrm{m}), 30 \mathrm{~min}(2.4 \pm 0.4 \mu \mathrm{m})$ and $60 \mathrm{~min}$ incubation $(2.1 \pm 0.3 \mu \mathrm{m})$ was present at day 1. Values remained constant between $60 \mathrm{~min}$ and $180 \mathrm{~min}$ incubation. On day 3 , day 5 , and day 7, ALH decreased significantly between 15 and 30 min incubation $(\mathrm{P}<0.05$, Figure $2 \mathrm{C})$. Values remained constant during further incubation.

In contrast to the moderate changes observed for CASA parameters, the percentage of live sperm with high mitochondrial transmembrane potential (hMMP) declined dramatically during incubation at each day of storage (Figure 1B). After 15 min incubation, the percentage of live spermatozoa with hMMP ranged between $92.5 \%$ (day 0) and $82.5 \%$ (day 7). These values stepwise decreased to less than $40 \%$ after 60 min incubation (max: $38.9 \%$ at day 1; min: $13.5 \%$ at day 7). After 120 min incubation, the amount of live spermatozoa with hMMP was at all days of storage below $10 \%$ (max: $9.3 \%$ at day 1; min: $2.6 \%$ at day 5). After 180 min incubation, live sperm with hMMP were virtually absent in the samples (Figure 1B; Supplemental Table 1). The decline in live spermatozoa with hMMP was consistent with a general decline in fluorescence intensity for all live spermatozoa over incubation time, independent of the days of storage (Supplemental Figure 1).

\section{3. 3. ATP content and energy charge of samples incubated at $38^{\circ} \mathrm{C}$}

Both, storage time prior to incubation and duration of incubation at $38^{\circ} \mathrm{C}$, had a significant influence on the ATP content and energy charge of diluted boar spermatozoa (Figure 3A). At all days of storage, ATP levels remained at a comparable level for at least 60 min during incubation at $38^{\circ} \mathrm{C}$. A step-wise decrease was noted on day 0 and day 5, starting between $60 \mathrm{~min}$ and $120 \mathrm{~min}$ of incubation. On all other days, ATP values fluctuated, but remained comparable to those after 15 min incubation.

Values for energy charge showed a different pattern. With ongoing storage, values remained more and more stable during incubation at $38^{\circ} \mathrm{C}$ (Figure $3 \mathrm{~B}$ ). On day 0 , a 
step-wise decrease occurred between $15 \mathrm{~min}$ and $30 \mathrm{~min}$ as well as between $30 \mathrm{~min}$ and 180 min incubation $(P<0.05)$. On day 1 , values decreased between 30 and 60 min incubation and remained constant thereafter. On day 3 and day 5, EC was stable for at least $60 \mathrm{~min}$, before values decreased after $180 \mathrm{~min}$ (day 3) or $120 \mathrm{~min}$ (day 5), respectively. On day 7, values for EC fluctuated during incubation, but never were lower than the value after 15 min incubation.

ATP concentrations and EC values were compared after incubation at $38^{\circ} \mathrm{C}$ between days of storage (Supplemental Table 1). On day 1, day 5, and day 7, ATP levels were lower than on day 0 within the first $60 \mathrm{~min}$ at $38^{\circ} \mathrm{C}(P<0.05$; Supplemental Table 1). Thereafter, no systematic pattern was visible. No systematic difference between samples on day 0 and the following days of storage were detectable for EC (Supplemental Table 1)

\section{3. 4. Relation of ATP content and energy charge in samples stored at $17^{\circ} \mathrm{C}$} with mitochondrial activity and sperm motility after incubation at $38^{\circ} \mathrm{C}$

There was no significant correlation of ATP content or energy charge in samples stored at $17^{\circ} \mathrm{C}$ with motility parameters or percentage of sperm with high mitochondrial transmembrane potential after incubation at $38^{\circ} \mathrm{C}$ for $15,30,60,120$ or 180 minutes, respectively ( $n=35$; data not shown). Only exceptions were a significant correlation between ATP content at $17^{\circ} \mathrm{C}$ and total motility after incubation at $38^{\circ} \mathrm{C}$ for 30 minutes $(r=0.35, P<0.05)$ and energy charge at $17^{\circ} \mathrm{C}$ and straightness of the motility trajectory after 180 minutes incubation at $38^{\circ} \mathrm{C}(r=0.55$, $\mathrm{P}<0.001)$.

\section{3. 5. Relation of ATP content and energy charge in samples incubated at} $38^{\circ} \mathrm{C}$ with mitochondrial activity and sperm motility

The ATP content was positively related to total motility $(r=0.48)$, progressive motility $(r=0.45)$, the percentage of sperm with high MMP $(r=0.38)$ and the percentage of live, acrosome intact sperm $(r=0.29$; all $P<0.001$; all $n=175)$. Sperm velocity and other motility descriptors were not or only weakly (ALH, BCF) related to the ATP content (Table 4). 
Energy charge correlated highest with the percentage of sperm with high MMP $(r=$ $0.47)$, the percentage of live, acrosome intact sperm $(r=0.39$; both $P<0.001)$ and, to a lesser extent, with total motility $(r=0.26)$ and progressive motility $(r=0.23$; both $P<0.01$ ). Weak to moderate positive correlations existed with sperm velocity (VAP and VCL), ALH and BCF. Consequently, a weak negative correlation between EC and descriptors of the sperm trajectory (STR, LIN, WOB) were present (Table 4).

The percentage of live sperm with high MMP showed positive correlation with total motility $(r=0.43)$, progressive motility $(r=0.40)$, and the percentage of live, acrosome intact sperm $(r=0.49$; all $P<0.001)$. A high percentage of live sperm with high MMP also positively correlated with the average curvilinear velocity $(r=0.41)$, amplitude of lateral head-displacement $(r=0.46)$, and beat cross frequency in progressive motile spermatozoa $(r=0.34$; all $P<0.001)$. At the same time, a high percentage of live sperm with high MMP was negatively correlated with the linearity and straightness of the sperm trajectory, $(r=-0.59$ and $r=-0.60$; both $P<0.001)$. Similar, but weaker correlations were also observed for energy charge and motility parameters (c.f. Table 4).

\section{4. Discussion}

In the present study, boar spermatozoa were challenged in two ways. They were first held for prolonged time at $17^{\circ} \mathrm{C}$ in commonly used BTS extender medium. After hypothermic in vitro-storage, they were subjected to a prolonged incubation at $38^{\circ} \mathrm{C}$ mimicking the temperature situation after insemination. In the female reproductive tract, spermatozoa have to sustain such thermal conditions for several hours until ovulation occurs. Therefore, it is wise to include thermal stress challenges when studying metabolic activity of in vitro stored boar semen. Consistent with previous observations (Guthrie \& Welch 2005; Long \& Guthrie 2006, Henning et al. 2012. 2015), a high degree of motile and viable sperm, ATP content and EC was maintained throughout semen storage. However, sperm parameters and energy measures of stored semen changed throughout incubation at $38^{\circ} \mathrm{C}$ under aerobic conditions in presence of glucose (188 $\mathrm{mM}$ in BTS extender). Independent of storage time, a high degree of viable spermatozoa re-established a high mitochondrial transmembrane potential within $15 \mathrm{~min}$ of incubation at $38^{\circ} \mathrm{C}$. Thereafter, with ongoing incubation the proportion of these cells declined rapidly. 
Noteworthy, neither viability and overall motility, nor ATP levels and energy charge were immediately affected. Significant decreases in ATP content and energy charge, if any, were only observed after a prolonged incubation period. This observation supports the view that the contribution of oxidative phosphorylation to the total ATP pool is relatively low compared to glycolysis. Indeed, other researchers suggest that the dominant source of ATP production in boar spermatozoa in the presence of glucose is glycolysis (Marin et al. 2003). Notably, the establishment of a high mitochondrial transmembrane potential within 15 minutes of incubation was accompanied by a decrease in ATP content and (in part) EC at each storage day. This indicates that ATP consuming processes are slowed down at $17^{\circ} \mathrm{C}$ and regain effect at body temperature. Thus, re-warming of spermatozoa can be viewed as a "switch on" situation that forces the cell to regain balance between energy consumption and production. ATP levels in stored semen samples did not vary considerably during long-term storage. However, the relative expense in ATP that the cells spent to regain a functional, i.e. motile state, during rewarming increased considerably with storage length. This observation indicates that ATP-dependent cell functions get more and more vulnerable with increasing storage length due to a depletion of the ATP pool during rewarming.

The high mitochondrial transmembrane potential in plenty of spermatozoa shortly after rewarming may be indicative for a pivotal role of mitochondria in regaining motility and sperm functionality. However, mitochondria seem to have only a shortterm effect as with ongoing incubation the transmembrane potential decreases. This decrease may indicate a transition in energy metabolism from high punctual activation to steady state maintenance in vitro. Activated sperm motility, e.g. after ejaculation is characterised by a symmetrical wave pattern of the flagellum and relatively linear sperm trajectories. In contrast, hyper-activated motility is characterised by an asymmetrical beating of the sperm tail, increased curvilinear velocity, and more circular movement (Suarez et al. 1992; Kojima et al. 2015). Similar to the transition in energy metabolism, a transition in motility patterns was found in the current experiment. Spermatozoa showed a hyper-activation-like motility pattern with high curvilinear velocity, low linearity and high amplitude of lateral headdisplacement after 15 minutes incubation and switched to a slower curvilinear velocity, with a more straight swimming path less lateral head-displacement 
thereafter. As mentioned earlier, the steady state motility might be maintained predominantly be glycolysis. This hypothesis is indirectly supported by the observation that the percentage of sperm with high MMP is stronger correlated with descriptors of the sperm motility pattern than ATP levels and EC. However, motility of boar spermatozoa is not fully independent from mitochondrial activity as indicated by positive correlations with total and progressive motility. Similar rapid, transitory increases of mitochondrial activity with concomitant increase in ATP levels have been described after inducing the acrosome reaction in vitro with progesterone (Ramio-Lluch et al. 2011). Such patterns of short extra activation of mitochondria with later steady state maintenance, may provide tempero-spatial restricted extra energy supply in spermatozoa playing a pivotal role in various stages of sperm's journey in the female genital. Spermatozoa with insufficient increase in available ATP from mitochondria may fail to switch their motility pattern to a more activated motility pattern and thus may fail to actively pass the viscomucous barriers of the uterotubal junction or release from the oviductal sperm reservoir before ascending to the site of fertilization. In fact, spermatozoa bound to the oviduct epithelial cells in the sperm reservoir show a (hyper-)activated motility pattern upon release (reviewed by Suarez 2008). Such changes in motility may likewise be facilitated by spikes of mitochondrial activity to generate extra ATP.

ATP levels in this study have been assessed at the level of each individual sample. With respect to selection mechanisms in vivo, it would be interesting to know how heterogeneous single spermatozoa are with respect to their ATP content or energy charge. Recent comparisons between tail length adjusted ATP content in spermatozoa of mice breeds with different mating behaviours suggest that spermatozoa from mice breeds in which females mate with different males, i.e. sperm competition for oocyte fertilization is high, can maintain higher ATP levels over time (Tourmente et al. 2015). An extrapolation of ATP levels from a whole sample to a single spermatozoon is delicate. This would require a sample with approx. $100 \%$ viable sperm and no ATP in medium. These conditions are most closely fulfilled at day 0 after 15 minute incubation at $38^{\circ} \mathrm{C}$ with $92.2 \%$ motile and $92.4 \%$ viable sperm with high mitochondrial transmembrane potential, respectively. At that time, each spermatozoon would have an average ATP content of $4.21 \mathrm{fMol}$. 
The adenylate energy charge is regarded as a more destinct indicator of the metabolic energy status of living cells than ATP concentrations alone (Du Toit et al. 1993). An energy charge of more than 0.8 is considered as indicative for highly active proliferating somatic cells. Values of about 0.6 have been considered to be an indicator of somatic cells in the stationary phase of growth, while an energy charge below 0.5 is interpreted as being indicative for resting or dying cells (Ford and Leach 1998 and references therein). Semen samples in our study had an average energy charge between 0.7 and 0.8 at $17^{\circ} \mathrm{C}$ and an energy charge between 0.5 and 0.8 at $38^{\circ} \mathrm{C}$, which is consistent with a majority of plasma membrane intact and motile cells. Similar values have been reported by others for diluted boar semen (Kamp et al. 2003; Jones and Milmlow 1997). Our experimental set up resembled semen processing and storage conditions similar to these used in routine laboratories of $\mathrm{Al}$ centers. Thus, data from our study provide a first reference range for judging energy charge in stored semen samples for purposes of quality assessment.

In conclusion, although storage does not affect the resting level of ATP and energy charge in liquid stored boar spermatozoa, the cells spend an increasing degree of energy for reactivation of motility with increasing storage length. A spike in mitochondrial activity is associated with motility activation. The increased expense of energy for reactivating motility is associated with deficits in keeping the energy metabolisms stable after prolonged storage with subsequent incubation at body temperature. This may be part of the explanation, why energy dependent sperm functions, e.g. capacitation, are hampered in long-term stored boar spermatozoa. 


\section{References}

1. Du Toit D, Bornman MS, Van Der Merwe MP. , Du Plessis DJ, Oosthuizen JM (1993) Differential sperm motility scoring and sperm ATP concentrations. Andrology 30: 69- 71.

2. Dziekońska A, Fraser L, Majewska A, Lecewicz M, Zasiadczyk L, Kordan W (2013) Effect of commercial long- term extenders on metabolic activity and membrane integrity of boar spermatozoa stored at $17^{\circ} \mathrm{C}$. Pol J Vet Sci 16: 517525.

3. Ford SR, Leach FR (1998). Bioluminescent assay of the adenylate energy charge. Method Mol Biol 102: 69- 81.

4. Fraser L; Lecewicz M, Strzezek J (2002) Fluorometric assessments of viability and mitochondrial status of boar spermatozoa following liquid storage. Pol $\mathrm{J}$ Vet Sci 5: 85- 92.

5. Gogol P, Fabianczyk BS, Hilczer AW (2008) The photon emission, ATP level and motility of boar spermatozoa during liquid storage. Repro Bio 9: 39- 49.

6. Guthrie HD, Welch GR (2005) Effects of hypothermic liquid storage and cryopreservation disorder and acrosome exocytosis in boar spermatozoa. Repro Fert Development 17: 467- 477.

7. Haugen T, Reksen O, Gröhn YT, Graustad AH, Hofmo PO (2005) A retrospective study on effects of storage time of liquid boar semen on reproductive performance in Norwegian swine. Theriogenology 64: 891- 901.

8. Henning H, Petrunikin AM, Harrison RAP, Waberski D (2012) Bivalent Response to long- term storage in liquid- preserved boar semen: a flow cytometric analysis. Cytometry A 81: 576-587.

9. Johnson LA, Weitze KF, Fiser P, Maxwell WMC (2000) Storage of boar semen. Animal Repro Science 62: 143- 172.

10. Jones AR, Milmlow D (1997) Endogenous energy production by mature boar spermatozoa. J Reprod Fert 111: 285- 290.

11. Kamp G, Büsselmann G, Lauterwein J (1996). Spermatozoa: models for studying regulatory aspects of energy metabolism. Experiemtia 52: 487- 494.

12. Kamp G, Busselmann G, Jones,B.Wiesner N, Lauterwein J (2003) Energy metabolism and intracellular $\mathrm{pH}$ in boar spermatozoa. Reproduction 126: 517525. 
13. Kojima A, Matsushita Y, Ogura Y, Ishikawa S, Noda T, Murase T, Harayama H (2015) Roles of extracellular $\mathrm{Ca}^{2+}$ in the occurrence of full- type hyperactivation in boar ejaculated spermatozoa pre- incubated to induce the cAMP- triggered events. Andrology 3: 321- 331.

14. Long J. A, Guthrie H.D (2006) Validation of a rapid, large-scale assay to quantify ATP concentration in spermatozoa. Theriogenology 65: 1620- 1630.

15. Marin S, Chiang K, Bassilian S, Lee WN, Boros LG, Fernández-Novell JM, Centelles JJ, Medrano A, Rodriguez-Gil JE, Cascante M (2003) Metabolic strategy of boar spermatozoa revealed by a metabolomic characterization. FEBS Lett 554:342-346.

16. Miki K, Qu W, Goulding EH, Willis WD, Bunch DO, Strader LF, Perreault SD, Eddy EM, O’Brien DA (2004) Glyceraldehyde 3-phosphate dehydrogenase-S, a sperm-specific glycolytic enzyme, is required for sperm motility and male fertility. PNAS 101: $16501-160506$

17. Miki K (2007) Energy metabolism and sperm function. Society of Repro Fert suppl $65: 309-325$.

18. Nguyen QT, Wallner U, Piechotta M, Waberski D, Henning H (unpubliced) A revised protocol for efficient extraction of ATP from boar spermatozoa

19. Ramio- Lluch L, Fernandez- Novell JM, Colas C, Cebrian- Perez JA, MuinoBlanco T, Ramirez A, Concha II, Rigau T, Rodriguer- Gil JE (2011) Invitro capacitation and acrosome reaction are concomitant with specific changes in mitochondrial activity in boar sperm. Evidence for a nucleated mitochondrial activation and for the existence of a capacitation- sensitive subpopulational structure. Reprod Dom Anim 46: 664- 673.

20. Rodriguez- Gil JE (2013) . Biological Aspects of the mature boar spermatozoon . in: S. Bonet, I. Casas, W.V. Holt, M. Yeste (Eds.) Boar reproduction. Springer Verlag, Berlin Heidelberg: 49-64.

21. Schmid S., H. Henning, H. Oldenhof, W. F. Wolkers, A. Petrunkina, and D. Waberski (2013). The specific response to capacitating stimuli is a sensitive indicator of chilling injury in hypothermically stored boar spermatozoa. Andrology $1: 376-386$

22. Suarez SS, Dai XB, Demott RP, Redfern K, Mirando MA (1992) Movement characteristics of boar sperm obtained from the oviduct or hyperactivated in vitro. Andrology 13: 75- 80. 
23. Suarez SS (2008) Control of hyperactivation in sperm. Human Reprod Update 14: $647-657$.

24. Tourmente M, Villar-Moya $P$, Varea-Sánchez M, Luque-Larena JJ, Rial E, Roldan ER (2015) Performance of Rodent Spermatozoa Over Time Is Enhanced by Increased ATP Concentrations: The Role of Sperm Competition. Biol Reprod. 2015 Jul 8. pii: biolreprod.114.127621.

25. Waberski D, Dirksen G, Weitze KF, Leiding C, Hahn R. Field (1990) Studies of the effect of sperm motility and morphology on the fertility of boars used for insemination. Tierarztl Prax 18: 591-594. German.

26. Waberski D, Weitze KF, Lietmann C, Lübbert W, Bortolozzo FP, Wilmen T, Petzoldt R (1994). The initial fertilizing capacity of long term- stored liquid boar semen following pre- and postovulatory insemination. Theriogenology 41: 13671377.

27. Yi YJ, Li ZH, Kim ES, Song ES, Kim HB, Cong PQ, Lee JM, Park CS (2008) Comparision of motility, acrosome, viability and ATP of boar sperm with or without cold shock, resistance in liquid semen at $17^{\circ} \mathrm{C}$ and $4^{\circ} \mathrm{C}$, and frozenthawed semen. Asian- Aust. J. Anim. Sci 21: 190- 197. 
Figures and Tables

A

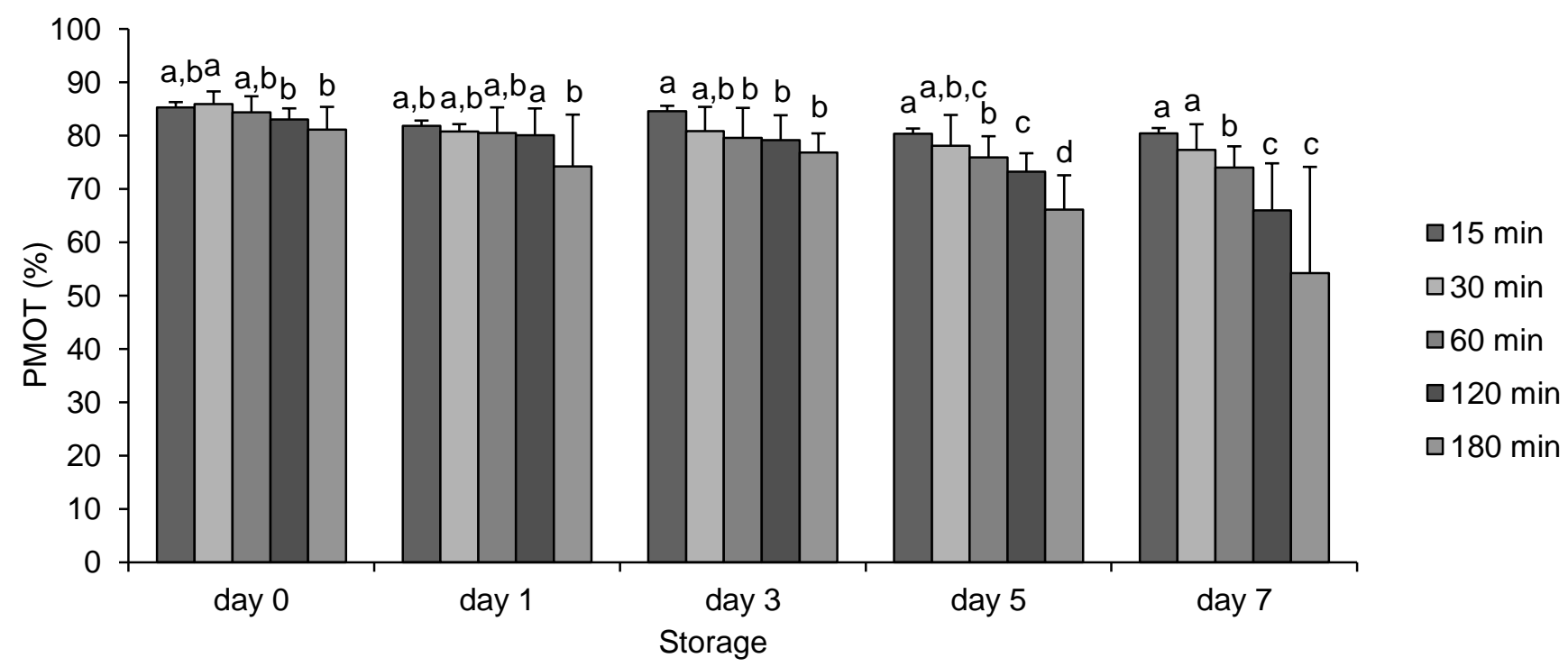

B

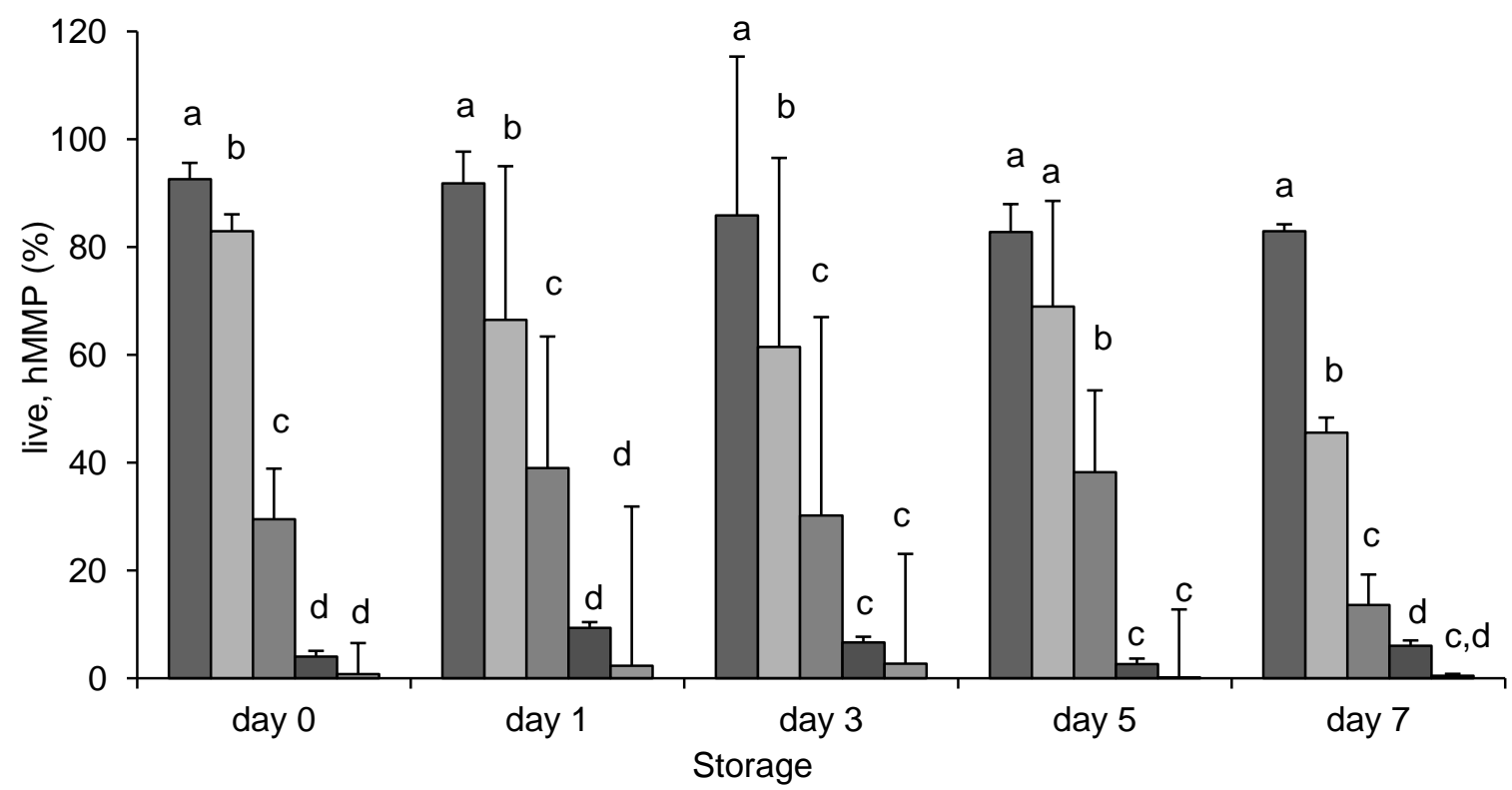

口15 min

30 min

$\square 60 \mathrm{~min}$

口 $120 \mathrm{~min}$

․180 min

Figure 1. (A) Progressive motility, PMOT, and (B) amount of live spermatozoa with a high mitochondrial transmembrane potential, hMMP, of boar semen samples following incubation at $38^{\circ} \mathrm{C}$ at different time points. Values are expressed as means and standard deviations $(n=7)$. Different letters $(a-d)$ at a given storage day indicate significant differences between incubation times $(P<0.05)$. 
A

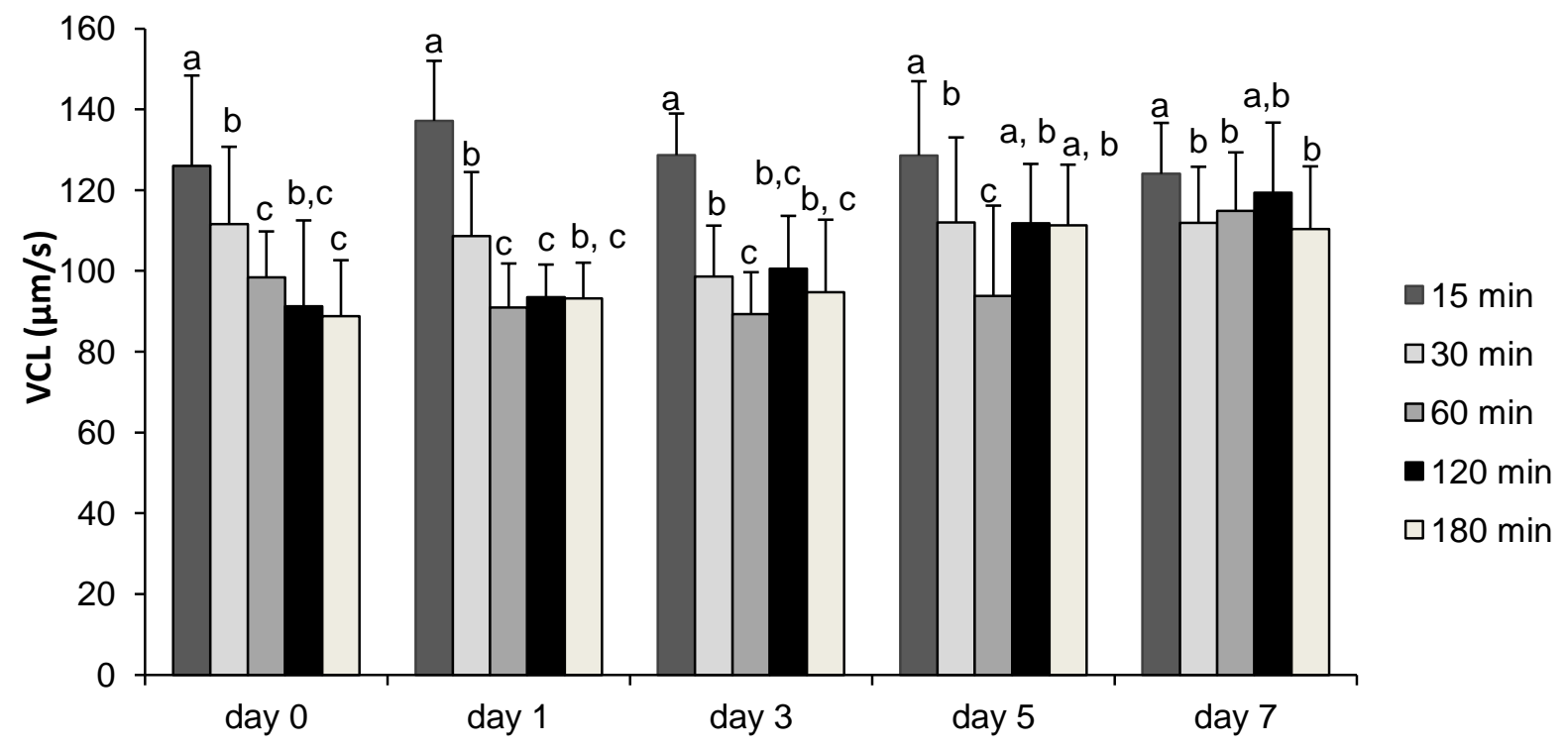

B

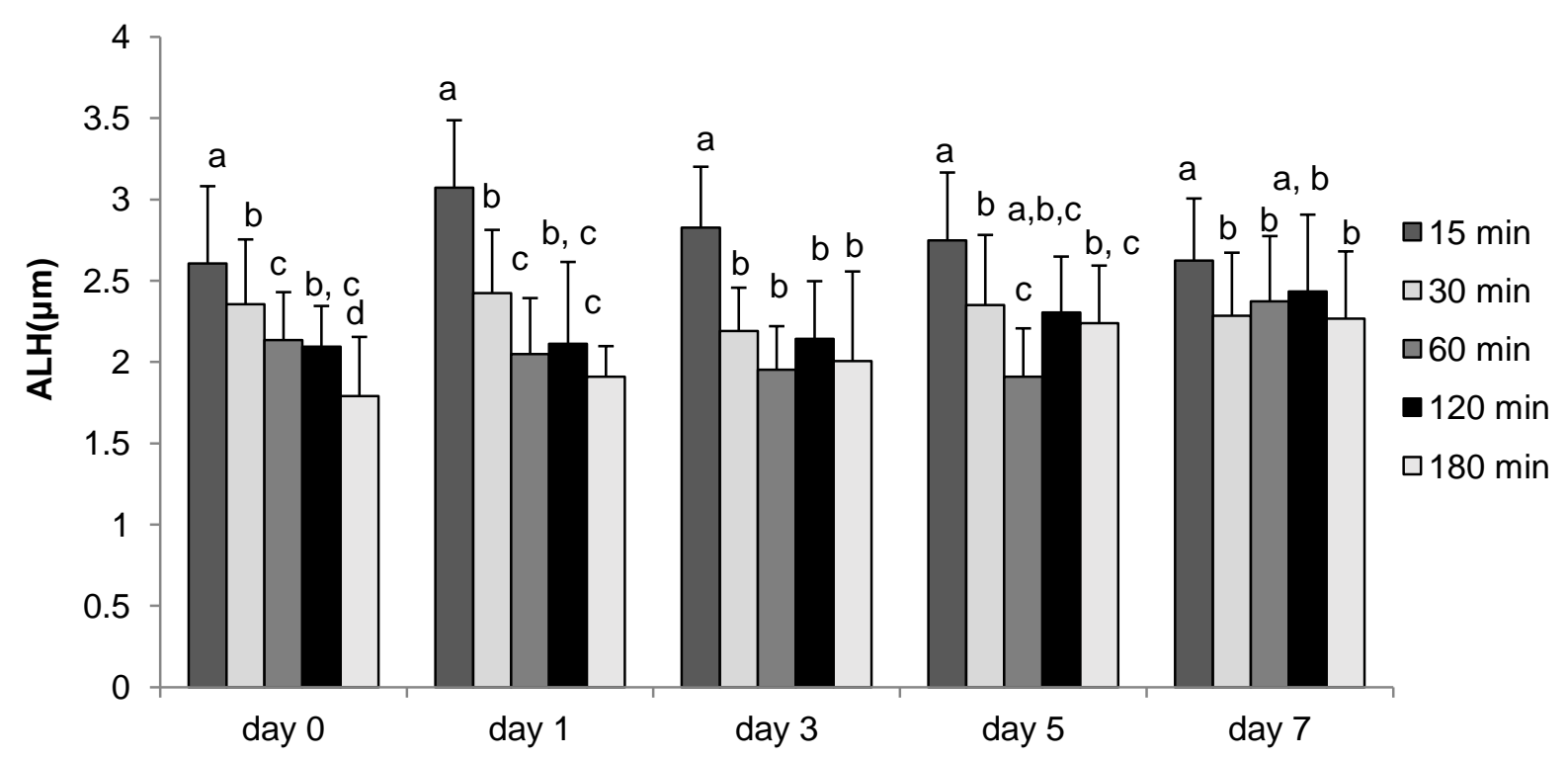




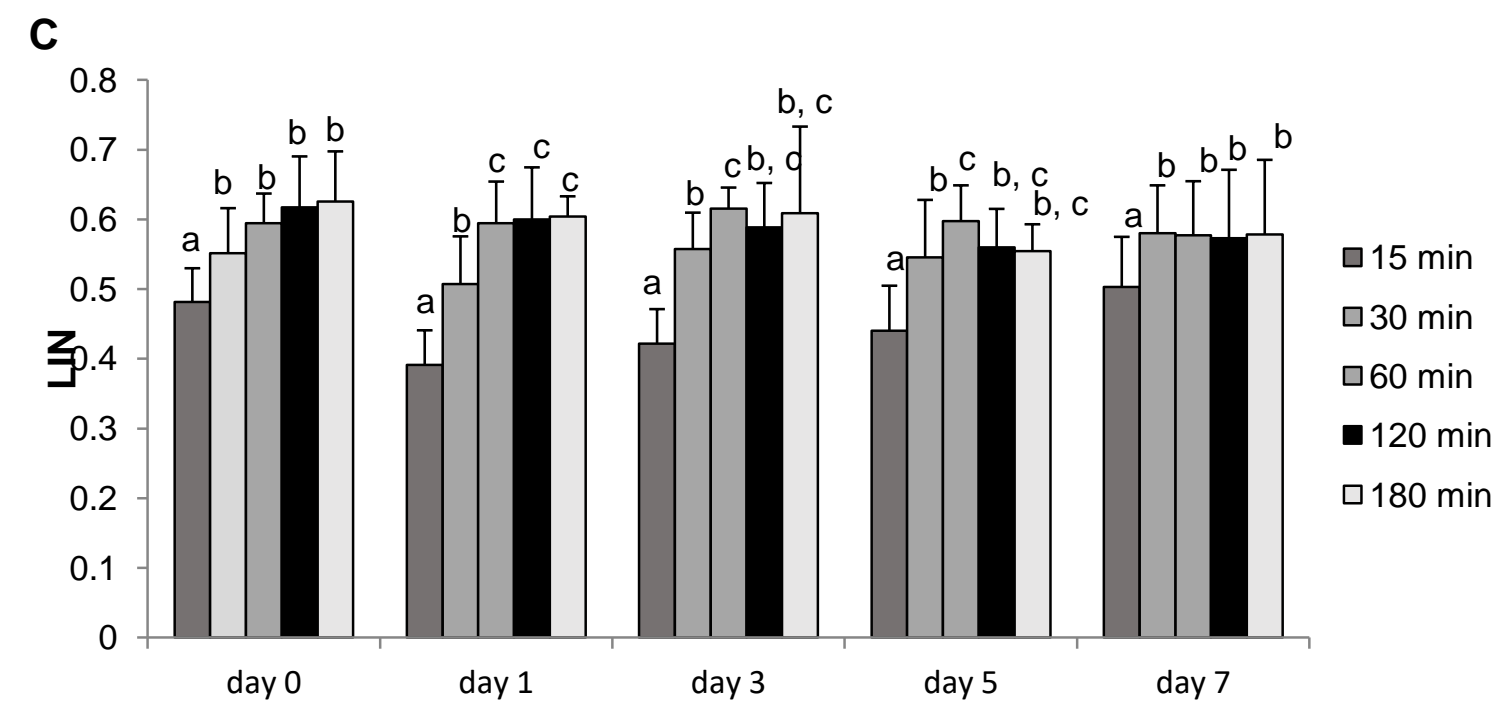

Figure 2. A) Curvilinear velocity (VCL), B) linearity (LIN), and C) amplitude of lateral head-displacement (ALH) of progressive motility spermatozoa following semen incubation at $38^{\circ} \mathrm{C}$. Samples were incubated at the day of dilution (day 0 ) or after up to seven days of storage at $17^{\circ} \mathrm{C}$. Values are expressed as means and standard deviations ( $\mathrm{n}=7$ ejaculates per boar and time). Different letters (a-c) on columns at a given day of storage indicate significant differences between incubation times $(P<$ 0.05). 
A

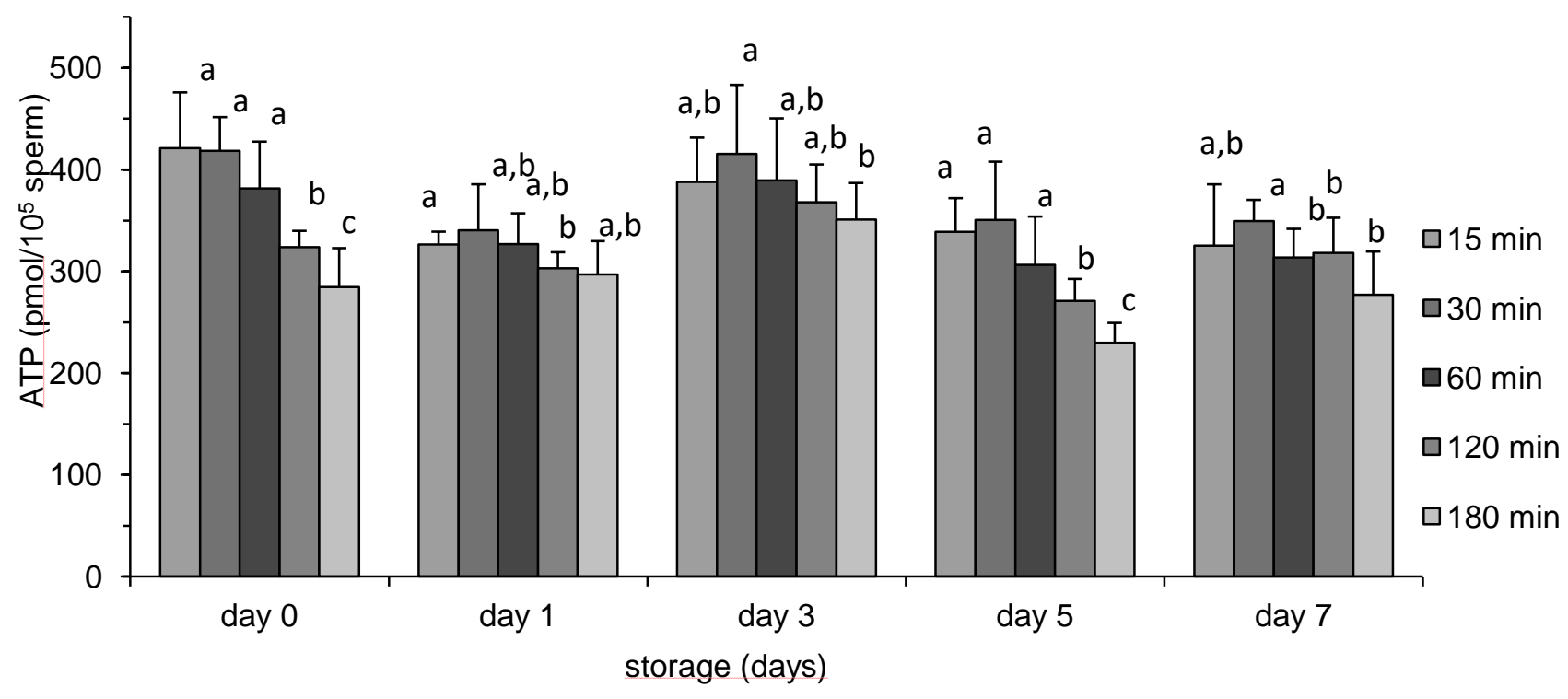

B

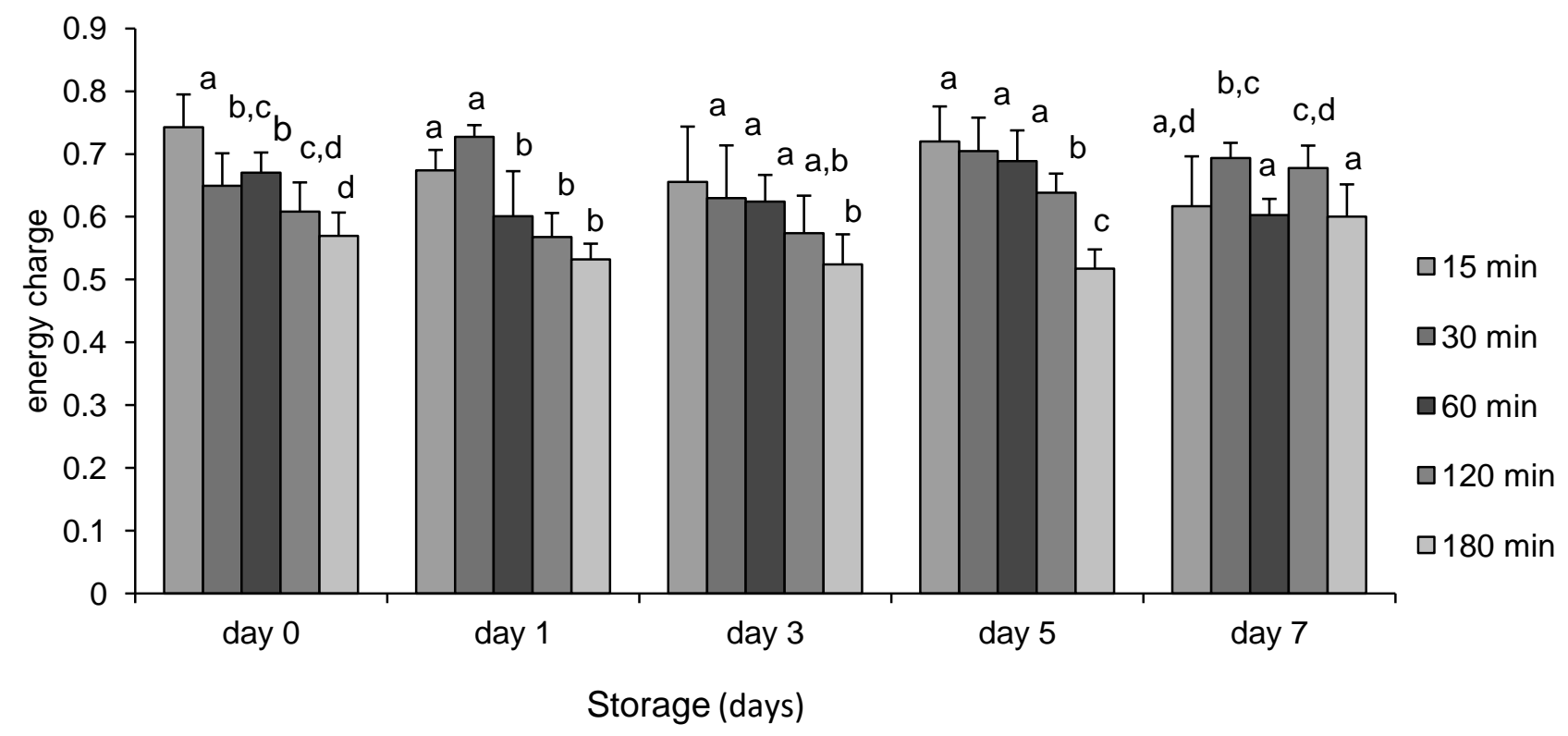

Fig 3. ATP (A) and energy charge (B) of boar spermatozoa following liquid semen incubation at $38^{\circ} \mathrm{C}$ at different time point. Values are expressed as means and standard deviations ( $n=7$ ejaculates per boar and time). In the same incubation time, the value with different letter $(a-e)$ differs significantly $(p<0.05)$. 
Table 1. Parameters of semen samples stored at $17^{\circ} \mathrm{C}(n=7)$. Different lowercase letters $(\mathrm{a}-\mathrm{c})$ within a column indicate significant differences $(\mathrm{P}<0.05)$ between different days of storage. All values are means and standard deviations.

\begin{tabular}{c|c|c|c}
\hline storage & $\begin{array}{c}\text { PI \& PNA-FITC } \\
\text { negative (\%) }\end{array}$ & $\begin{array}{c}\text { ATP } \\
\left(\mathrm{pMol} / 10^{5} \text { sperm }\right)\end{array}$ & EC \\
\hline Day 0 & $93.7 \pm 0.49^{\mathrm{a}} *$ & $438.5 \pm 21.4^{\mathrm{a}, \mathrm{b}}$ & $0.78 \pm 0.05^{\mathrm{a}}$ \\
Day 1 & $92.1 \pm 2.12^{\mathrm{a}}$ & $384.5 \pm 14.0^{\mathrm{c}}$ & $0.70 \pm 0.07^{\mathrm{b}}$ \\
Day 3 & $90.6 \pm 2.69^{\mathrm{a}}$ & $484.4 \pm 44.0^{\mathrm{a}}$ & $0.73 \pm 0.12^{\mathrm{a}, \mathrm{b}}$ \\
Day 5 & $90.7 \pm 2.35^{\mathrm{b}}$ & $451.8 \pm 56.8^{\mathrm{a}}$ & $0.77 \pm 0.08^{\mathrm{a}, \mathrm{b}}$ \\
Day 7 & $89.0 \pm 3.11^{\mathrm{c}}$ & $397.9 \pm 67.1^{\mathrm{b}, \mathrm{c}}$ & $0.71 \pm 0.07^{\mathrm{b}}$ \\
& & & \\
$* \mathrm{n}=3$ & & &
\end{tabular}


Table 2. Motility parameters of computer-assisted semen analysis (CASA) after 15, 30, 60, 120 and 180 minutes incubation in a water bath at $38^{\circ} \mathrm{C}(n=7)$. All values are mean and standard deviation. Different lowercase alphabets $(a-e)$ in each column show significant differences $(P<0.05)$ between storage days.

Incubation time

\begin{tabular}{|c|c|c|c|c|c|c|}
\hline & Storage & $15 \mathrm{~min}$ & $30 \mathrm{~min}$ & $60 \mathrm{~min}$ & $120 \min$ & $180 \min$ \\
\hline \multirow{5}{*}{$\begin{array}{l}\text { TM } \\
(\%)\end{array}$} & Day 0 & $92.2 \pm 1.6^{a}$ & $91.9 \pm 1.2^{\mathrm{a}}$ & $91.6 \pm 2.1^{a}$ & $90.1 \pm 1.0^{a}$ & $89.2 \pm 1.8^{a}$ \\
\hline & Day 1 & $89.6 \pm 2.8^{b}$ & $89.9 \pm 1.9^{b}$ & $88.3 \pm 3.1^{\mathrm{b}, \mathrm{c}}$ & $88.6 \pm 2.4^{\mathrm{a}, \mathrm{b}}$ & $84.9 \pm 3.6^{b}$ \\
\hline & Day 3 & $92.0 \pm 1.9^{a, b}$ & $90.1 \pm 2.0^{\mathrm{a}, \mathrm{b}}$ & $88.7 \pm 3.0^{b}$ & $88.0 \pm 0.3^{b}$ & $83.2 \pm 3.0^{b}$ \\
\hline & Day 5 & $89.1 \pm 2.4^{c}$ & $87.3 \pm 3.4^{c}$ & $87.5 \pm 1.8^{b, c}$ & $82.6 \pm 4.0^{c}$ & $76.9 \pm 3.3^{c}$ \\
\hline & Day 7 & $90.5 \pm 1.2^{b, c}$ & $87.0 \pm 3.1^{c}$ & $84.7 \pm 3.6^{c}$ & $80.3 \pm 5.1^{c}$ & $70.7 \pm 1.7^{c}$ \\
\hline \multirow{5}{*}{$\begin{array}{l}\text { PM } \\
(\%)\end{array}$} & Day 0 & $85.3 \pm 2.8^{\mathrm{a}}$ & $85.9 \pm 2.4^{a}$ & $84.4 \pm 3.0^{a}$ & $83.0 \pm 2.1^{a}$ & $81.1 \pm 4.29^{a}$ \\
\hline & Day 1 & $81.8 \pm 4.1^{\mathrm{a}, \mathrm{b}}$ & $80.8 \pm 1.4^{\mathrm{b}, \mathrm{c}}$ & $80.5 \pm 4.8^{\mathrm{b}}$ & $80.1 \pm 5.0^{a}$ & $74.2 \pm 9.7^{b}$ \\
\hline & Day 3 & $84.6 \pm 4.1^{a, b}$ & $80.8 \pm 4.6^{b}$ & $79.6 \pm 5.6^{a, b}$ & $79.2 \pm 4.7^{\mathrm{a}}$ & $76.9 \pm 3.6^{b}$ \\
\hline & Day 5 & $80.4 \pm 4.7^{b}$ & $78.1 \pm 5.8^{\mathrm{b}, \mathrm{c}}$ & $75.9 \pm 4.9^{b}$ & $73.3 \pm 3.4^{b}$ & $66.1 \pm 6.5^{c}$ \\
\hline & Day 7 & $80.4 \pm 3.6^{b}$ & $77.4 \pm 4.8^{c}$ & $74.0 \pm 4.0^{c}$ & $66.0 \pm 8.8^{c}$ & $54.2 \pm 20.0^{\circ}$ \\
\hline
\end{tabular}




\begin{tabular}{|c|c|c|c|c|c|c|}
\hline & \multirow[b]{2}{*}{ Storage } & \multicolumn{5}{|c|}{ Incubation time } \\
\hline & & $15 \mathrm{~min}$ & $30 \mathrm{~min}$ & $60 \mathrm{~min}$ & $120 \mathrm{~min}$ & $180 \mathrm{~min}$ \\
\hline \multirow{2}{*}{$\begin{array}{l}\text { VAP } \\
(\mu \mathrm{m} / \mathrm{s})\end{array}$} & Day 1 & $79.3 \pm 4.8^{a, b}$ & $69.8 \pm 5.8^{\mathrm{b}}$ & $63.7 \pm 7.4^{\mathrm{a}}$ & $66.6 \pm 3.1^{\mathrm{a}}$ & $66.2 \pm 4.5^{\mathrm{a}}$ \\
\hline & Day 3 & $76.9 \pm 3.0^{\mathrm{a}}$ & $67.1 \pm 7.3^{\mathrm{a}, \mathrm{b}}$ & $65.0 \pm 8.4^{\mathrm{a}}$ & $71.4 \pm 7.1^{\mathrm{a}, \mathrm{b}}$ & $68.0 \pm 8.8^{a, b}$ \\
\hline \multirow{3}{*}{$\begin{array}{l}\text { VCL } \\
(\mu \mathrm{m} / \mathrm{s})\end{array}$} & Day 0 & $126.0 \pm 22.4^{\mathrm{a}, \mathrm{b}}$ & $111.6 \pm 19.2^{a, b}$ & $98.4 \pm 11.4^{\mathrm{a}}$ & $91.27 \pm 21.2^{\mathrm{a}, \mathrm{b}}$ & $88.8 \pm 13.8^{a, b}$ \\
\hline & Day 1 & $137.2 \pm 14.8^{a}$ & $108.7 \pm 15.8^{a, b}$ & $91.0 \pm 10.9^{a}$ & $93.5 \pm 8.09^{\mathrm{a}}$ & $93.2 \pm 8.8^{\mathrm{a}}$ \\
\hline & Day 3 & $128.7 \pm 10.3^{\mathrm{a}, \mathrm{b}}$ & $98.6 \pm 12.6^{a}$ & $89.3 \pm 10.4^{a}$ & $100.6 \pm 13.1^{\mathrm{a}, \mathrm{b}}$ & $94.7 \pm 18.0^{a, b}$ \\
\hline \multirow{5}{*}{$\begin{array}{c}\text { VSL } \\
(\mu \mathrm{m} / \mathrm{s})\end{array}$} & Day 0 & $53.3 \pm 4.4^{\mathrm{a}}$ & $61.2 \pm 4.6^{\mathrm{a}, \mathrm{c}}$ & $58.9 \pm 5.7^{\mathrm{a}}$ & $55.6 \pm 8.2^{a, b}$ & $55.6 \pm 6.8^{\mathrm{a}, \mathrm{b}}$ \\
\hline & Day 1 & $53.9 \pm 5.1^{\mathrm{a}, \mathrm{b}}$ & $55.2 \pm 5.2^{b}$ & $54.4 \pm 7.2^{\mathrm{a}}$ & $56.4 \pm 3.5^{\mathrm{a}}$ & $56.8 \pm 3.3^{\mathrm{a}}$ \\
\hline & Day 3 & $54.5 \pm 3.6^{b}$ & $55.0 \pm 5.4^{\mathrm{a}, \mathrm{b}}$ & $55.3 \pm 6.5^{a}$ & $59.1 \pm 4.9^{a, b}$ & $56.8 \pm 7.8^{a, b}$ \\
\hline & Day 5 & $56.4 \pm 6.5^{\mathrm{b}, \mathrm{c}}$ & $60.4 \pm 6.2^{c}$ & $55.8 \pm 11.1^{\mathrm{a}}$ & $61.9 \pm 6.4^{b}$ & $62.0 \pm 5.5^{\mathrm{b}}$ \\
\hline & Day 7 & $62.5 \pm 3.7^{c}$ & $62.6 \pm 4.6^{c}$ & $66.2 \pm 5.1^{\mathrm{b}}$ & $67.7 \pm 3.1^{c}$ & $63.8 \pm 10.4^{b}$ \\
\hline
\end{tabular}


Incubation time

\begin{tabular}{|c|c|c|c|c|c|c|}
\hline & Storage & $15 \mathrm{~min}$ & $30 \mathrm{~min}$ & $60 \mathrm{~min}$ & $120 \mathrm{~min}$ & $180 \mathrm{~min}$ \\
\hline & Day 0 & $0.74 \pm 0.07^{a}$ & $0.82 \pm 0.05^{a}$ & $0.85 \pm 0.03^{\mathrm{a}, \mathrm{b}}$ & $0.85 \pm 0.04^{a}$ & $0.85 \pm 0.04^{a}$ \\
\hline & Day 1 & $0.67 \pm 0.05^{b}$ & $0.79 \pm 0.04^{b}$ & $0.85 \pm 0.03^{a}$ & $0.84 \pm 0.04^{a}$ & $0.85 \pm 0.02^{a}$ \\
\hline \multirow[t]{5}{*}{ STR } & Day 3 & $0.70 \pm 0.03^{a, b}$ & $0.81 \pm 0.02^{\mathrm{a}, \mathrm{b}}$ & $0.85 \pm 0.02^{\mathrm{a}, \mathrm{b}}$ & $0.83 \pm 0.04^{b}$ & $0.83 \pm 0.06^{\mathrm{a}, \mathrm{b}}$ \\
\hline & Day 5 & $0.73 \pm 0.05^{a}$ & $0.81 \pm 0.04^{\mathrm{a}}$ & $0.85 \pm 0.02^{a, b}$ & $0.82 \pm 0.04^{b}$ & $0.82 \pm 0.02^{b}$ \\
\hline & Day 7 & $0.76 \pm 0.06^{c}$ & $0.83 \pm 0.03^{c}$ & $0.83 \pm 0.04^{b}$ & $0.83 \pm 0.05^{\mathrm{a}, \mathrm{b}}$ & $0.83 \pm 0.05^{a, b}$ \\
\hline & Day 0 & $0.48 \pm 0.05^{\mathrm{a}}$ & $0.55 \pm 0.06^{a}$ & $0.59 \pm 0.04^{a}$ & $0.62 \pm 0.07^{a}$ & $0.63 \pm 0.07^{\mathrm{a}}$ \\
\hline & Day 1 & $0.39 \pm 0.05^{b}$ & $0.51 \pm 0.07^{b}$ & $0.59 \pm 0.06^{a}$ & $0.60 \pm 0.07^{a}$ & $0.60 \pm 0.03^{a}$ \\
\hline \multirow[t]{5}{*}{ LIN } & Day 3 & $0.42 \pm 0.05^{\mathrm{b}}$ & $0.56 \pm 0.05^{\mathrm{a}, \mathrm{b}}$ & $0.62 \pm 0.03^{a}$ & $0.59 \pm 0.06^{a}$ & $0.61 \pm 0.12^{\mathrm{a}}$ \\
\hline & Day 5 & $0.44 \pm 0.06^{c}$ & $0.55 \pm 0.08^{a, b}$ & $0.60 \pm 0.05^{\mathrm{a}}$ & $0.56 \pm 0.06^{a}$ & $0.55 \pm 0.04^{\mathrm{a}}$ \\
\hline & Day 7 & $0.50 \pm 0.07^{\mathrm{a}, \mathrm{d}}$ & $0.56 \pm 0.07^{\mathrm{a}}$ & $0.58 \pm 0.08^{a}$ & $0.57 \pm 0.01^{a}$ & $0.58 \pm 0.11^{a}$ \\
\hline & Day 0 & $0.62 \pm 0.05^{\mathrm{a}}$ & $0.67 \pm 0.05^{\mathrm{a}}$ & $0.70 \pm 0.03^{a}$ & $0.70 \pm 0.01^{a}$ & $0.73 \pm 0.05^{a}$ \\
\hline & Day 1 & $0.58 \pm 0.04^{b}$ & $0.64 \pm 0.06^{b}$ & $0.70 \pm 0.05^{\mathrm{a}, \mathrm{b}}$ & $0.71 \pm 0.05^{\mathrm{a}}$ & $0.71 \pm 0.03^{\mathrm{a}, \mathrm{b}}$ \\
\hline \multirow[t]{3}{*}{ WOB } & Day 3 & $0.59 \pm 0.05^{b}$ & $0.68 \pm 0.05^{a, b}$ & $0.72 \pm 0.03^{b}$ & $0.71 \pm 0.04^{a}$ & $0.72 \pm 0.09^{a, b}$ \\
\hline & Day 5 & $0.60 \pm 0.06^{c}$ & $0.66 \pm 0.08^{\mathrm{a}, \mathrm{b}}$ & $0.71 \pm 0.06^{a, b}$ & $0.68 \pm 0.04^{a}$ & $0.67 \pm 0.05^{b}$ \\
\hline & Day 7 & $0.66 \pm 0.05^{d}$ & $0.67 \pm 0.06^{a}$ & $0.69 \pm 0.06^{a, b}$ & $0.69 \pm 0.08^{a}$ & $0.69 \pm 0.08^{a, b}$ \\
\hline
\end{tabular}




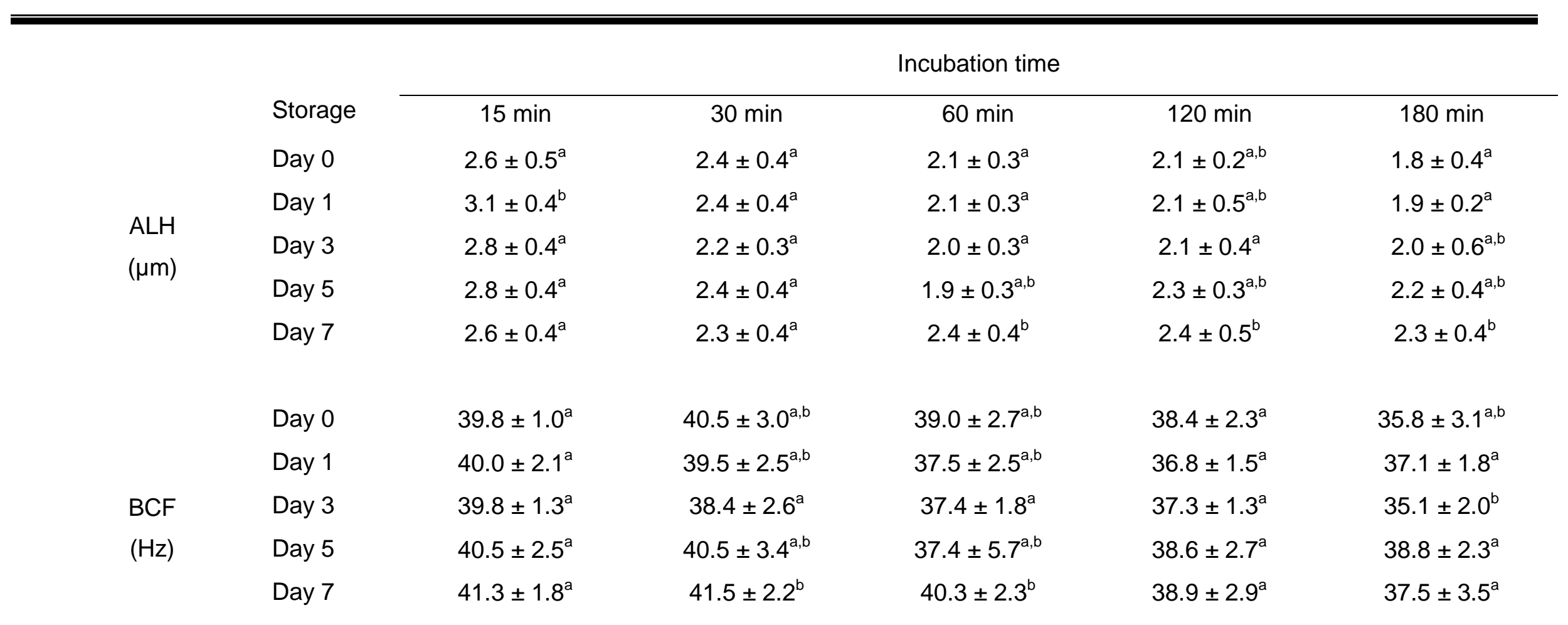


Table 3. Plasma membrane integrity of boar spermatozoa following semen incubation at $38^{\circ} \mathrm{C}(\mathrm{n}=7)$. Different lowercase alphabets $(a-d)$ in each column show significant differences $(P<0.05)$ among days of storage. All values are mean and standard deviation.

\begin{tabular}{llcccc} 
& \multicolumn{5}{c}{ Incubation (min) } \\
\cline { 2 - 6 } storage & \multicolumn{1}{c}{15} & 30 & 60 & 120 & 180 \\
Day 0 & $89.3 \pm 3.59^{\mathrm{a}, \mathrm{b}, \mathrm{c}}$ & $89.2 \pm 2.04^{\mathrm{a}}$ & $87.8 \pm 2.44^{\mathrm{a}}$ & $85.1 \pm 2.81^{\mathrm{a}}$ & $80.9 \pm 6.14^{\mathrm{a}, \mathrm{c}}$ \\
Day 1 & $89.8 \pm 1.69^{\mathrm{a}}$ & $88.5 \pm 3.58^{\mathrm{a}, \mathrm{b}}$ & $88.1 \pm 2.81^{\mathrm{b}}$ & $74.5 \pm 16.92^{\mathrm{a}, \mathrm{b}}$ & $83.0 \pm 5.84^{\mathrm{a}, \mathrm{b}}$ \\
Day 3 & $87.3 \pm 1.96^{\mathrm{b}, \mathrm{c}}$ & $86.5 \pm 2.61^{\mathrm{b}}$ & $83.6 \pm 2.07^{\mathrm{a}, \mathrm{c}}$ & $80.1 \pm 7.83^{\mathrm{b}}$ & $74.0 \pm 12.14^{\mathrm{b}, \mathrm{d}}$ \\
Day 5 & $85.6 \pm 2.96^{\mathrm{d}}$ & $86.3 \pm 2.49^{\mathrm{b}}$ & $85.1 \pm 3.69^{\mathrm{c}}$ & $81.2 \pm 6.03^{\mathrm{a}, \mathrm{b}}$ & $75.9 \pm 9.94^{\mathrm{c}, \mathrm{d}}$ \\
Day 7 & $87.1 \pm 2.59^{\mathrm{c}}$ & $84.4 \pm 3.07^{\mathrm{b}}$ & $83.9 \pm 3.25^{\mathrm{c}}$ & $80.4 \pm 4.75^{\mathrm{b}}$ & $71.8 \pm 8.78^{\mathrm{d}}$
\end{tabular}


Table 4 Pearson correlation coefficients between selected parameters for samples incubated at $38^{\circ} \mathrm{C}$. Data from all incubation times and days of storage were combined $(n=175)$

\begin{tabular}{|c|c|c|c|c|c|c|c|c|c|c|c|c|}
\hline & $\begin{array}{l}\text { PI \& } \\
\text { PNA- } \\
\text { FITC } \\
\text { neg. } \\
\\
{[\%]}\end{array}$ & $\begin{array}{c}\text { Total } \\
\text { motility } \\
{[\%]}\end{array}$ & $\begin{array}{c}\text { Progress } \\
\text { ive } \\
\text { motility } \\
{[\%]}\end{array}$ & $\begin{array}{c}\text { VAP } \\
{[\mu \mathrm{m} / \mathrm{s}]}\end{array}$ & $\begin{array}{c}\mathrm{VCL} \\
{[\mu \mathrm{m} / \mathrm{s}]}\end{array}$ & $\begin{array}{c}\text { VSL } \\
{[\mu \mathrm{m} / \mathrm{s}]}\end{array}$ & STR & LIN & WOB & $\begin{array}{l}\text { ALH } \\
{[\mu \mathrm{m}]}\end{array}$ & $\begin{array}{l}\text { BCF } \\
{[\mathrm{Hz}]}\end{array}$ & $\begin{array}{c}\text { hMMP } \\
{[\%]}\end{array}$ \\
\hline $\begin{array}{c}\text { ATP } \\
\mathrm{pmol} / 10^{5} \\
\text { sperm }\end{array}$ & $0.29 * * *$ & $0.48^{* * *}$ & $0.45^{* \star *}$ & 0.08 & 0.10 & -0.03 & -0.15 & -0.13 & -0.11 & $0.16 *$ & $0.16 *$ & $0.38^{* \star *}$ \\
\hline EC & $0.39 * * \star$ & $0.26^{* \star *}$ & 0.23 ** & 0.25 ** & $0.31^{* * *}$ & 0.09 & $-0.23^{* \star}$ & $-0.26 * * *$ & $-0.28^{* * *}$ & 0.22 ** & $0.37^{\star \star \star}$ & $0.47^{* * *}$ \\
\hline $\begin{array}{c}\text { hMMP } \\
(\%)\end{array}$ & $0.49 * * *$ & $0.43^{* * *}$ & $0.40^{* * *}$ & $0.17^{*}$ & $0.41^{* * *}$ & $-0.25^{* * *}$ & $-0.60 * * *$ & $-0.59 * * *$ & $-0.55^{* * *}$ & $0.46^{* * *}$ & $0.34^{* * *}$ & - \\
\hline${ }^{*} P<0.05$ & & ${ }^{* *} \mathrm{P}$ & $<0.01$ & & ${ }^{* * *} \mathrm{P}<C$ & .001 & & & & & & \\
\hline \multicolumn{4}{|c|}{$\mathrm{VAP}=$ average path velocity } & \multicolumn{3}{|c|}{ VCL $=$ curvilinear velocity } & \multicolumn{6}{|c|}{ VSL = straight-line velocity } \\
\hline \multicolumn{4}{|c|}{ STR $=$ straightness } & \multicolumn{3}{|c|}{ LIN = linearity } & \multicolumn{6}{|c|}{ WOB $=$ wobble } \\
\hline \multicolumn{4}{|c|}{ ALH = amplitude of lateral head-displacement } & \multicolumn{3}{|c|}{$\mathrm{BCF}=$ beat cross frequency } & \multicolumn{6}{|c|}{$E C=$ energy charge } \\
\hline \multicolumn{7}{|c|}{ hMMP = sperm with high mitochondrial transmembrane potential } & \multicolumn{6}{|c|}{ ATP $=$ adenosine triphosphate } \\
\hline
\end{tabular}




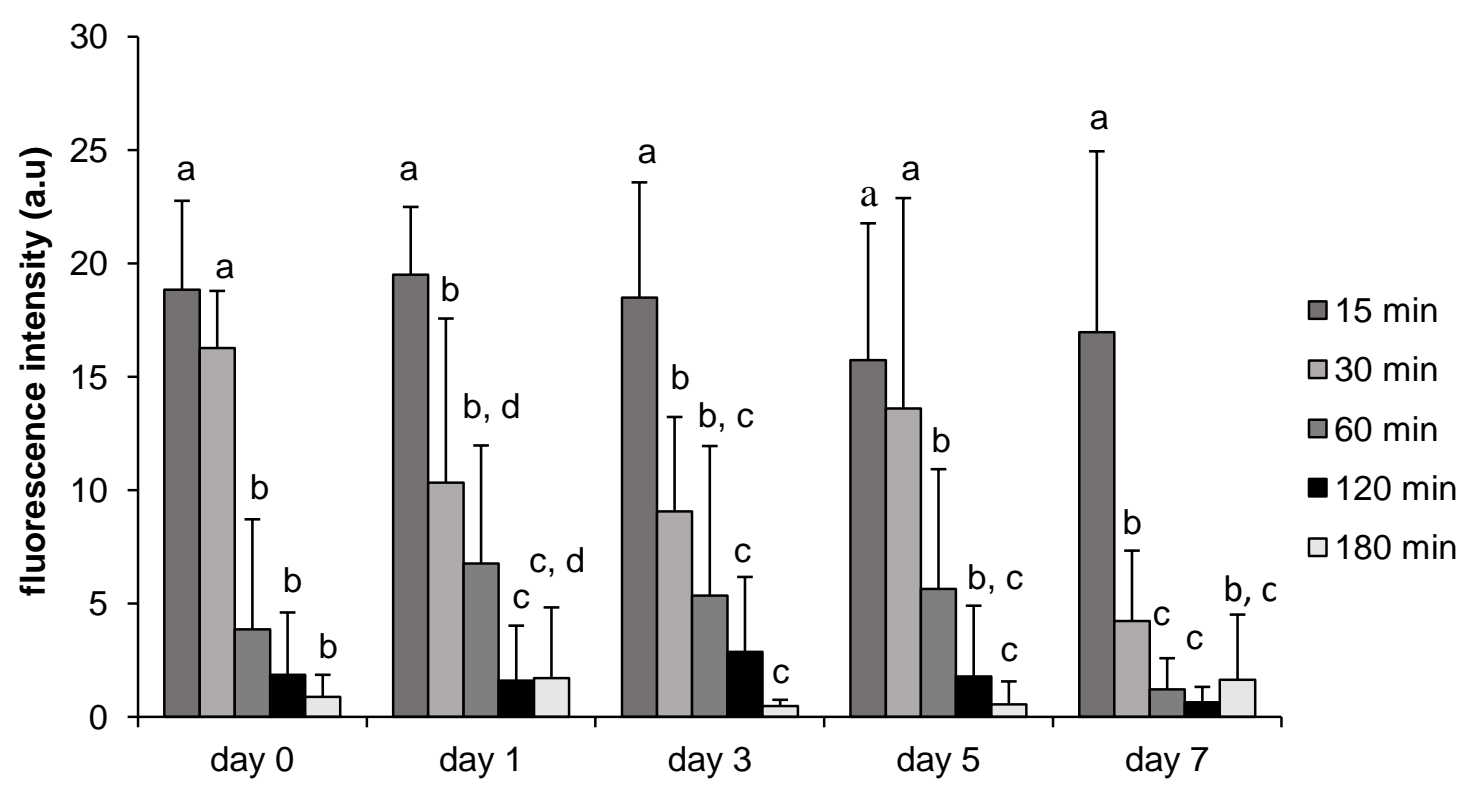

Supplemental Figure 1. Average fluorescence intensity for JC-1 aggregates (a.u. = arbitrary units) in live (PI negative) boar spermatozoa following liquid semen incubation at $38^{\circ} \mathrm{C}$. Values are expressed as means and standard deviations $(\mathrm{n}=7$ ejaculates per boar and time). Columns with different letters (a-e) at a given storage day indicate significant differences between incubation times $(P<0.05)$. 

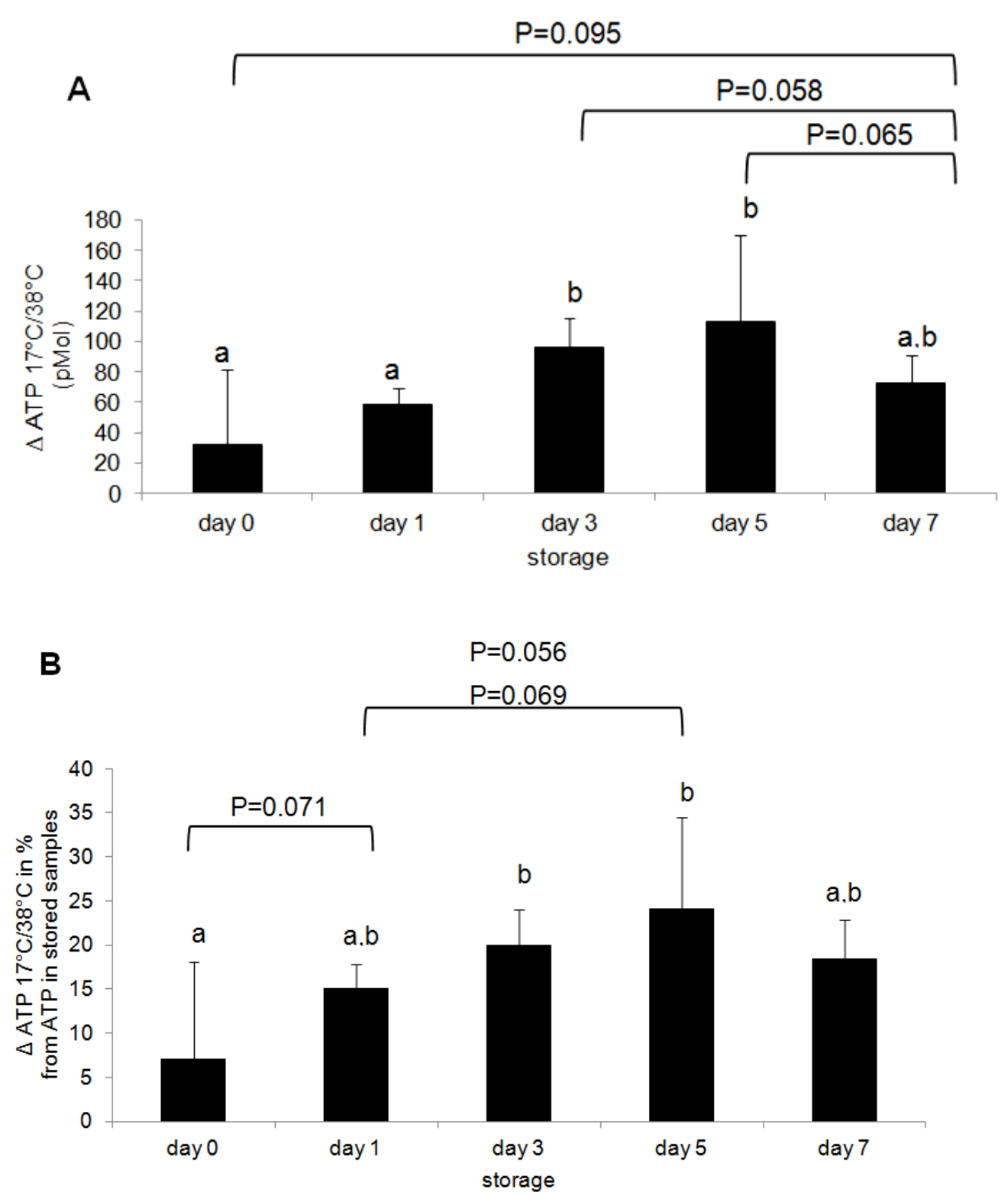

Supplemental Figure 2

(A) Difference $(\Delta)$ in ATP concentration for semen samples at storage temperature $\left(17^{\circ} \mathrm{C}\right)$ and after $15 \mathrm{~min}$ incubation at $38^{\circ} \mathrm{C}(\mathrm{n}=7)$. (B) Differences in ATP concentration expressed as percentage of ATP concentration in samples stored at $17^{\circ} \mathrm{C}$ (starting values). Different lowercase letters $(\mathrm{a}-\mathrm{b})$ indicate significant differences $(P<0.05)$ between different days of storage. All values are means and standard deviations. 
Supplemental Table 1. Percentage of sperm with high mitochondrial transmembrane potential (hMMP), ATP content, and energy charge (EC) of semen samples after 15, 30,60, 120 and 180 minutes incubation in a water bath at $38^{\circ} \mathrm{C}(n=7)$. All values are mean and standard deviation. Different lowercase alphabets $(a-d)$ in each column show significant differences $(P<0.05)$ between storage days.

\begin{tabular}{|c|c|c|c|c|c|c|}
\hline & & & & Incubation tim & & \\
\hline & Storage & $15 \mathrm{~min}$ & $30 \mathrm{~min}$ & $60 \mathrm{~min}$ & $120 \mathrm{~min}$ & $180 \mathrm{~min}$ \\
\hline \multirow{5}{*}{$\begin{array}{l}\text { hMMP } \\
(\%)\end{array}$} & Day 0 & $92.5 \pm 3.02^{\mathrm{a}}$ & $82.9 \pm 5.87^{a}$ & $32.95 \pm 29.4^{\mathrm{a}}$ & $4.0 \pm 5.14^{\mathrm{a}}$ & $0.7 \pm 1.29^{\mathrm{a}, \mathrm{b}}$ \\
\hline & Day 1 & $91.8 \pm 3.08^{\mathrm{a}}$ & $66.5 \pm 28.5^{\mathrm{a}, \mathrm{b}}$ & $38.9 \pm 35.0^{a, b}$ & $9.3 \pm 19.56^{a}$ & $2.3 \pm 2.74^{\mathrm{a}, \mathrm{b}}$ \\
\hline & Day 3 & $85.8 \pm 9.38^{a, b}$ & $61.5 \pm 24.4^{b}$ & $30.1 \pm 36.81^{\mathrm{a}, \mathrm{b}}$ & $6.6 \pm 15.15^{a}$ & $2.7 \pm 5.64^{\mathrm{a}, \mathrm{b}}$ \\
\hline & Day 5 & $82.8 \pm 11.08^{a, b}$ & $69.0 \pm 33.49^{\mathrm{a}, \mathrm{b}}$ & $38.2 \pm 33.66^{a, b}$ & $2.6 \pm 4.64^{\mathrm{a}}$ & $0.1 \pm 0.11^{a}$ \\
\hline & Day 7 & $82.9 \pm 5.75^{b}$ & $45.6 \pm 29.53^{b}$ & $13.5 \pm 20.32^{b}$ & $6.0 \pm 12.58^{a}$ & $0.4 \pm 0.3^{b}$ \\
\hline \multirow{5}{*}{$\begin{array}{l}\text { ATP } \\
\left(\mathrm{pmol} / 10^{5} \text { sperm }\right)\end{array}$} & Day 0 & $421.3 \pm 54.6^{a}$ & $418.5 \pm 33.1^{\mathrm{a}}$ & $381.3 \pm 46.2^{a}$ & $323.8 \pm 16.0^{a}$ & $284.7 \pm 38.1^{\mathrm{a}, \mathrm{d}}$ \\
\hline & Day 1 & $326.5 \pm 12.6^{b}$ & $340.3 \pm 45.3^{b}$ & $326.8 \pm 30.3^{b}$ & $303.2 \pm 15.6^{b}$ & $296.9 \pm 32.9^{a}$ \\
\hline & Day 3 & $387.9 \pm 43.6^{\mathrm{a}, \mathrm{c}}$ & $415.5 \pm 67.8^{a, c}$ & $389.5 \pm 60.9^{a}$ & $367.9 \pm 37.2^{c}$ & $350.8 \pm 36.0^{b}$ \\
\hline & Day 5 & $338.9 \pm 33.1^{b, c}$ & $356.5 \pm 57.3^{b, c}$ & $306.5 \pm 47.4^{b}$ & $270.94 \pm 21.6^{d}$ & $222.95 \pm 19.4^{c}$ \\
\hline & Day 7 & $325.1 \pm 60.5^{\mathrm{b}}$ & $349.3 \pm 21.0^{b}$ & $313.5 \pm 28.3^{b}$ & $318.1 \pm 34.7^{\mathrm{a}, \mathrm{b}, \mathrm{c}}$ & $277.0 \pm 42.4^{d}$ \\
\hline \multirow{5}{*}{ EC } & Day 0 & $0.74 \pm 0.05^{\mathrm{a}}$ & $0.65 \pm 0.05^{\mathrm{a}, \mathrm{c}}$ & $0.67 \pm 0.03^{a, b}$ & $0.61 \pm 0.05^{a, b}$ & $0.57 \pm 0.04^{\mathrm{a}, \mathrm{c}}$ \\
\hline & Day 1 & $0.67 \pm 0.03^{b}$ & $0.72 \pm 0.02^{b}$ & $0.60 \pm 0.07^{a, c}$ & $0.57 \pm 0.04^{a}$ & $0.53 \pm 0.02^{b}$ \\
\hline & Day 3 & $0.66 \pm 0.09^{\mathrm{a}, \mathrm{b}, \mathrm{c}}$ & $0.63 \pm 0.08^{a}$ & $0.62 \pm 0.04^{a, c}$ & $0.57 \pm 0.06^{a}$ & $0.52 \pm 0.05^{b}$ \\
\hline & Day 5 & $0.72 \pm 0.06^{a, b}$ & $0.70 \pm 0.05^{b, c}$ & $0.69 \pm 0.05^{b}$ & $0.64 \pm 0.03^{b}$ & $0.52 \pm 0.03^{b}$ \\
\hline & Day 7 & $0.62 \pm 0.08^{c}$ & $0.69 \pm 0.02^{a, b, c}$ & $0.60 \pm 0.03^{c}$ & $0.68 \pm 0.04^{c}$ & $0.60 \pm 0.05^{c}$ \\
\hline
\end{tabular}




\section{Chapter 3}

\section{Revisiting storage temperature for liquid preserved boar semen from the perspective of energy metabolism}

\section{Abstract}

The optimum storage temperature for liquid preservation of boar semen has been empirically determined to be between $16^{\circ} \mathrm{C}$ and $18^{\circ} \mathrm{C}$. The aim of the present study was to revisit the current critical storage temperature recommendations from the perspective of sperm energy metabolism. The relationship between energy measures and sperm function at different storage conditions was examined. Moreover, extender influences were considered. Split ejaculates from seven boars were diluted with a standard extender (Beltsville Thawing Solution, BTS) and coldshock protective extender (Androstar $\AA^{\circledR}$ Plus; Minitüb $\mathrm{GmbH}$, Tiefenbach), cooled down to $25,17,10$ and $5^{\circ} \mathrm{C}$ and stored up to $120 \mathrm{~h}$. After $24 \mathrm{~h}, 72 \mathrm{~h}$ and $120 \mathrm{~h}$. ATP levels and energy charge were assessed at storage temperature and after rewarming of spermatozoa to body temperature. Semen samples were assessed for sperm motility (CASA), integrity of plasma and acrosomal membranes (PI and FITCPNA staining), and mitochondria activity (JC-1/PI assay). Motility and membrane status were significantly influenced by storage length, storage temperature and extender $(P<0.05)$. Average total motility and viability were higher than $75 \%$ in both extenders for samples stored up to 5 days at $25^{\circ} \mathrm{C}, 17^{\circ} \mathrm{C}$ or $10^{\circ} \mathrm{C}$. Neither ATP levels, nor energy charge or motility differed for samples stored at $17^{\circ} \mathrm{C}$ or $25^{\circ} \mathrm{C}$. Hypothermic storage at $10^{\circ} \mathrm{C}$ and $5^{\circ} \mathrm{C}$, respectively, lead to a storage-length related decrease of both intracellular ATP levels and AEC and to a concomitant appearance of adenine nucleotides in the extender medium. The energy charge found in Androstar Plus samples at $5^{\circ} \mathrm{C}$ and $10^{\circ} \mathrm{C}$ storage was significantly higher than that in samples diluted in BTS, but no did not differ after re-warming of samples, although Androstar Plus samples contained more motile and viable spermatozoa $(P<0.05)$. The percentage of live sperm with high mitochondrial transmembrane potential decreased with lower storage temperatures $(P<0.05)$. In conclusion, contrary to common expectation, an elevated cell activity during long-term storage at $25^{\circ} \mathrm{C}$ does not lead to a metabolic exhaustion or loss of boar sperm quality. Long-term cooling 
stress at 10 and $5^{\circ} \mathrm{C}$ affects sperm energy metabolism which may contribute to irreversible failure of cell function. The extent of this can be influenced by cold-shock protecting extenders.

Keywords: energy metabolism, cold shock, chilling, long-term storage 


\subsection{Introduction}

Liquid preservation of boar spermatozoa at $16-18^{\circ} \mathrm{C}$ for up to three days is common practice in porcine artificial insemination (Johnson et al. 2000; Riesenbeck 2011). Although spermatozoa from other species are commonly stored at temperatures as low as $5^{\circ} \mathrm{C}$ for artificial insemination (horse: Brogan et al. 2015, bull: Vishwanath and Shannon 2000), this has not become common practice for boar spermatozoa owing to their high cold-shock sensitivity (Drobnis et al. 1993). A lower cholesterol to phospholipid ratio in spermatozoa from pigs compared to less cold-shock sensitive spermatozoa from other species is assumed to be the underlying cause (De Leeuw et al. 1990).

The upper and lower temperature limits for storage of liquid-preserved boar semen have been empirically determined. The common view is that storage at room temperature $\left(20^{\circ} \mathrm{C}\right.$ to $\left.25^{\circ} \mathrm{C}\right)$ has the disadvantage that sperm metabolism is not fully inhibited and thus leads to a depletion of sperm energy reserves (Paulenz et al. 2000, Althouse et al. 1998). In agreement with this theory, the upper temperature limit for storage of liquid boar semen has been suggested to be $20^{\circ} \mathrm{C}$ (Paulenz et al. 2000). A higher percentage of spermatozoa with low mitochondrial membrane potential and a lower average oxidoreductive capability of spermatozoa at $25^{\circ} \mathrm{C}$ compared to $17^{\circ} \mathrm{C}$ point in the same direction (Gaczarewicz et al. 2015).

Lowering the storage temperature below $16-18^{\circ} \mathrm{C}$ would, in theory, further slow-down sperm metabolism. At the same time the probability for a sub-lethal chilling injury increases. The lower temperature limit for boar semen storage has been suggested to be at $12^{\circ} \mathrm{C}$ to $10^{\circ} \mathrm{C}$ which is in agreement with the lower boundary for lipid phase transition processes in whole spermatozoa (Althouse et al. 1998; Schmid et al. 2013).

Chilling of boar spermatozoa below $10^{\circ} \mathrm{C}$ is associated with leakage of ions, ATP and enzymes into the surrounding medium due to membrane disruption (reviewed in White 1993). Recent data indicate that spermatozoa require an increasing amount of ATP to re-activate a fully motile state when stored at $17^{\circ} \mathrm{C}$ (Henning $H$, Nguyen QT, Wallner U, Beyerbach M, Waberski D, unpublished). Low motility in cold-shocked samples is commonly associated with low ATP levels and with a loss in specific 
regulation of ATP-dependent processes, such as calcium influx during capacitation (Dziekońska et al. 2009, Schmid et al. 2013). A non-compensable loss of ATP from the intracellular ATP pool or an unbalanced energy charge may be causative factors in a gradual loss of sperm function in cold-shocked spermatozoa. The sensitivity of boar spermatozoa to cold-shock can be modulated by the composition of the extender (Dziekońska et al. 2009, Schmid et al. 2014, Schulze et al. 2013). Higher percentage of motile and viable spermatozoa at storage temperatures of $10^{\circ} \mathrm{C}$ and $5^{\circ} \mathrm{C}$ have for Androstar Plus extender have been recently reported (Schmid et al. 2014). Whether such protective effects are mediated by a stabilization of the sperm energy metabolism during cooling and storage has not yet been investigated.

The aim of the present study was to revisit the current critical storage temperature recommendations from the perspective of sperm energy metabolism. Therefore, the influence of different storage temperatures, i.e. $25^{\circ} \mathrm{C}, 17^{\circ} \mathrm{C}, 10^{\circ} \mathrm{C}$ and $5^{\circ} \mathrm{C}$, and storage times on energy metabolism of boar spermatozoa was investigated. The relation between sperm energy metabolism and sperm functional parameters was then assessed. In addition, it was tested whether stabilization of membrane integrity and motility at low storage temperatures by using a cold-shock protective extender is associated with a stabilization of the energy metabolism.

\section{2. Material and Methods}

\section{2. 1. Experimental design}

Boar semen $(n=7)$ was split in two parts and diluted in Beltsville Thawing Solution (BTS) or Androstar ${ }^{\circledR}$ Plus (ASP) to a sperm concentration of $20 \times 10^{6} \mathrm{sperm} / \mathrm{ml}$. Split samples were stored at $25^{\circ} \mathrm{C}, 17^{\circ} \mathrm{C}, 10^{\circ} \mathrm{C}$ and $5^{\circ} \mathrm{C}$, respectively, and analyzed after $24 \mathrm{~h}, 72 \mathrm{~h}$, and $120 \mathrm{~h}$ storage, respectively. ATP concentration, adenylate energy charge (EC), as well as viability and acrosome integrity were assessed in stored samples and after $15 \mathrm{~min}$ incubation of the samples at $38^{\circ} \mathrm{C}$. The percentage of live sperm with high mitochondrial transmembrane potential, and motility parameters as assessed by computer assisted semen analysis (CASA) were determined only in samples incubated for $15 \mathrm{~min}$ at $38^{\circ} \mathrm{C}$. 


\section{2. 2. Chemicals}

All chemicals were of analytical grade and, unless otherwise stated, obtained from Sigma-Aldrich (Steinheim, Germany), Merck (Darmstadt, Germany), and Roth (Karlsruhe, Germany), respectively. Propidium iodide (PI) was obtained from Sigma Aldrich (Steinheim, Germany), while Hoechst 33342 (H342) was purchased from life technologies (Darmstadt, Germany). Peanut agglutinin conjugated to fluoresceinisothiocyanate (PNA-FITC) and 5,5',6,6'-tetrachloro-1,1',3,3'-tetraethylimidacarbocyanine iodide (JC-1) were both from Enzo Life Sciences (Lörrach, Germany).

\section{2. 3. Semen processing}

Semen was collected from seven healthy, mature boars housed at the facilities of the Unit for Reproductive Medicine, University of Veterinary Medicine Hannover. From each boar, one ejaculate was collected by the gloved hand method into disposable collection bags with integrated filter to remove the gel fraction. Collection bags were mounted in pre-warmed thermos cups $\left(38^{\circ} \mathrm{C}\right)$ to prevent any cold-shock for the spermatozoa. After collection, the semen was immediately transferred to the laboratory in Styrofoam boxes. Sperm motility was evaluated subjectively for native ejaculates within 15 min after collection. Sperm concentration was determined using a "Thoma neu" counting chamber with phase-contrast microscope (Zeiss, Jena, Germany) at 200x magnification (ocular 10x, objective 20x, phase 1). Morphology of fixed spermatozoa was evaluated as described in Nguyen et al. (unpublished). Ejaculates with more than $70 \%$ motile and less than $25 \%$ morphologically abnormal sperm were diluted isothermically $\left(33^{\circ} \mathrm{C}\right)$ on a split-sample basis with Beltsville Thawing Solution (BTS) or Androstar ${ }^{\circledR}$ Plus (both from Minitube, Tiefenbach, Germany) to a concentration of $20 \times 10^{6}$ cells $/ \mathrm{ml}$. Four samples of $100 \mathrm{~mL}$ semen for each extender were prepared in screw cap bottles for semen storage (Minitube), i.e. one bottle for each storage temperature. The samples were stepwise cooled to $25^{\circ} \mathrm{C}$, $17^{\circ} \mathrm{C}, 10^{\circ} \mathrm{C}$, and $5^{\circ} \mathrm{C}$, respectively. Bottles were kept at room temperature for 1 hour. Thereafter, one bottle from each extender was transferred to an incubator and stored at $25^{\circ} \mathrm{C}$. After a total of $1.5 \mathrm{~h}$ at room temperature, all remaining samples were transferred to a $17^{\circ} \mathrm{C}$ storage unit. A subset of samples was kept for $60 \mathrm{~min}$ at $17^{\circ} \mathrm{C}$ and then transferred to a storage unit set at $10^{\circ} \mathrm{C}$. After a further $60 \mathrm{~min}$ at $10^{\circ} \mathrm{C}$, one 
bottle each of BTS or Androstar ${ }^{\circledR}$ Plus diluted semen was finally transferred to a $5^{\circ} \mathrm{C}$ storage unit. Semen samples were analysed after 24 h, 72 h, and 120 h storage, respectively. During storage semen samples were gently mixed once daily.

\section{2. 4. Computer-assisted semen analysis (CASA)}

Semen samples were analysed as described in Nguyen et al. (unpublished). Briefly, $2 \mathrm{ml}$ semen were incubated at $38^{\circ} \mathrm{C}$ for $15 \mathrm{~min}$ before motility was analysed on a computer-assisted sperm analysis system (Sperm Vision®; Minitube, Tiefenbach, Germany). Total motility (TM; \%) and progressive motility (PM; \%) were recorded as well as average path velocity (VAP, $\mu \mathrm{m} / \mathrm{s})$, curvilinear velocity $(\mathrm{VCL}, \mu \mathrm{m} / \mathrm{s})$, straightline velocity $(V S L ; \mu \mathrm{m} / \mathrm{s})$, straightness (STR = VSL/VAP), linearity $(\mathrm{LIN}=\mathrm{VSL} / \mathrm{VCL})$, wobble $(\mathrm{WOB}=\mathrm{VAP} / \mathrm{VCL})$, amplitude of lateral head-displacement $(\mathrm{ALH} ; \mu \mathrm{m})$, and beat cross frequency (BCF; Hz) for each single spermatozoon. Average values of all sperm kinematic parameters were calculated for progressive motile spermatozoa. $A$ spermatozoon was defined by a head area between $23 \mu \mathrm{m}^{2}$ and $120 \mu \mathrm{m}^{2}$. It was considered to be motile when its average head orientation change (AOC) was higher than $2.5^{\circ}$, and considered to be progressively motile when the distance moved from $A$ to $B$ in a straight line (VSL) exceeded $4.5 \mu \mathrm{m}$

\section{2. 5. Assessment of viability and acrosome integrity}

The integrity of the plasma and acrosomal membrane was assessed using a triple stain procedure with propidium iodide $(\mathrm{PI})$, fluorescein-isothiocyanate-conjugated peanut agglutinin (PNA-FITC) and Hoechst 33342. Spermatozoa with intact plasma membrane and damaged plasma membrane are differentially stained with propidium iodide (PI). PNA-FITC was used to distinguish between spermatozoa with intact and defective outer acrosomal membrane. Hoechst 33342 stains the chromatin of all DNA-containing particles in the sample, thereby allowing to distinguish between cells and debris.

Aliquots of $2 \mathrm{ml}$ diluted semen were incubated for 10 minutes in a water bath at $38^{\circ} \mathrm{C}$. An aliquot of incubated semen was mixed with $\mathrm{PI}$ (final concentration: 5 $\mu \mathrm{g} / \mathrm{mL}$ ), PNA-FITC (final concentration: $3 \mu \mathrm{g} / \mathrm{mL}$ ) and Hoechst 33342 (final concentration: $0.75 \mu \mathrm{g} / \mathrm{mL}$ ). Samples were incubated for another 5 minutes at $38^{\circ} \mathrm{C}$ 
and then transferred to a HEPES-buffered saline solution (HBS; $137 \mathrm{mM} \mathrm{NaCl}, 20$

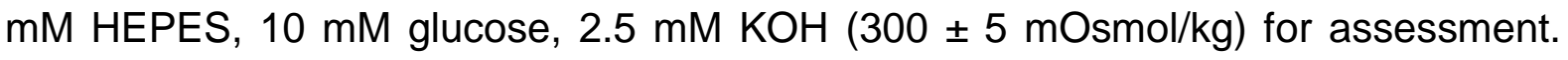
Analysis of stained samples was performed on a DAKO Galaxy flow cytometer (Dako Cytomation GmbH, Hamburg, Germany), equipped with a 488-nm blue argon laser (15 mW), an HBO lamp (excitation main peak at $365 \mathrm{~nm}$ ) and filters for green (537.5/22.5 nm, FL-1), orange (590/25 nm, FL-2), red (630 nm LP, FL-3) and blue emitted light (465 nm BP, FL-4), respectively. In total, 10,000 events were recorded per sample. The sperm population was defined as DNA-containing events $(\mathrm{H} 342$ positive) in the size range of single spermatozoa as assessed by characteristic forward scatter distribution patterns. The percentage of viable (PI negative) spermatozoa with an intact acrosome (PNA-FITC negative) was evaluated using FloMax ${ }^{\circledR}$ software (version 2.8, Partec, Münster, Germany). Overlap of emission spectra between FITC and PI was compensated post acquisition.

\section{2. 6. Assessment of mitochondrial transmembrane potential in live spermatozoa}

The mitochondrial transmembrane potential (MMP) in spermatozoa was assessed using 5,5',6,6'-tetrachloro-1,1',3,3'-tetraethyl-imidacarbocyanine iodide (JC-1) in combination with propidium iodide (PI) and Hoechst 33342 (H342) as described in Nguyen et al. (2015, unpublished). Hoechst 33342 (H342) allowed to distinguish between DNA-containing events (predominantly spermatozoa) and debris. The use of PI allowed to restrict data evaluation to live (PI negative) spermatozoa. A semen sample $(970 \mu \mathrm{l})$ was mixed with $1 \mu \mathrm{JC}-1$ stock solution $(1.53 \mathrm{mM}), 10 \mu \mathrm{l}$ Hoechst 33342 stock solution $(150 \mu \mathrm{g} / \mathrm{ml})$, and $20 \mu \mathrm{l}$ Pl stock solution $(1 \mathrm{mg} / \mathrm{ml})$. Subsequently, samples were incubated for $15 \mathrm{~min}$ at $38^{\circ} \mathrm{C}$ in a water bath. A $5 \mu \mathrm{l}$ subsample was transferred into preheated HBS solution $\left(38^{\circ} \mathrm{C}\right)$ and 10,000 events were analysed on the DAKO Galaxy flow cytometer described above. Data evaluation was restricted to live, single spermatozoa, i.e. H342 positive, but PI negative events with a forward scatter signal in the range of single spermatozoa. Live spermatozoa with a high green, but low orange fluorescence intensity were considered as having a low mitochondrial transmembrane potential (IMMP) while spermatozoa with low green, but high orange fluorescence intensity were considered as having a high mitochondrial transmembrane potential (hMMP). 


\section{2. 7. ATP and energy charge assay}

The ATP concentration and adenylate energy charge $(E C)$ were determined using a luciferase reaction kit according as described in Henning et al. (unpublished; FL-AA kit, Sigma-Aldrich, Steinheim, Germany). Samples of diluted boar semen (100 $\mu$ l) were directly taken at the storage temperatures of $25,17,10$ and $5^{\circ} \mathrm{C}$ and after having incubated the samples for $15 \mathrm{~min}$ at $38^{\circ} \mathrm{C}$. They were mixed with $1 \mu \mathrm{l}$ phosphatase inhibitor cocktail (P5726, Sigma-Aldrich, Steinheim, Germany) and kept on ice for $30 \mathrm{~min}$. After inhibitor treatment samples were stored at $-20^{\circ} \mathrm{C}$ for later ATP and EC assessment. For extraction of nucleotides, a heated boiling buffer (50 $\mathrm{mM}$ Tricine, $10 \mathrm{mM} \mathrm{MgSO}_{4}, 2 \mathrm{mM}$ EDTA, $\mathrm{pH}=7,8$ ) was added to aliquots of frozen semen samples and the mixture was kept for $10 \mathrm{~min}$ at $95^{\circ} \mathrm{C}$ to $96^{\circ} \mathrm{C}$. Thereafter, the tubes were chilled on ice for $10 \mathrm{~min}$ and subsequently centrifuging at $5000 \mathrm{xg}$ for 30 min at $4^{\circ} \mathrm{C}$ (Universal $30 \mathrm{RF}$, Hettich, Germany). The supernatant was used for determination of ATP and EC. All procedures were carried out as detailed in Henning et al (unpublished). ATP concentration was calculated as pmol ATP per $10^{6}$ spermatozoa. The energy charge was calculated as described by Ball and Atkinson (1975) by the formula:

$$
\text { Adenylate energy charge }(\mathrm{EC})=\frac{[\mathrm{ATP}]+0.5[\mathrm{ADP}]}{[\mathrm{ATP}]+[\mathrm{ADP}]+[\mathrm{AMP}]}
$$

\section{2. 8. Statistical analysis}

Data were analysed with Excel (Microsoft Office 2010, Microsoft Corporation, Washington, USA) and Statistical Analysis Software (SAS, version 9.3, Cary, NC, USA). Data from all parameters were tested for normal distribution with a Shapiro Wilk test. The majority of parameters was not normal distributed even after logarithmic or quadratic transformation. Pair-wise comparisons of data from different storage temperatures and extenders were done with Wilcoxon's signed rank test for paired samples. Spearman rank correlation coefficients were calculated for selected parameters. The significance level was set at $P<0.05$. 


\section{3. Results}

\section{3. 1. ATP content, energy charge, and membrane integrity of boar sperm at different storage temperatures}

Samples stored at $17^{\circ} \mathrm{C}$ were considered as reference point for all comparisons, because this temperature has been accepted as optimal storage temperature for liquid preserved pig spermatozoa. The ATP content of semen samples at $5^{\circ} \mathrm{C}$ in BTS extender was on all days of storage lower $(P<0.05)$ when compared to samples at $17^{\circ} \mathrm{C}$ (Figure $1 \mathrm{~A}$ ). The ATP content did not differ between semen stored at $25^{\circ} \mathrm{C}$, $17^{\circ} \mathrm{C}$ and $10^{\circ} \mathrm{C}$ at each day of storage for a given extender. On day 1 and day 5 , samples stored at $5^{\circ} \mathrm{C}$ in Androstar $^{\circledR}$ Plus had even similar ATP levels when compared to samples at higher storage temperatures. A significant difference between both extenders was noted on day 1 for samples stored at $5^{\circ} \mathrm{C}$. Samples stored in Androstar $^{\circledR}$ Plus had a higher ATP content than samples stored in BTS $(\mathrm{P}<0.05)$.

The energy charge did not differ between samples stored at $17^{\circ} \mathrm{C}$ or $25^{\circ} \mathrm{C}$ for both extenders (Figure 1B). The average value was on all days higher than 0.65 for each combination of extender and storage temperature (Figure 1B). At all days, Samples stored at $10^{\circ} \mathrm{C}$ or $5^{\circ} \mathrm{C}$ had always a lower energy charge when compared to samples at $17^{\circ} \mathrm{C}$ and $25^{\circ} \mathrm{C}(\mathrm{P}<0.05)$. The energy charge in samples stored at $5^{\circ} \mathrm{C}$ was lower than the energy charge for samples at $10^{\circ} \mathrm{C}$ when BTS extender was used $(P<0.05)$. When samples were stored at $5^{\circ} \mathrm{C}$ and $10^{\circ} \mathrm{C}$ in Androstar ${ }^{\circledR}$ Plus, the energy charge did not differ $(P>0.05)$. A drop in energy charge to values of less or equal than 0.50 was present on day 3 for samples stored at $5^{\circ} \mathrm{C}$, and on day 5 for samples stored at $5^{\circ} \mathrm{C}$ and $10^{\circ} \mathrm{C}$, respectively. A difference in energy charge for samples stored either in BTS or Androstar ${ }^{\circledR}$ Plus was only noted on day 1 at $10^{\circ} \mathrm{C}$ and $5^{\circ} \mathrm{C}$.

The sum of nucleotides, i.e. AMP, ADP, and ATP, that could be detected in the extender was the higher, the lower the storage temperature was (Supplemental Figure 1). Almost no nucleotides could be detected in samples stored at $25^{\circ} \mathrm{C}$ and $17^{\circ} \mathrm{C}$. The nucleotide concentration was between 50 and 100 pMol per $25 \mu \mathrm{l}$ extender at $10^{\circ} \mathrm{C}$ and higher than $200 \mathrm{pmol}$ per $25 \mu$ l extender for samples stored at $5^{\circ} \mathrm{C}$. Fluctuations over time at a given storage temperature were not detected. 
The percentage of viable sperm with intact acrosomes (PI \& PNA-FITC negative) was on average higher than $65 \%$ for all combinations of storage temperature and storage time in both extenders (Figure $1 \mathrm{C}$ ). For samples stored at $25^{\circ} \mathrm{C}, 17^{\circ} \mathrm{C}$ and $10^{\circ} \mathrm{C}$, respectively, the average values were higher than $80 \%$ throughout the whole experiment irrespectively of the extender. On day 1 and day 3, samples stored at $10^{\circ} \mathrm{C}$ or $5^{\circ} \mathrm{C}$ in BTS contained less viable, acrosome-intact sperm than samples stored at $17^{\circ} \mathrm{C}$ or $25^{\circ} \mathrm{C}$ in BTS $(\mathrm{P}<0.05)$. On day 5 , only samples at $5^{\circ} \mathrm{C}(67.2 \pm$ $12.10 \%)$ differed from the samples at $17^{\circ} \mathrm{C}(89.2 \pm 5.39 \%)$ and $25^{\circ} \mathrm{C}(87.3 \pm 6.81$ $\%$; both $\mathrm{P}<0.05)$. A differences between samples stored at $10^{\circ} \mathrm{C}$ and $5^{\circ} \mathrm{C}$ was present on all days of storage. In BTS extender, no difference in the percentage of viable, acrosome intact spermatozoa was detected between samples stored at $25^{\circ} \mathrm{C}$ or $17^{\circ} \mathrm{C}$. When Androstar ${ }^{\circledR}$ Plus was used, samples stored at $25^{\circ} \mathrm{C}$ contained less viable, acrosome intact spermatozoa than samples stored at $17^{\circ} \mathrm{C}$. At day 1 and 3 , samples stored at $10^{\circ} \mathrm{C}$ in Androstar ${ }^{\circledR}$ Plus had less viable, acrosome intact sperm than samples at $17^{\circ} \mathrm{C}$ ( $\Delta$ day $1: 2.2 \% ; \Delta$ day $3: 1.5 \%$; both $\left.\mathrm{P}<0.05\right)$. On day 5 samples in Androstar ${ }^{\circledR}$ Plus did not differ at $17^{\circ} \mathrm{C}(90.3 \pm 3.76 \%)$ and $10^{\circ} \mathrm{C}(87.8 \pm$ $5.78 \% ; \mathrm{P}>0.05)$. Samples at $5^{\circ} \mathrm{C}$ had always lower values when compared to samples at $17^{\circ} \mathrm{C}$ or $10^{\circ} \mathrm{C}$, but were still on a high level (day 5: $81.6 \pm 6.03 \%$ ) in Androstar ${ }^{\circledR}$ Plus. Differences between both extenders were most prominent for samples stored at $5^{\circ} \mathrm{C}$, with values of $85.0 \pm 4.16 \%$ for Androstar ${ }^{\circledR}$ Plus and $70.2 \pm$ $8.09 \%$ for BTS already at day 1. Smaller differences between both extenders for samples stored at $10^{\circ} \mathrm{C}$ were detectable on day 1 and day 3 with a maximum average difference of $7 \%$ on day 3 .

\section{3. 2. ATP content, energy charge, mitochondrial transmembrane potential and membrane integrity after incubation at $38^{\circ} \mathrm{C}$}

The ATP content of the semen samples after incubation at $38^{\circ} \mathrm{C}$ on day 1 was similar irrespectively of the storage temperature (Figure $2 A ; P>0.05$ ). On day 3 and day 5 , samples stored at $5^{\circ} \mathrm{C}$ in BTS had lower ATP content than samples stored at $17^{\circ} \mathrm{C}$. On day 3 , this was only a trend for samples stored in Androstar ${ }^{\circledR}$ Plus $(P=0.0781)$, but became significant on day $5(P<0.05)$. The ATP levels for samples stored at $10^{\circ} \mathrm{C}$ where lower compared to samples stored at $17^{\circ} \mathrm{C}$ only on day 5 of 
storage in BTS. Samples at $25^{\circ} \mathrm{C}$ and $17^{\circ} \mathrm{C}$ did not differ at the different days of storage for both extenders.

In general, the energy charge tended to be lower after incubation at $38^{\circ} \mathrm{C}$ when compared to values at storage temperature. This was especially evident for samples stored at $25^{\circ} \mathrm{C}$ and $17^{\circ} \mathrm{C}$. On day 1 , values ranged between $0.71 \pm 0.09$ and $0.45 \pm$ 0.12 for samples stored in $\mathrm{BTS}$ at $25^{\circ} \mathrm{C}$ and $5^{\circ} \mathrm{C}$, respectively. After incubation at $38^{\circ} \mathrm{C}$, the values for the same samples were $0.60 \pm 0.09$ and $0.46 \pm 0.13$, respectively. However, at day 1 , no differences were detected between samples stored at different temperatures in BTS after incubation at $38^{\circ} \mathrm{C}$ (Figure 2). On day 3 and 5 , samples stored at $5^{\circ} \mathrm{C}$ had a lower energy charge compared to samples at $17^{\circ} \mathrm{C}(\mathrm{P}<0.05)$. On day 5 , also samples stored at $10^{\circ} \mathrm{C}(0.50 \pm 0.09)$ had a distinct lower energy charge compared to samples at $17^{\circ} \mathrm{C}(0.68 \pm 0.1 ; \mathrm{P}<0.05)$. A similar pattern was observed for spermatozoa preserved in Androstar ${ }^{\circledR}$ Plus . Only exception was that already on day 1 , samples stored at $5^{\circ} \mathrm{C}(0.49 \pm 0.10)$ had a lower energy charge after incubation than samples stored at $17^{\circ} \mathrm{C}(0.67 \pm 0.10 \mathrm{P}<0.05)$.

The percentage of live spermatozoa with high mitochondrial transmembrane potential (hMMP) after incubation at $38^{\circ} \mathrm{C}$ was on day 1 and 3 always highest in samples stored at $25^{\circ} \mathrm{C}$ and $17^{\circ} \mathrm{C}$ (Figure 2C). On day 1 , the percentage of live sperm with hMMP was the lower, the colder the spermatozoa had been stored in BTS $\left(17^{\circ} \mathrm{C}\right.$ : $85.3 \pm 5.9 \%, 10^{\circ} \mathrm{C}$ : $77.4 \pm 8.8 \%, 5^{\circ} \mathrm{C} 69.2 \pm 12.1 \%$; all $\left.\mathrm{P}<0.05\right)$. The gradual differences between storage temperatures became the more evident the loner semen was stored. On day 5 , gradual differences between samples stored at $25^{\circ} \mathrm{C}(85.5 \pm 10.2 \%), 17^{\circ} \mathrm{C}(76.5 \pm 18.6 \%)$ and $10^{\circ} \mathrm{C}(67.2 \pm 22.5 \%)$ were observed, samples stored at $5^{\circ} \mathrm{C}(60.4 \pm 22.5 \%$, contained less live sperm with hMMP than samples stored at $25^{\circ} \mathrm{C}$ and $17^{\circ} \mathrm{C}(P<0.05)$, but were not different from samples stored at $10^{\circ} \mathrm{C}(P>0.05)$. In samples diluted with Androstar ${ }^{\Theta} P$ lus , storage at $10^{\circ} \mathrm{C}$ resulted at all days in lower percentages of live sperm with hMMP (day 1: 77.4 $\pm 8.8 \%$, day $3: 62.8 \pm 23.6 \%$, day $5: 67.3 \pm 22.5 \%$ ) compared to samples stored at $17^{\circ} \mathrm{C}$ (day $1: 85.4 \pm 5.9 \%$, day $3: 71.1 \pm 14.7 \%$, day $5: 76.5 \pm 18.6 \%$; all $P<0.05$; Figure $2 \mathrm{C}$ ). For samples stored at $5^{\circ} \mathrm{C}$ this was only the case on day 3 and day 5 of storage. Differences between extenders were not detected for any combination of storage temperature and storage time. 
The percentage of viable, acrosome intact spermatozoa after incubation at $38^{\circ} \mathrm{C}$ was on average higher than $80 \%$ for all combinations of extender, storage temperature and storage length, except for samples stored in BTS at $5^{\circ} \mathrm{C}$ (day $1: 70.2 \pm 8.1 \%$, day 3: $67.6 \pm 15.9 \%$, day 5: $67.2 \pm 12.1 \%$; Supplemental Figure 2). Samples stored at $25^{\circ} \mathrm{C}$ did not differ from samples stored at $17^{\circ} \mathrm{C}$. Samples stored BTS at $17^{\circ} \mathrm{C}$ had higher values for live, acrosome intact spermatozoa than samples stored at $10^{\circ} \mathrm{C}$. Samples stored at $5^{\circ} \mathrm{C}$ contained always the lowest percentage of live, acrosome intact sperm. A similar relation was present on day 1 and day 3 for samples stored in Androstar ${ }^{\circledR}$ Plus. Samples stored in BTS had lower values for live, acrosome intact spermatozoa at $10^{\circ} \mathrm{C}$ and $5^{\circ} \mathrm{C}$ compared to samples stored in Androstar ${ }^{\circledR}$ Plus on all days of storage $(\mathrm{P}<0.05)$.

\section{3. 3. Motility of samples stored at different temperatures}

The average total motility was higher than $75 \%$ in both extenders for samples stored up to 5 days at $25^{\circ} \mathrm{C}, 17^{\circ} \mathrm{C}$ or $10^{\circ} \mathrm{C}$ (Supplemental Table 1 and 2). Samples stored at $5^{\circ} \mathrm{C}$ had a total motility of less than $60 \%$ in BTS, but of more than $70 \%$ in samples stored in Androstar ${ }^{\circledR}$ Plus (c.f. Supplemental Table 1 and 2). Progressive motility was chosen for a detailed comparisons between storage temperatures, because average parameters for motility descriptors are given for progressive motile sperm.

Similar to total motility, progressive motility was higher than $65 \%$ for all samples stored up to five days at $25^{\circ} \mathrm{C}, 17^{\circ} \mathrm{C}$ or $10^{\circ} \mathrm{C}$ (Figure $3 \mathrm{~A}$ ). No difference between samples stored at $25^{\circ} \mathrm{C}$ or $17^{\circ} \mathrm{C}$ were noted at any day of storage. Samples stored at $5^{\circ} \mathrm{C}$ had a progressive motility of less than $40 \%$ in BTS, but of more than $55 \%$ in samples stored in Androstar ${ }^{\circledR}$ Plus (Figure 3A). On all days of storage, progressive motility was lower for samples stored in BTS at $10^{\circ} \mathrm{C}$ when compared to $17^{\circ} \mathrm{C}$. Likewise, motility after storage at $5^{\circ} \mathrm{C}$ was lower when compared to motility after storage at $10^{\circ} \mathrm{C}$. The same relations were observed for samples stored in Androstar ${ }^{\circledR}$ Plus on day 3 and 5 of storage. On day 1 , only samples stored at $5^{\circ} \mathrm{C}$ had a lower progressive motility when compared to samples from higher storage temperatures. Samples in BTS had a lower progressive motility on day 1 and day 3 after storage at $5^{\circ} \mathrm{C}$ or $10^{\circ} \mathrm{C}$ compared to samples stored in Androstar ${ }^{\circledR}$ Plus $(\mathrm{P}<0.05)$. On day 5 , this was only the case for samples stored at $5^{\circ} \mathrm{C}$. 
The curvilinear velocity of progressive motile spermatozoa is on day 1 and day 5 lower for samples stored at $25^{\circ} \mathrm{C}$ (day $1: 85.2 \pm 7.9 \mu \mathrm{m} / \mathrm{s}$, day $5: 82.0 \pm 13.2 \mu \mathrm{m} / \mathrm{s}$ ) and $5^{\circ} \mathrm{C}$ (day 1: $82.9 \pm 9.4 \mu \mathrm{m} / \mathrm{s}$, day $5: 80.1 \pm 13.3 \mu \mathrm{m} / \mathrm{s}$ ) when compared to samples stored at $17^{\circ} \mathrm{C}$ (day 1: $91.2 \pm 12.3 \mu \mathrm{m} / \mathrm{s}$, day 5: $95.0 \pm 15.5 \mu \mathrm{m} / \mathrm{s}$ ) in BTS (Figure 3B, all $\mathrm{P}<0.05$ ). There is at no day a difference between samples stored at $17^{\circ} \mathrm{C}$ or $10^{\circ} \mathrm{C}$ in BTS $(P>0.05)$. On the contrary, progressive motile sperm in Androstar ${ }^{\circledR}$ Plus are significantly faster after storage at $10^{\circ} \mathrm{C}$ and $5^{\circ} \mathrm{C}$ for 3 or 5 days compared to samples held at $17^{\circ} \mathrm{C}$. Their VCL increases during storage at $10^{\circ} \mathrm{C}$ or $5^{\circ} \mathrm{C}$ (Supplemental Table 1). At the same time the linearity, straightness and wobble for spermatozoa stored in Androstar ${ }^{\circledR}$ Plus at $10^{\circ} \mathrm{C}$ and $5^{\circ} \mathrm{C}$ decreased while their amplitude of lateral head-displacement increased (c.f. Supplemental Table 1). For sperm stored in BTS only an increase in VCL between day 1 and day 3 of storage was noted (Supplemental Table 2). Progressive motile spermatozoa displayed a higher VCL in Androstar ${ }^{\circledR}$ Plus at $10^{\circ} \mathrm{C}$ (day 1) and $5^{\circ} \mathrm{C}$ (day 3 and day 5 ) when compared to samples stored in BTS $(\mathrm{P}<0.05)$.

The storage temperature had no influence on linearity of the sperm track in BTSdiluted samples in day 1 (Figure $3 \mathrm{C}$ ). On day 3 and day 5, LIN was lower for samples stored at $10^{\circ} \mathrm{C}$ when compared to $17^{\circ} \mathrm{C}(\mathrm{P}<0.05)$. In Androstar ${ }^{\circledR}$ Plus, samples stored at $5^{\circ} \mathrm{C}$ or $10^{\circ} \mathrm{C}$ had always lower LIN when compared to samples at $17^{\circ} \mathrm{C}$ or $25^{\circ} \mathrm{C}(\mathrm{P}<0.05)$.

The amplitude of lateral head-displacement showed no difference for BTS-stored semen from all temperatures (Figure 3D). On day 3, the ALH was higher for spermatozoa stored at $10^{\circ} \mathrm{C}(2.35 \pm 0.35 \mu \mathrm{m})$ compard to cells stored at $25^{\circ} \mathrm{C}(1.98$ $\pm 0.3 \mu \mathrm{m}), 17^{\circ} \mathrm{C}(2.09 \pm 0.38 \mu \mathrm{m})$ or $5^{\circ} \mathrm{C}(2.05 \pm 0.33 \mu \mathrm{m}$; all $\mathrm{P}<0.05)$. On day $5, \mathrm{ALH}$ for spermatozoa stored at $10^{\circ} \mathrm{C}$ differed only from those stored at $25^{\circ} \mathrm{C}$ and $5^{\circ} \mathrm{C}$. In Androstar ${ }^{\circledR}$ Plus, values for $\mathrm{ALH}$ were already significantly increased after $5^{\circ} \mathrm{C}$ storage $(2.11 \pm 0.18 \mu \mathrm{m})$ when compared to samples stored at $17^{\circ} \mathrm{C}(1.91 \pm 0.25$ $\mu \mathrm{m} ; \mathrm{P}<0.05)$. After 3 days storage, ALH was increased in both, samples at $10^{\circ} \mathrm{C}$ $(2.47 \pm 0.41 \mu \mathrm{m})$ and $5^{\circ} \mathrm{C}(2.49 \pm 0.35 \mu \mathrm{m})$, compared to $17^{\circ} \mathrm{C}(2.15 \pm 0.28 \mu \mathrm{m})$ or $25^{\circ} \mathrm{C}(2.17 \pm 0.34 \mu \mathrm{m})$. The most distinct differences were observed after five days storage. Samples stored at $25^{\circ} \mathrm{C}(2.12 \pm 0.23 \mu \mathrm{m})$ and $17^{\circ} \mathrm{C}(2.11 \pm 0.32 \mu \mathrm{m})$ had still similar values, while $\mathrm{ALH}$ in samples from $10^{\circ} \mathrm{C}$ had increased further $(2.47 \pm$ 
$0.34 \mu \mathrm{m})$. Samples stored at $5^{\circ} \mathrm{C}$ had the highest ALH $(2.72 \pm 0.44 \mu \mathrm{m})$ on day 5 (Figure 3D).

\section{3. 4. Correlation of energy metabolism with sperm function and integrity}

The data from both extenders and all storage temperatures were combined in one data set to calculate correlations for ATP levels and energy charge with parameters of sperm function and integrity (Table 1). The energy charge of samples at storage temperature was significantly correlated with total motility $(r=0.70 ; p<0.001)$, progressive motility $(r=0.71 ; p<0.001)$, the percentage of live spermatozoa with hMMP $(r=0.49 ; p<0.001)$, and the percentage of live acrosome intact cells at $38^{\circ} \mathrm{C}$ $(r=0.62 ; p<0.001)$. The ATP content of samples at storage temperature was also positive correlated to the afore-mentioned parameters, but all correlations coefficients were lower $(0.23$ to 0.42 ; c.f. Table 1$)$. The energy charge and ATP levels measured at storage temperature were also weak to moderate correlated to descriptors of the sperm motility trajectory. In addition to Table 1, correlations were also calculated separately for samples at each different storage temperature (Supplemental Table 3). Correlations between ATP levels or energy charge at storage temperature with sperm parameters similar to the full data set were only present for samples at $5^{\circ} \mathrm{C}$. Correlations of ATP levels at $5^{\circ} \mathrm{C}$ with total motility $(r=0.53 ; p<0.001)$, progressive motility $(r=0.54 ; p<0.001)$, the percentage of live spermatozoa with hMMP $(r=0.33 ; p<0.001)$, and the percentage of live acrosome intact cells at $38^{\circ} \mathrm{C}(r=0.55 ; p<0.001)$ were higher when compared to the full data set. Also correlations of ATP levels with sperm velocity and ALH and BCF were higher when compared to the full data set. Notably, energy charge at $5^{\circ} \mathrm{C}, 10^{\circ} \mathrm{C}$ or $25^{\circ} \mathrm{C}$, but not $17^{\circ} \mathrm{C}$, was consistently positive correlated with progressive motility $(r=0.33$ to $0.45 ; p<0.01)$ and the percentage of live spermatozoa with hMMP $(r=0.34$, $p<0.001$ to $r=0.56 ; p<0.001)$. Similarly, ATP levels at $5^{\circ} \mathrm{C}(r=0.49 ; p<0.001), 17^{\circ} \mathrm{C}$ $(r=0.46 ; p<0.001)$, and $25^{\circ} \mathrm{C}(r=0.57 ; p<0.001)$ were positively correlated with $A L H$.

Surprisingly, the correlations between energy charge after incubation at $38^{\circ} \mathrm{C}$ and total motility $(r=0.58 ; p<0.001)$, progressive motility $(r=0.59 ; p<0.001)$, the percentage of live spermatozoa with hMMP $(r=0.39 ; p<0.001)$, and the percentage of live acrosome intact cells at $38^{\circ} \mathrm{C}(r=0.20 ; p<0.01)$ were weaker than for energy charge at storage temperature. The correlations between ATP levels after incubation 
at $38^{\circ} \mathrm{C}$ and total motility $(r=0.42 ; p<0.001)$, progressive motility $(r=0.48 ; p<0.001)$, the percentage of live spermatozoa with hMMP $(r=0.20 ; p<0.01)$, and the percentage of live acrosome intact cells at $38^{\circ} \mathrm{C}(r=0.38 ; p<0.001)$ were similar to those for ATP levels measured at storage temperature.

\section{4. Discussion}

In the present study, diluted boar semen samples were subjected to different storage temperatures between $25^{\circ} \mathrm{C}$ and $5^{\circ} \mathrm{C}$ to revisit the storage temperature limits for liquid preserved boar spermatozoa from the perspective of cell energy metabolism. The optimum temperature for storage of boar spermatozoa has been determined empirically to be $16-18^{\circ} \mathrm{C}$ (Johnson et al. 2000). This temperature range is a compromise between slowing down sperm activity (as visually judged by motility) and disruption of sperm integrity due to cold shock. Storage temperatures above $20^{\circ} \mathrm{C}$ have been thought to insufficiently slow down sperm metabolism leading to an exhaustion of sperm (Paulenz et al. 2000). Indeed, in individual samples a flagella beating of sperm can be observed when stored at $25^{\circ} \mathrm{C}$. However, the current data clearly show that the potential risk of higher sperm activity and exhaustion due to a lack in energy cannot be confirmed. Neither ATP levels, nor energy charge, nor motility differed for samples stored at $17^{\circ} \mathrm{C}$ or $25^{\circ} \mathrm{C}$ in BTS extender. Mitochondrial function in terms of a stable mitochondrial transmembrane potential in live cells is even slightly better preserved at the higher storage temperature.

The critical lower storage temperature for boar spermatozoa has been suggested to be $12^{\circ} \mathrm{C}$ when using Androhep extender (Althouse et al. 1998) or $10^{\circ} \mathrm{C}$ when using Androstar ${ }^{\circledR}$ Plus (Schmid et al. 2014). At both temperatures, fertility data obtained under field conditions did not differ compared to samples stored at $17^{\circ} \mathrm{C}$. Noteworthy, $9^{\circ} \mathrm{C}$ to $10^{\circ} \mathrm{C}$ is also the lower end point for major phase transition processes in boar spermatozoa (Schmid et al. 2014; Drobnis et al. 1993). The classical view on chilling injury is that due to lipid phase transition and phase separation processes the sperm membranes become leaky (White 1993). In agreement with these observations, a decrease in viable and motile spermatozoa at $10^{\circ} \mathrm{C}$ and $5^{\circ} \mathrm{C}$ was accompanied with a leakage of adenine nucleotides into the extender. The most abundant nucleotide in the extender was AMP. It is most likely that also ATP and ADP leaked into the extracellular environment, but were readily 
degraded to AMP. The presence of AMP in the medium might explain that ATP levels in stored spermatozoa did not differ for samples at $10^{\circ} \mathrm{C}$ and $17^{\circ} \mathrm{C}$, but energy charge was already lower in samples stored at $10^{\circ} \mathrm{C}$. In this respect, samples preserved in an extender with a cold-shock protective substance (Androstar ${ }^{\circledR} \mathrm{Plus}$ ), had a higher energy charge at $10^{\circ} \mathrm{C}$ and $5^{\circ} \mathrm{C}$ which might be due to the stabilization of the plasma membrane.

An important aspect of the study is that ATP levels and energy charge were not only assessed at a given storage temperature, but also after re-warming of samples to body temperature. Surprisingly, lower ATP levels and EC for samples stored at $5^{\circ} \mathrm{C}$ for $24 \mathrm{~h}$ could not be confirmed once samples had been incubated at $38^{\circ} \mathrm{C}$ after. At the same time, the percentage of motile cells in BTS extender was considerably decreased while only a moderate decrease in live sperm with high MMP was found. Earlier research found a high activity of mitochondria shortly after re-warming which may produce a spatio-temporal overshoot in available ATP (Henning H, Nguyen QT, Wallner U, Beyerbach M, Waberski D,unpublished). However, ATP produced by oxidative phosphorylation in the mitochondria has been found dispensable for maintenance of general flagellar beating (Miki et al. 2004). The lack of a phosphagen system in porcine spermatozoa which acts as a transport shuttle for transporting ATP from the mitochondria to the distal dynein-ATPases would preclude the usage of mitochondria-derived ATP (Kamp et al. 1996). The relative high ATP levels after re-warming of samples stored for $24 \mathrm{~h}$ at $5^{\circ} \mathrm{C}$ cannot solely be attributed to mitochondria activity. Glycolysis is supposed to be the main source of ATP in boar spermatozoa in the presence of glucose (Marin et al. 2003). Assuming that glycolysis is still active in sperm after chilling and re-warming, the discrepancy between ATP levels and motility points to a disruption of motility regulating cellular processes by irreversible failure in utilization of ATP. With progressing storage time, also energy balance and production of ATP become highly disturbed.

The differences between extenders for progressive motile and viable, acrosome intact sperm were quite prominent for samples stored at $5^{\circ} \mathrm{C}$. These differences were not reflected in energy charge or ATP content. Only after the most extreme combination of temperature and time $\left(120 \mathrm{~h}, 5^{\circ} \mathrm{C}\right)$, small differences were also found in energy charge. This may point to a stabilizing mechanism of Androstar ${ }^{\circledR}$ Plus on 
the level of the plasma membrane which has, if any, only indirect influence on the intracellular energy balance. Values for energy charge below 0.5 after re-warming of samples stored at $5^{\circ} \mathrm{C}$ to $38^{\circ} \mathrm{C}$ suggest a seriously impaired energy metabolism. The data indicate that motility at $38^{\circ} \mathrm{C}$ can be maintained over a wide range of ATP levels and energy charge. Using an extender with a cold-shock protective substance resulted in the preservation of a high percentage of (progressive) motile and viable sperm in the present study. A protective effect against cold shock has also been reported in other studies (Schmid et al. 2014, Schulze et al. 2013). The discrepancy in observations from measures of sperm energy metabolism and functional parameters might be due the fact that ATP and EC are not related to a single spermatozoon. Both parameters are assessed for the whole sample. An extrapolation of values to single spermatozoa is hardly possible, because of an increasing number of non-viable, leaky spermatozoa and the presence of nucleotides in the extender. Probably, very heterogeneous subpopulations of spermatozoa are present in a given sample with respect to energy metabolism

Chilling and rewarming of spermatozoa below $15^{\circ} \mathrm{C}$ has been associated with capacitation-like changes (Green and Watson 2001). Samples in Androstar ${ }^{\circledR}$ Plus show signs of hyperactivation-like motility patterns that were not detected in BTS stored spermatozoa. The fact that this observation was restricted to one extender is most likely to due to the fact that in Androstar ${ }^{\circledR}$ Plus a much higher percentage of spermatozoa were still able to exhibit progressive motility at later storage times. Intracellular changes may occur due to the temperature decrease that cannot be compensated for.

Spermatozoa require ATP for reactivation of motility (Henning $H$,Nguyen QT, Wallner $U$, Beyerbach $M$, Waberski D, unpublished). The increasing demand of samples for ATP with storage time at $17^{\circ} \mathrm{C}$ to reactivate motility could not be confirmed in this study (data not shown). However, the relatively strong correlations between EC on storage temperature level and motility after subsequent re-warming at $38^{\circ} \mathrm{C}$ suggest that EC at storage temperature might to some extent be determinative for success of motility activation. The relevance of ATP levels for sperm velocity and movement characteristics remains unclear. Correlation coefficients indicate that the relation is rather weak. Indeed, speed of sperm motility and the flagella wave pattern are not 
only dependent on ATP but are highly regulated amongst others by intracellular $\mathrm{pH}$, calcium concentration and protein phosphorylation (reviewed by Harayama 2013; Suarez 2008).

In conclusion, storing semen samples at temperatures between $25^{\circ} \mathrm{C}$ and $10^{\circ} \mathrm{C}$ results only in minor effects on sperm quality. Semen samples exposed to long-term cooling stress at 10 and $5^{\circ} \mathrm{C}$ exhibit a gradual loss of ATP and energy charge which may contribute to irreversible failure of cell function. Extending the possible range of storage temperatures to $5^{\circ} \mathrm{C}$ is facilitated by cold-chock protective extenders. However, the choice of extender had only a minor impact on energy metabolism and ATP levels after rewarming of spermatozoa. Contrary to common expectation, an elevated cell activity during long-term storage at $25^{\circ} \mathrm{C}$ does not lead to a lack of energy and metabolic exhaustion of sperm. 


\section{References}

1. Althouse GC, Wilson ME, Kuster C, Parsley M (1998) Characterization of lower temperature storage limitations of fresh-extended porcine semen. Theriogenology 50: 535-43.

2. Ball WJ Jr, Atkinson DE (1975) Adenylate energy charge in Saccharomyces cerevisiae during starvation. J. Bacteriol. 121: 975-82.

3. Brogan PT, Beitsma M, Henning H, Gadella BM, Stout TA (2015) Liquid storage of equine semen: Assessing the effect of d-penicillamine on longevity of ejaculated and epididymal stallion sperm. Anim. Reprod. Sci 159:155-62.

4. De Leeuw FE, Chen HC, Colenbrander B, Verkleij AJ (1990) Cold-induced ultrastructural changes in bull and boar sperm plasma membranes. Cryobiology 27:171-83.

5. Drobnis EZ, Crowe LM, Berger T, Anchordoguy TJ, Overstreet JW, Crowe JH (1993) Cold shock damage is due to lipid phase transitions in cell membranes: a demonstration using sperm as a model. J Exp Zool. 265: 432437

6. Dziekońska A, Fraser L, StrzeżekJ (2009) Effect of different storage temperatures on the metabolic activity of spermatozoa following liquid storage of boar semen. J. Anim and Feed. Sci. 18:638-649

7. Dziekońska A, Strzezek J (2011) Boar variability affects sperm metabolism activity in liquid stored semen at 5 degrees C. Pol. J. Vet. Sci.14:21- 27.

8. Gaczarzewicz D, Udala J, Piasecka M, Blaszczyk B, Stankiewicz T (2015) Storage temperature of boar semen and its relationship to changes in sperm plasma membrane integrity, mitochondrial membrane potential, and oxidoreductive capability.Turk. J. Biol. 39: 582-594

9. Green CE, Watson PF (2001) Comparison of the capacitation-like state of cooled boar spermatozoa with true capacitation. Reproduction 122: 889-98.

10. Harayama H (2013) Roles of intracellular cyclic AMP signal transduction in the capacitation and subsequent hyperactivation of mouse and boar spermatozoa. J Reprod Dev. 59:421-30.

11. Henning H, Nguyen QT, Wallner U, Piechotta M, Waberski D (unpubliced) The energy status of thermically stressed boar spermatozoa after long-term storage in vitro is not dependent on high mitochondrial membrane potential 
12. Johnson LA, Weitze KF, Fiser P, Maxwell WM (2000)Storage of boar semen. Anim Reprod Sci. 62:143-172.

13. Kamp G, Büsselmann G, Lauterwein J (1996) Spermatozoa: models for studying regulatory aspects of energy metabolism. Experientia 52:487-494.

14. Marin S, Chiang K, Bassilian S, Lee WN, Boros LG, Fernández-Novell JM, Centelles JJ, Medrano A, Rodriguez-Gil JE, Cascante M (2003) Metabolic strategy of boar spermatozoa revealed by a metabolomic characterization. FEBS Lett 554: 342-346.

15. Miki K, Qu W, Goulding EH, Willis WD, Bunch DO, Strader LF, Perreault SD, Eddy EM, O'Brien DA (2004) Glyceraldehyde 3-phosphate dehydrogenase-S, a sperm-specific glycolytic enzyme, is required for sperm motility and male fertility. Proc Natl Acad Sci U S A. 101:16501-16506.

16. Nguyen QT, Wallner U, Beyerback M, Waberski D, Henning H (unpubliced). A revised protocol for efficient extraction of ATP from boar spermatozoa.

17. Paulenz H, Kommisrud E, Hofmo PO (2000) Effect oflong-term storage at different temperatures on the quality of liquid boar semen. Reprod Domest Anim 35: 83-87.

18. Riesenbeck A (2011) Review on international trade with boar semen. Reprod Domest Anim 46 Suppl 2:1-3.

19. Schmid S, Henning $H$, Oldenhof $H$, Wolkers WF, Petrunkina AM, Waberski D (2013). The specific response to capacitating stimuli is a sensitive indicator of chilling injury in hypothermically stored boar spermatozoa. Andrology 1: 376386.

20.Schmid S, Henning H, Petrunkina AM, Weitze KF, Waberski D (2014) Response to capacitating stimuli indicates extender-related differences in boar sperm function. J Anim Sci. 91:5018- 5025.

21. Schulze M, Henning H, Rüdiger K, Wallner U, Waberski D (2013)Temperature management during semen processing: Impact on boar sperm quality under laboratory and field conditions. Theriogenology $80: 990-998$.

22. Suarez SS (2008) Control of hyperactivation in sperm. Hum. Reprod. Update 14: 647-657.

23. Vishwanath $R$, Shannon $P$ (2000) Storage of bovine semen in liquid and frozen state. Anim Reprod Sci. 62: 23-53. 
24. White IG (1993) Lipids and calcium uptake of sperm in relation to cold shock and preservation: a review. Reprod Fertil Dev. 5: 639- 658. 
Figures and Tables

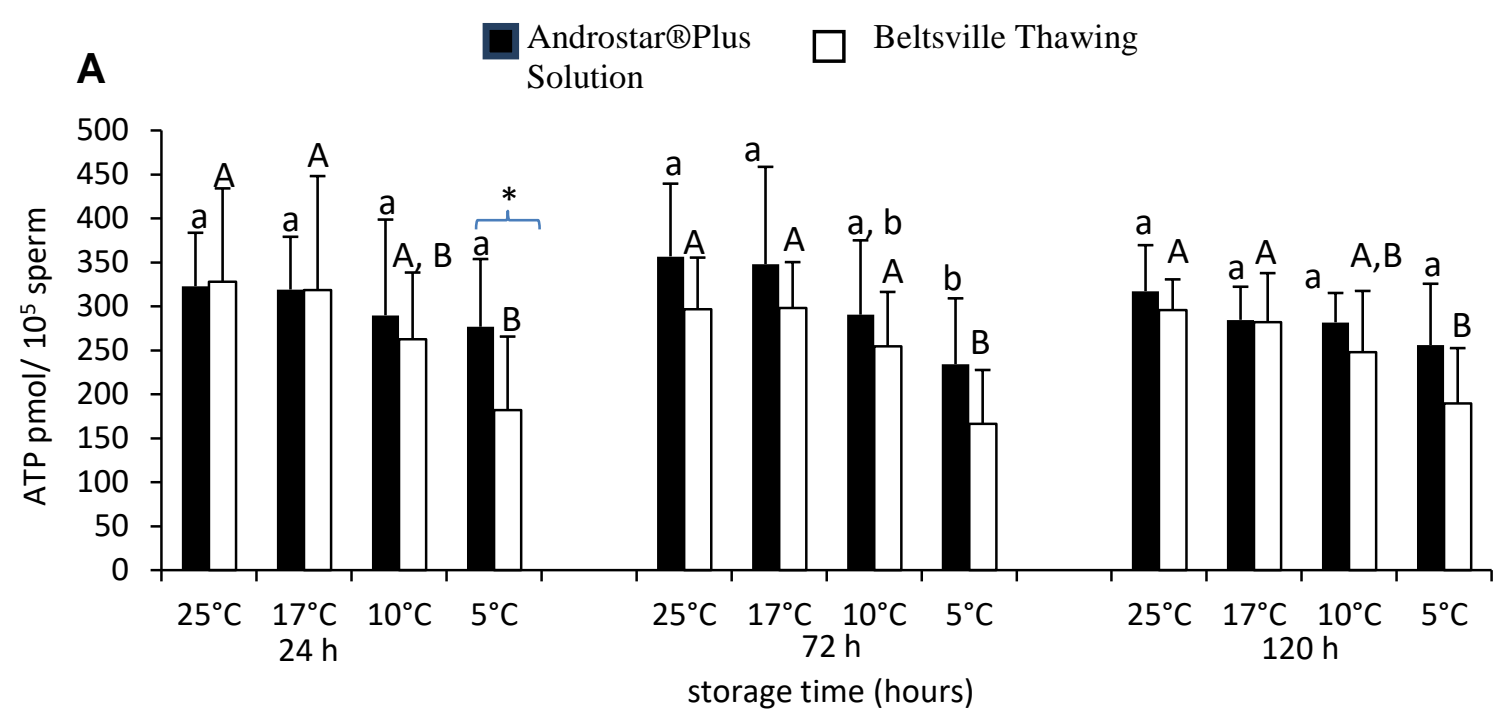

B
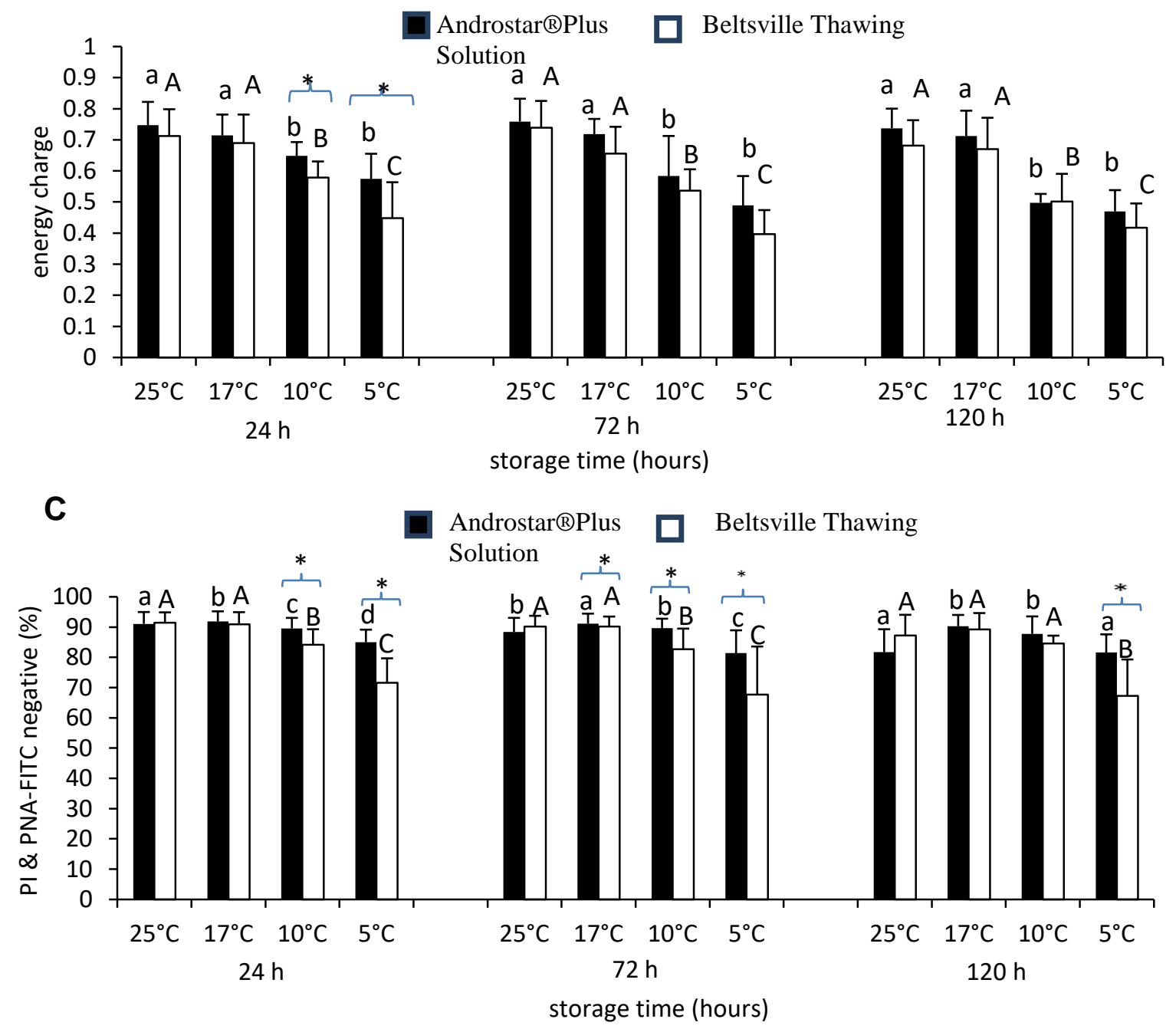
Figure 1. ATP content (A), energy charge $(B)$ and percentage live and acrosome intact sperm (PI \& PNA-FITC negative; $\mathrm{C}$ ) of boar semen samples stored at various temperatures in either Beltsville Thawing Solution (BTS) or Androstar ${ }^{\circledR}$ Plus (ASP). Samples were analysed directly after storage. Data are presented as means \pm standard deviation $(n=7)$. Different letters indicate significant differences between storage temperatures within extenders and days $(P<0.05)$ : ${ }^{a-c}$ for samples diluted in Androstar Plus and ${ }^{A-C}$ for samples diluted in BTS $(P<0.05)$. An asterisk indicates significant differences between extenders $(P<0.05)$. 

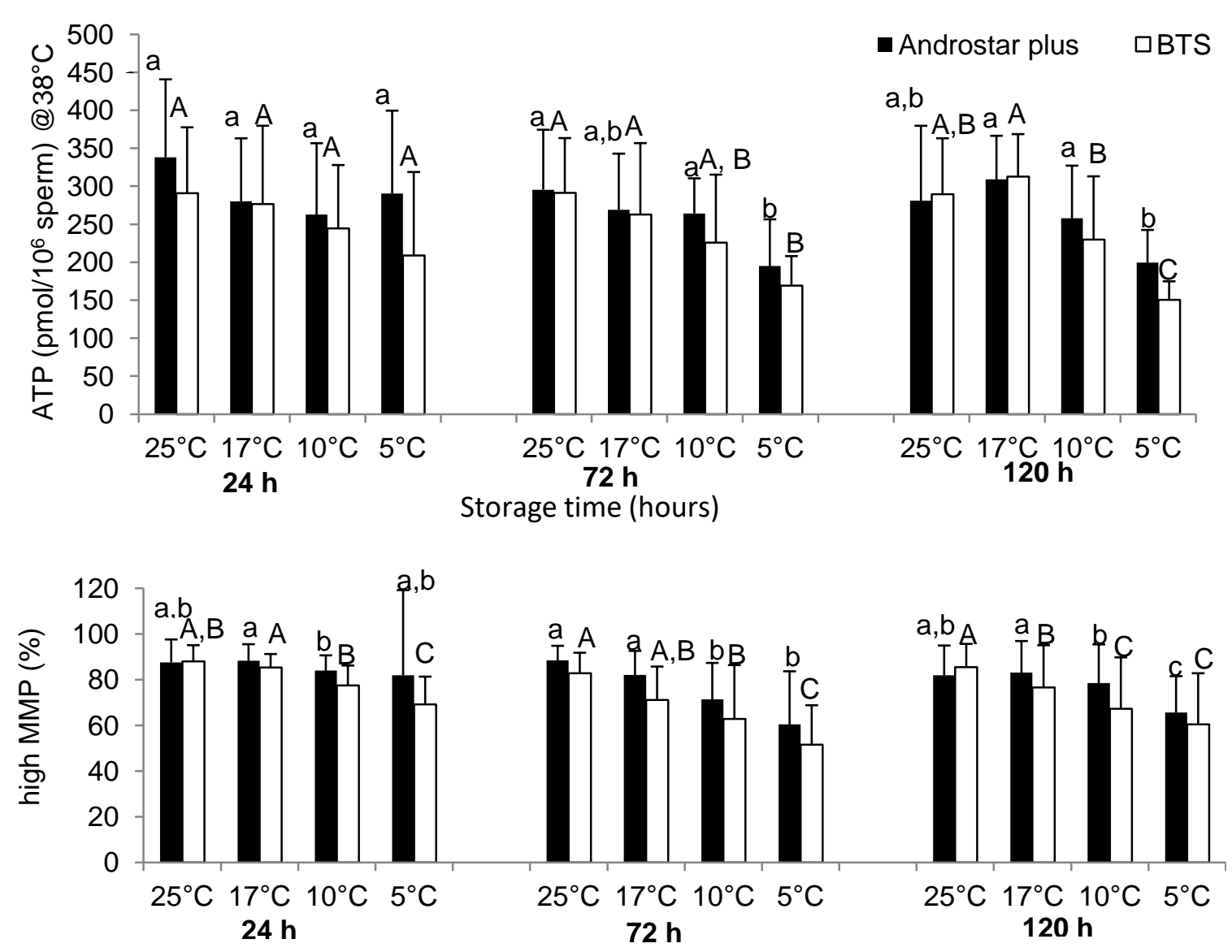

Storage time (hours)

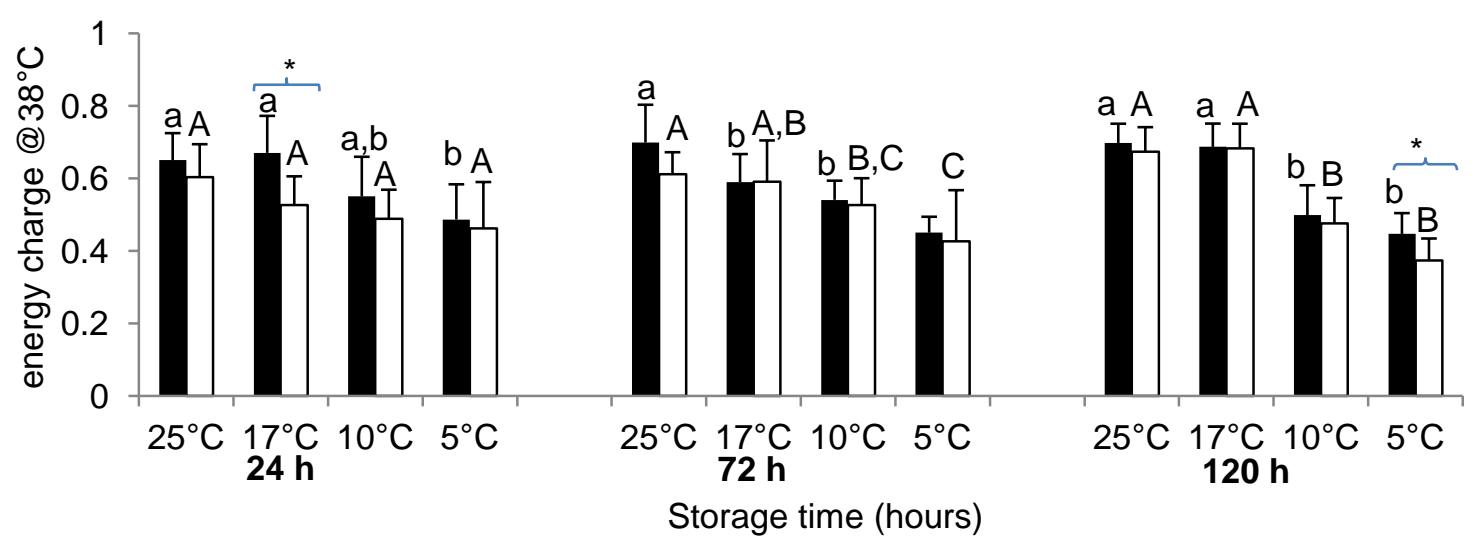

Figure. 2. ATP content (A), energy charge (B) and percentage of sperm with high mitochondrial transmembrane potential $(\mathrm{C})$ after $15 \mathrm{~min}$ incubation at $38^{\circ} \mathrm{C}$ for boar semen samples stored at various temperatures in either Beltsville Thawing Solution (BTS) or Androstar® Plus (ASP). Data are presented as means \pm standard deviation $(n=7)$. Different letters indicate significant differences between storage temperatures within extenders and days $(P<0.05)$ : ${ }^{a-c}$ for samples diluted in Androstar Plus and ${ }^{A-C}$ for samples diluted in BTS $(P<0.05)$. An asterisk indicates significant differences between extenders $(P<0.05)$. 


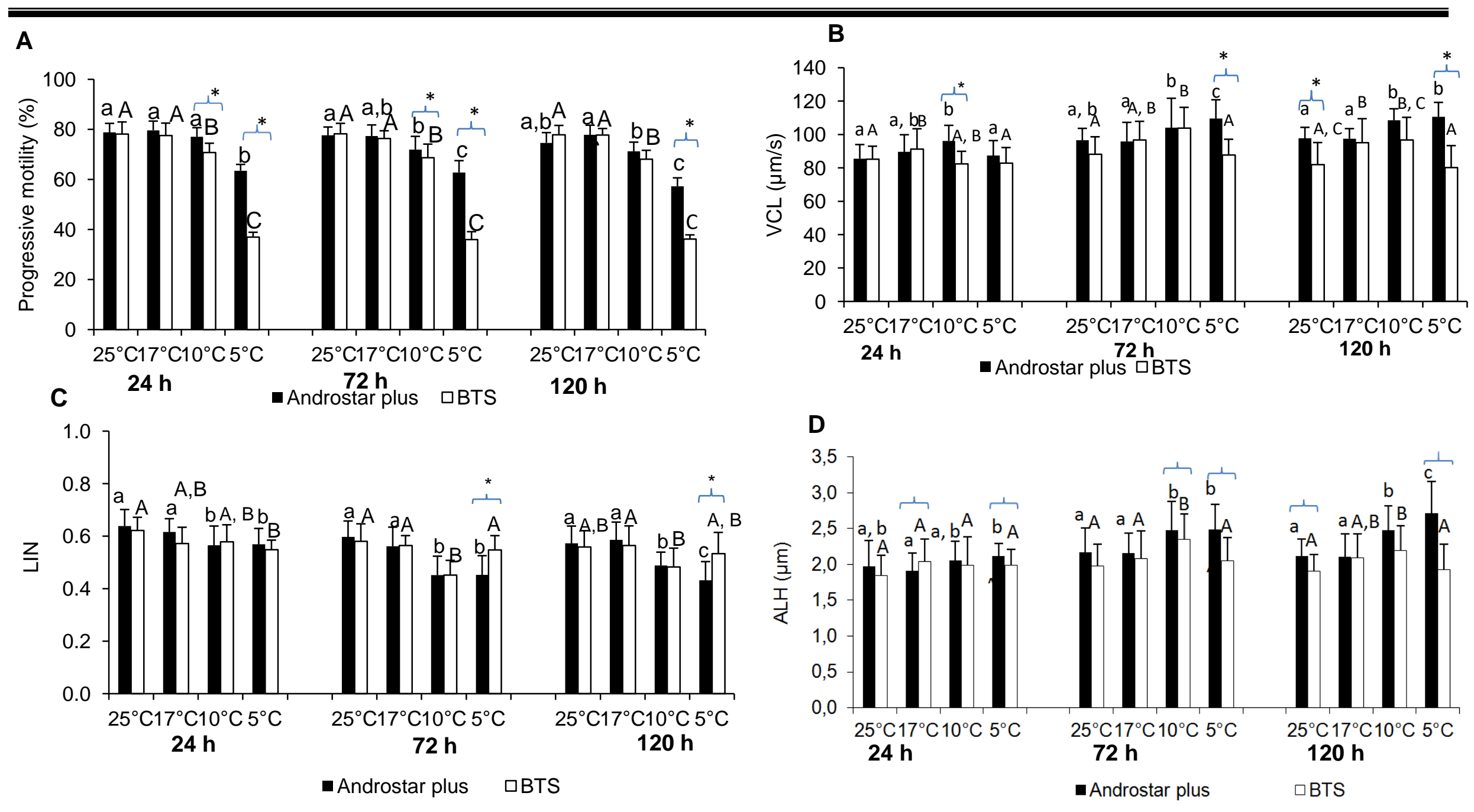

Figure 3. Progressive motility (A), curvilinear velocity (B) and linearity (B) of boar spermatozoa stored at various temperatures in either Beltsville Thawing Solution (BTS) or Androstar ${ }^{\circledR}$ Plus (ASP). Data are presented as means \pm standard deviation $(n=7)$. Different letters indicate significant differences between storage temperatures within extenders and days $(P<0.05)$ : ${ }^{a-c}$ for samples diluted in Androstar Plus and ${ }^{A-C}$ for samples diluted in BTS $(P<0.05)$. An asterisk indicates significant differences between extenders $(P<0.05)$. 


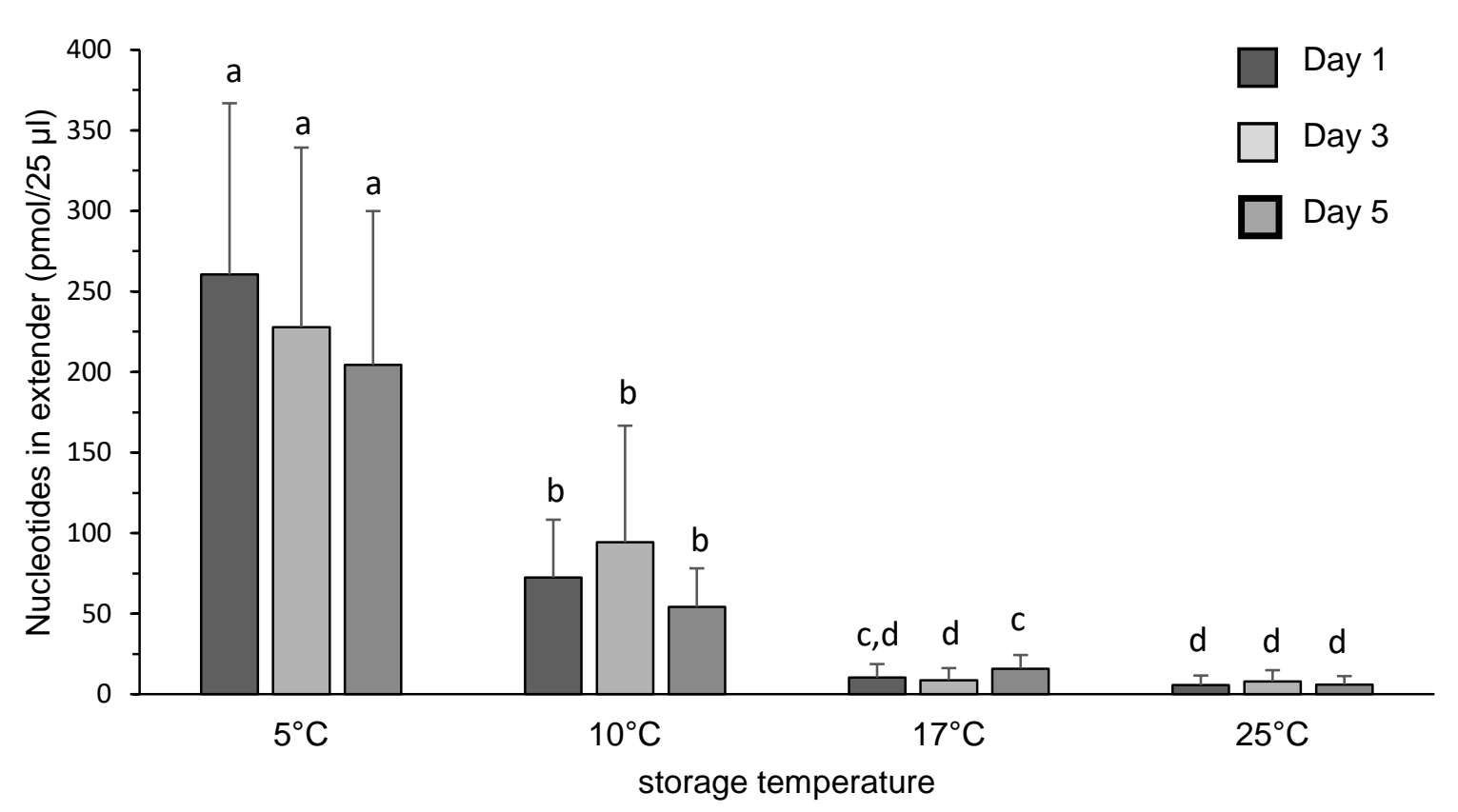

Supplemental Figure 1 Total amount of free nucleotides (AMP, ADP and ATP) in extender of semen samples after storage at different temperatures. Results from both extenders have been combined $(n=14)$. All values are means and standard deviations. Different letters $(a-d)$ indicate significant differences $(P<0.05)$. 


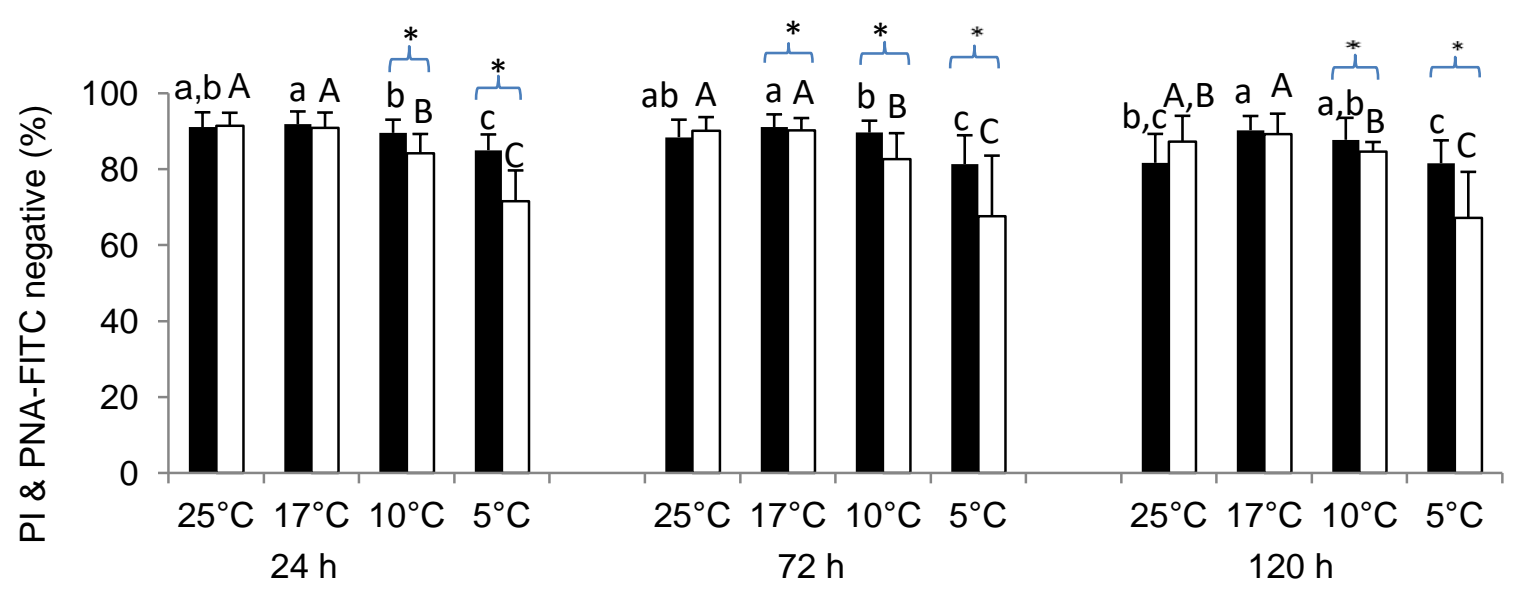

- Androstar plus aBTS

Supplement Figure 2.Membrane integrity of spermatozoa after $15 \mathrm{~min}$ incubation at $38^{\circ} \mathrm{C}$ for boar semen samples stored at various temperatures in either Beltsville Thawing Solution (BTS) or Androstar ${ }^{\circledR}$ Plus. Data are presented as means \pm standard deviation $(n=7)$. Different letters indicate significant differences between storage temperatures within extenders and days $(P<0.05)$ : ${ }^{a-c}$ for samples diluted in Androstar ${ }^{\circledR}$ Plus and ${ }^{A-C}$ for samples diluted in BTS $(P<0.05)$. An asterisk indicates significant differences between extenders $(P<0.05)$. 


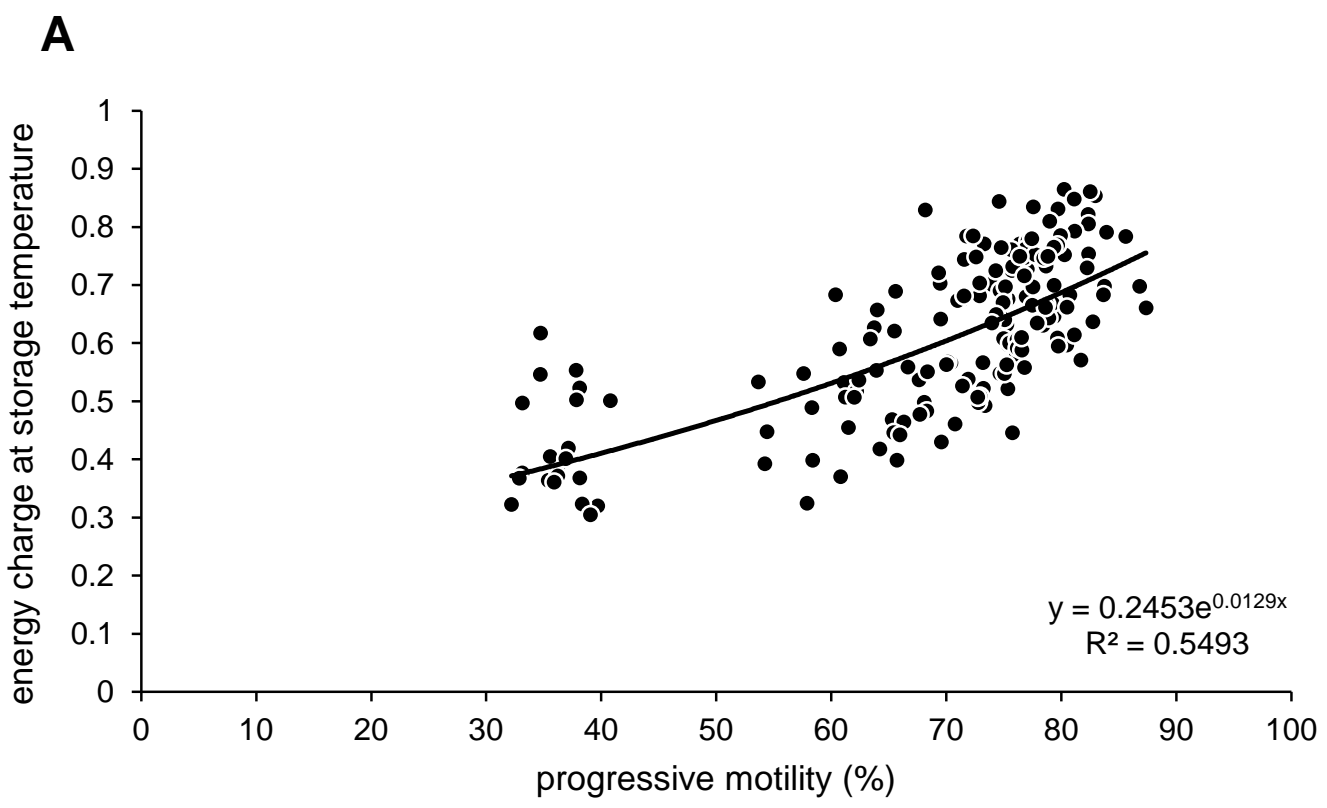

B

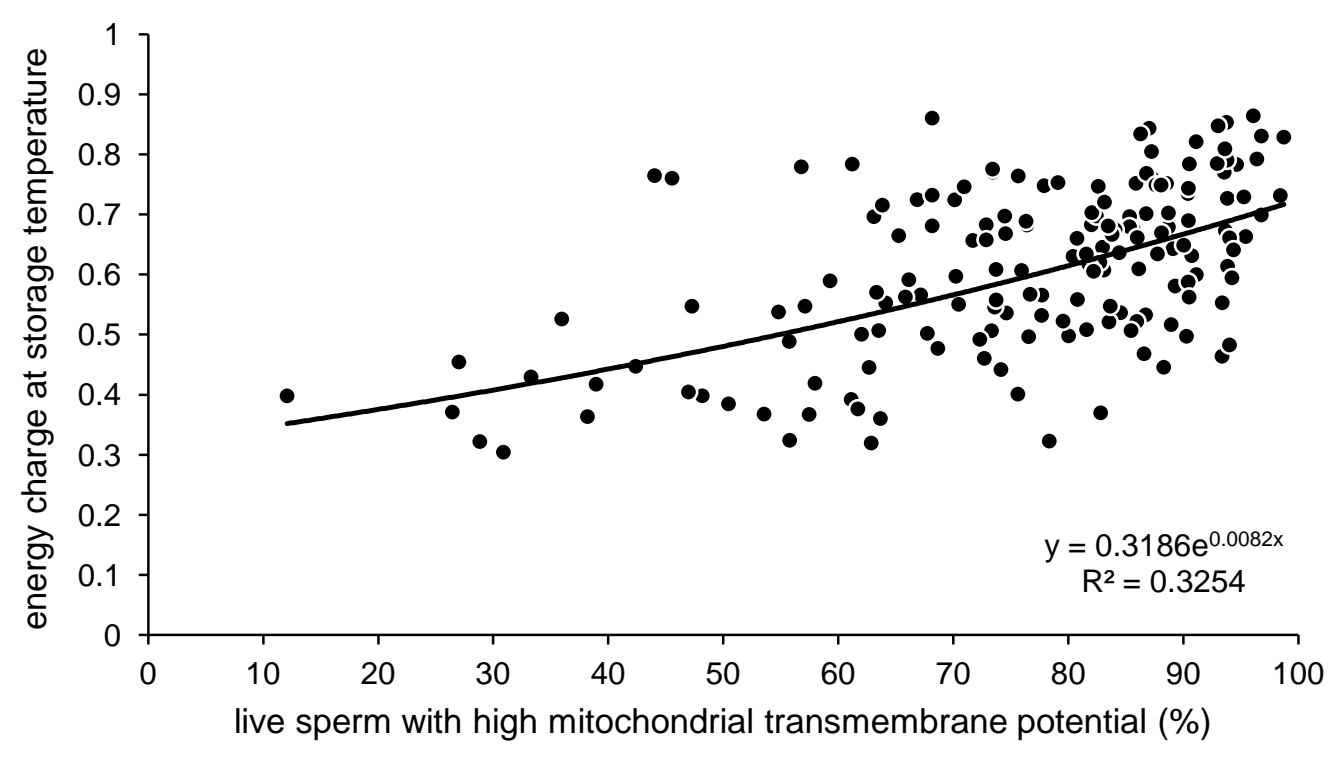

Supplemental Figure 03 Correlation between energy charge assessed at storage temperature with progressive motility $(r=0.71 ; P<0.001)$ and the percentage of live spermatozoa with high mitochondrial transmembrane potential $(r=0.49 ; P<0.001)$ after incubation at $38^{\circ} \mathrm{C}$. Data from all storage temperatures and days of storage were combined $(n=168)$. 
Table 1 Spearman correlation coefficients for ATP content and energy charge, assessed at storage temperature and after 15 minute incubation at $38^{\circ} \mathrm{C}$, with parameters after incubation at $38^{\circ} \mathrm{C}$. Data from all storage temperatures and days of storage were combined $(n=168)$.

\begin{tabular}{|c|c|c|c|c|c|c|c|c|c|c|c|c|c|}
\hline \multirow{4}{*}{ 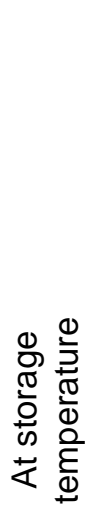 } & & \multicolumn{12}{|c|}{ At $38^{\circ} \mathrm{C}$} \\
\hline & & $\begin{array}{c}\text { Total } \\
\text { motility } \\
{[\%]}\end{array}$ & $\begin{array}{c}\text { Progress } \\
\text { ive } \\
\text { motility } \\
{[\%]}\end{array}$ & $\begin{array}{l}\text { VAP } \\
{[\mu \mathrm{m} / \mathrm{s}]}\end{array}$ & $\begin{array}{l}\mathrm{VCL} \\
{[\mu \mathrm{m} / \mathrm{s}]}\end{array}$ & $\begin{array}{l}\mathrm{VSL} \\
{[\mu \mathrm{m} / \mathrm{s}]}\end{array}$ & STR & LIN & WOB & $\begin{array}{l}\text { ALH } \\
{[\mu \mathrm{m}]}\end{array}$ & $\begin{array}{l}\mathrm{BCF} \\
{[\mathrm{Hz}]}\end{array}$ & $\begin{array}{c}\text { Live, } \\
\text { hMMP } \\
(\%)\end{array}$ & $\begin{array}{c}\text { PI \& PNA- } \\
\text { FITC neg. } \\
{[\%]}\end{array}$ \\
\hline & $\begin{array}{c}\text { ATP } \\
\left(\mathrm{pmol} / 10^{5} \text { sperm }\right)\end{array}$ & $0.49^{\star \star \star}$ & $0.51^{* * *}$ & 0.21 * & 0.16 * & $0.33^{* \star *}$ & $0.27^{\star \star \star}$ & 0.07 & 0.09 & 0.20 ** & $0.18^{*}$ & $0.32 * * *$ & $0.48^{\star \star \star}$ \\
\hline & Energy charge & $0.71^{\star \star \star}$ & $0.71^{\star \star \star}$ & -0.00 & -0.07 & 0.22 ** & $0.39 * * *$ & $0.30 * * *$ & $0.18^{*}$ & -0.18 ** & $0.27^{\star * *}$ & $0.54^{\star \star \star}$ & $0.57^{* \star *}$ \\
\hline \multirow{2}{*}{ 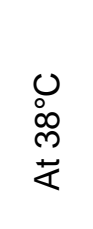 } & $\begin{array}{c}\text { ATP } \\
\left(\mathrm{pmol} / 10^{5} \text { sperm }\right)\end{array}$ & $0.45^{* \star *}$ & $0.47^{* \star *}$ & $0.18^{*}$ & 0.05 & $0.28^{\star * *}$ & $0.23^{\star \star}$ & $0.17^{*}$ & $0.15^{*}$ & 0.13 & 0.10 & $0.23^{* *}$ & $0.36^{* \star *}$ \\
\hline & Energy charge & $0.59^{\star \star \star}$ & $0.58^{* \star \star}$ & 0.08 & -0.00 & $0.20^{\star \star}$ & $0.24^{* *}$ & 0.20 ** & 0.09 & -0.02 & $0.15^{*}$ & $0.39^{\star \star \star}$ & $0.39^{\star \star \star}$ \\
\hline
\end{tabular}

${ }^{*} \mathrm{P}<0.05$

$$
{ }^{* *} \mathrm{P}<0.01
$$

${ }^{* * *} \mathrm{P}<0.001$

$\mathrm{VAP}=$ average path velocity

$\mathrm{VCL}=$ curvilinear velocity

STR $=$ straightness

$\mathrm{ALH}=$ amplitude of lateral head-displacement

Live, $\mathrm{hMMP}=\mathrm{Pi}$ negative sperm with high mitochondrial transmembrane potential

\section{$\mathrm{LIN}=$ linearity}

$\mathrm{BCF}=$ beat cross frequency
$V S L=$ straight-line velocity

WOB $=$ wobble

$E C=$ energy charge

ATP $=$ adenosine triphosphate 
Supplemental Table 1. Motility parameters from computer-assisted semen analysis (CASA) for samples stored at different temperatures in Androstar ${ }^{\circledR} \mathrm{Plus}(n=7)$. All values are mean and standard deviation. Different lowercase alphabets (a-e) in each column show significant differences $(P<0.05)$ between storage days.

\begin{tabular}{|c|c|c|c|c|c|}
\hline & & & Storage & perature & \\
\hline & storage & $25^{\circ} \mathrm{C}$ & $17^{\circ} \mathrm{C}$ & $10^{\circ} \mathrm{C}$ & $5^{\circ} \mathrm{C}$ \\
\hline & Day 1 & $89.3 \pm 2.9^{\mathrm{a}}$ & $88.7 \pm 3.3^{a}$ & $86.2 \pm 3.2^{\mathrm{a}}$ & $75.0 \pm 3.1^{\mathrm{a}}$ \\
\hline TM & Day 3 & $88.3 \pm 3.8^{\mathrm{a}}$ & $88.9 \pm 3.9^{a}$ & $86.0 \pm 5.0^{\mathrm{a}}$ & $74.8 \pm 4.4^{\mathrm{a}}$ \\
\hline (\%) & Day 5 & $86.0 \pm 3.9^{\mathrm{a}}$ & $88.4 \pm 3.4^{\mathrm{a}}$ & $82.7 \pm 3.9^{\mathrm{a}}$ & $71.3 \pm 3.9^{\mathrm{a}}$ \\
\hline & Day 1 & $78.8 \pm 3.6^{a}$ & $79.6 \pm 3.7^{\mathrm{a}}$ & $77.0 \pm 3.6^{\mathrm{a}}$ & $63.5 \pm 2.5^{\mathrm{a}}$ \\
\hline PM & Day 3 & $77.6 \pm 3.3^{\mathrm{a}}$ & $77.3 \pm 4.4^{\mathrm{a}}$ & $71.9 \pm 5.3^{b}$ & $62.7 \pm 4.8^{\mathrm{a}}$ \\
\hline (\%) & Day 5 & $74.6 \pm 4.1^{\mathrm{a}}$ & $77.8 \pm 3.9^{a}$ & $71.2 \pm 3.7^{b}$ & $57.3 \pm 3.3^{b}$ \\
\hline & Day 1 & $64.3 \pm 4.9^{\mathrm{a}}$ & $65.3 \pm 6.3^{\mathrm{a}}$ & $65.0 \pm 6.3^{\mathrm{a}}$ & $64.1 \pm 8.2^{\mathrm{a}}$ \\
\hline VAP & Day 3 & $67.1 \pm 7.8^{\mathrm{a}}$ & $66.9 \pm 5.5^{\mathrm{a}}$ & $68.8 \pm 6.4^{\mathrm{a}}$ & $66.9 \pm 8.9^{a}$ \\
\hline$(\mu \mathrm{m} / \mathrm{s})$ & Day 5 & $65.4 \pm 3.6^{a}$ & $69.4 \pm 2.8^{\mathrm{a}}$ & $69.7 \pm 3.0^{a}$ & $75.3 \pm 5.1^{a}$ \\
\hline & Day 1 & $85.6 \pm 8.5^{\mathrm{a}}$ & $89.6 \pm 10.3^{a}$ & $96.2 \pm 9.4^{\mathrm{a}}$ & $87.4 \pm 9.0^{\mathrm{a}}$ \\
\hline VCL & Day 3 & $96.6 \pm 7.1^{\mathrm{a}}$ & $95.8 \pm 11.5^{\mathrm{a}}$ & $104.1 \pm 17.7^{\mathrm{a}, \mathrm{b}}$ & $109.5 \pm 11.6^{b}$ \\
\hline$(\mu \mathrm{m} / \mathrm{s})$ & Day 5 & $97.7 \pm 6.7^{\mathrm{a}}$ & $97.5 \pm 6.1^{b}$ & $108.5 \pm 47.7^{\mathrm{b}}$ & $110.6 \pm 8.7^{b}$ \\
\hline & Day 1 & $54.9 \pm 4.4^{\mathrm{a}}$ & $54.6 \pm 6.4^{\mathrm{a}}$ & $51.9 \pm 5.1^{\mathrm{a}}$ & $50.9 \pm 6.7^{\mathrm{a}}$ \\
\hline VSL & Day 3 & $57.4 \pm 8.0^{\mathrm{a}}$ & $56.1 \pm 5.9^{a}$ & $52.8 \pm 5.7^{\mathrm{a}}$ & $51.6 \pm 8.6^{\mathrm{a}}$ \\
\hline$(\mu \mathrm{m} / \mathrm{s})$ & Day 5 & $54.8 \pm 5.5^{\mathrm{a}}$ & $57.5 \pm 4.5^{\mathrm{a}}$ & $50.2 \pm 7.2^{\mathrm{a}}$ & $52.1 \pm 4.5^{\mathrm{a}}$ \\
\hline
\end{tabular}




\begin{tabular}{|c|c|c|c|c|c|}
\hline & \multirow[b]{2}{*}{ storage } & \multicolumn{4}{|c|}{ Storage temperature } \\
\hline & & $25^{\circ} \mathrm{C}$ & $17^{\circ} \mathrm{C}$ & $10^{\circ} \mathrm{C}$ & $5^{\circ} \mathrm{C}$ \\
\hline & Day 1 & $0.9 \pm 0.04^{a}$ & $0.83 \pm 0.05^{\mathrm{a}}$ & $0.80 \pm 0.06^{b}$ & $0.79 \pm 0.06^{b}$ \\
\hline \multirow{2}{*}{ STR } & Day 3 & $0.85 \pm 0.04^{a}$ & $0.83 \pm 0.04^{\mathrm{a}}$ & $0.77 \pm 0.08^{a, b}$ & $0.77 \pm 0.07^{\mathrm{a}, \mathrm{b}}$ \\
\hline & Day 5 & $0.83 \pm 0.06^{a}$ & $0.82 \pm 0.04^{\mathrm{a}}$ & $0.71 \pm 0.08^{a}$ & $0.69 \pm 0.06^{a}$ \\
\hline \multirow{3}{*}{ LIN } & Day 1 & $0.64 \pm 0.06^{a}$ & $0.62 \pm 0.05^{\mathrm{a}}$ & $0.57 \pm 0.07^{\mathrm{a}}$ & $0.59 \pm 0.06^{a}$ \\
\hline & Day 3 & $0.60 \pm 0.06^{a}$ & $0.56 \pm 0.07^{\mathrm{a}}$ & $0.45 \pm 0.07^{b}$ & $0.45 \pm 0.07^{b}$ \\
\hline & Day 5 & $0.57 \pm 0.07^{\mathrm{a}}$ & $0.59 \pm 0.07^{\mathrm{a}}$ & $0.49 \pm 0.05^{\mathrm{a}, \mathrm{b}}$ & $0.43 \pm 0.07^{b}$ \\
\hline \multirow{3}{*}{ WOB } & Day 1 & $0.75 \pm 0.04^{a}$ & $0.73 \pm 0.04^{\mathrm{a}}$ & $0.71 \pm 0.06^{\mathrm{a}}$ & $0.70 \pm 0.05^{a}$ \\
\hline & Day 3 & $0.72 \pm 0.05^{a}$ & $0.71 \pm 0.06^{\mathrm{a}}$ & $0.68 \pm 0.07^{\mathrm{a}, \mathrm{b}}$ & $0.66 \pm 0.07^{\mathrm{a}, \mathrm{b}}$ \\
\hline & Day 5 & $0.66 \pm 0.06^{a}$ & $0.71 \pm 0.06^{\mathrm{a}}$ & $0.63 \pm 0.07^{b}$ & $0.61 \pm 0.07^{b}$ \\
\hline \multirow{3}{*}{$\begin{array}{l}\text { ALH } \\
(\mu \mathrm{m})\end{array}$} & Day 1 & $1.97 \pm 0.36^{a}$ & $1.91 \pm 0.25^{\mathrm{a}}$ & $2.06 \pm 0.26^{a}$ & $2.11 \pm 0.18^{a}$ \\
\hline & Day 3 & $2.17 \pm 0.34^{a}$ & $2.15 \pm 0.28^{a}$ & $2.47 \pm 0.41^{b}$ & $2.49 \pm 0.35^{b}$ \\
\hline & Day 5 & $2.12 \pm 0.23^{a}$ & $2.11 \pm 0.32^{\mathrm{a}}$ & $2.47 \pm 0.34^{b}$ & $2.72 \pm 0.44^{b}$ \\
\hline \multirow{3}{*}{$\begin{array}{l}\text { BCF } \\
(\mathrm{Hz})\end{array}$} & Day 1 & $35.3 \pm 1.5^{\mathrm{a}}$ & $37.2 \pm 2.1^{\mathrm{a}}$ & $37.2 \pm 1.8^{\mathrm{a}}$ & $35.6 \pm 1.9^{a}$ \\
\hline & Day 3 & $37.7 \pm 3.8^{\mathrm{a}}$ & $37.1 \pm 3.4^{a}$ & $36.3 \pm 4.6^{\mathrm{a}}$ & $37.0 \pm 2.8^{\mathrm{a}}$ \\
\hline & Day 5 & $37.4 \pm 2.1^{\mathrm{a}}$ & $38.3 \pm 2.1^{a}$ & $37.8 \pm 2.7^{\mathrm{a}}$ & $37.8 \pm 2.8^{\mathrm{a}}$ \\
\hline
\end{tabular}


Supplemental Table 2 Motility parameters from computer-assisted semen analysis (CASA) for samples stored at different temperatures in BTS $(n=7)$. All values are mean and standard deviation. Different lowercase alphabets $(A-C)$ in each column show significant differences $(P<0.05)$ between storage days.

\begin{tabular}{|c|c|c|c|c|c|}
\hline & & & Storage & perature & \\
\hline & storage & $25^{\circ} \mathrm{C}$ & $17^{\circ} \mathrm{C}$ & $10^{\circ} \mathrm{C}$ & $5^{\circ} \mathrm{C}$ \\
\hline & Day 1 & $88.3 \pm 2.5^{\mathrm{A}}$ & $87.9 \pm 3.3^{A}$ & $79.6 \pm 3.7^{\mathrm{A}}$ & $55.3 \pm 2.9^{A}$ \\
\hline TM & Day 3 & $87.7 \pm 2.6^{\mathrm{A}}$ & $88.1 \pm 3.4^{\mathrm{A}}$ & $80.8 \pm 3.4^{\mathrm{A}}$ & $51.5 \pm 2.4^{B}$ \\
\hline (\%) & Day 5 & $86.6 \pm 3.3^{\mathrm{A}}$ & $87.1 \pm 3.2^{A}$ & $78.8 \pm 4.4^{\mathrm{A}}$ & $47.3 \pm 2.6^{C}$ \\
\hline & Day 1 & $78.1 \pm 4.9^{\mathrm{A}}$ & $77.5 \pm 5.0^{\mathrm{A}}$ & $70.7 \pm 3.8^{A}$ & $40.0 \pm 1.9^{A}$ \\
\hline PM & Day 3 & $78.2 \pm 4.2^{\mathrm{A}}$ & $76.4 \pm 3.1^{\mathrm{A}}$ & $68.7 \pm 5.4^{\mathrm{A}}$ & $36.0 \pm 3.1^{A}$ \\
\hline (\%) & Day 5 & $77.8 \pm 3.8^{\mathrm{A}}$ & $77.7 \pm 2.6^{\mathrm{A}}$ & $68.1 \pm 3.6^{\mathrm{A}}$ & $36.1 \pm 1.7^{\mathrm{A}}$ \\
\hline & Day 1 & $62.8 \pm 4.4^{\mathrm{A}}$ & $63.0 \pm 7.4^{\mathrm{A}}$ & $64.5 \pm 11.5^{\mathrm{A}}$ & $62.2 \pm 8.7^{A}$ \\
\hline VAP & Day 3 & $62.5 \pm 5.6^{\mathrm{A}}$ & $66.9 \pm 9.5^{\mathrm{A}}$ & $64.7 \pm 13.2^{\mathrm{A}}$ & $59.3 \pm 8.8^{A}$ \\
\hline$(\mu \mathrm{m} / \mathrm{s})$ & Day 5 & $54.8 \pm 8.2^{A}$ & $64.7 \pm 7.6^{\mathrm{A}}$ & $60.8 \pm 12.1^{\mathrm{A}}$ & $55.1 \pm 14.7^{\mathrm{A}}$ \\
\hline & Day 1 & $85.2 \pm 7.8^{\mathrm{A}}$ & $91.2 \pm 12.3^{A}$ & $82.3 \pm 7.7^{\mathrm{A}}$ & $82.9 \pm 9.4^{A}$ \\
\hline VCL & Day 3 & $88.2 \pm 10.5^{A}$ & $96.7 \pm 11.3^{A}$ & $103.9 \pm 12.5^{B}$ & $87.7 \pm 9.5^{B}$ \\
\hline$(\mu \mathrm{m} / \mathrm{s})$ & Day 5 & $82.0 \pm 13.2^{A}$ & $95.1 \pm 14.5^{\mathrm{A}}$ & $96.8 \pm 13.6^{C}$ & $80.1 \pm 13.3^{A, B}$ \\
\hline & Day 1 & $54.1 \pm 4.8^{\mathrm{A}}$ & $51.9 \pm 7.7^{\mathrm{A}}$ & $51.8 \pm 11.9^{A}$ & $48.9 \pm 7.6^{A}$ \\
\hline VSL & Day 3 & $53.4 \pm 5.8^{\mathrm{A}}$ & $55.0 \pm 9.5^{\mathrm{A}}$ & $49.8 \pm 14.5^{\mathrm{A}}$ & $47.0 \pm 10.4^{\mathrm{A}}$ \\
\hline$(\mu \mathrm{m} / \mathrm{s})$ & Day 5 & $46.0 \pm 7.7^{\mathrm{A}}$ & $53.4 \pm 7.0^{\mathrm{A}}$ & $45.1 \pm 10.9^{A}$ & $44.2 \pm 13.3^{\mathrm{A}}$ \\
\hline
\end{tabular}




\begin{tabular}{|c|c|c|c|c|c|}
\hline & \multirow[b]{2}{*}{ storage } & \multicolumn{4}{|c|}{ Storage temperature } \\
\hline & & $25^{\circ} \mathrm{C}$ & $17^{\circ} \mathrm{C}$ & $10^{\circ} \mathrm{C}$ & $5^{\circ} \mathrm{C}$ \\
\hline & Day 1 & $0.86 \pm 0.03^{A}$ & $0.82 \pm 0.04^{A}$ & $0.79 \pm 0.07^{A}$ & $0.78 \pm 0.06^{A}$ \\
\hline \multirow{2}{*}{ STR } & Day 3 & $0.85 \pm 0.04^{\mathrm{A}}$ & $0.82 \pm 0.04^{\mathrm{A}}$ & $0.78 \pm 0.11^{\mathrm{A}}$ & $0.78 \pm 0.08^{A}$ \\
\hline & Day 5 & $0.83 \pm 0.03^{A}$ & $0.82 \pm 0.04^{A}$ & $0.73 \pm 0.08^{A}$ & $0.79 \pm 0.05^{A}$ \\
\hline \multirow{3}{*}{ LIN } & Day 1 & $0.62 \pm 0.05^{\mathrm{A}}$ & $0.57 \pm 0.06^{\mathrm{A}}$ & $0.58 \pm 0.07^{\mathrm{A}}$ & $0.55 \pm 0.04^{\mathrm{A}}$ \\
\hline & Day 3 & $0.58 \pm 0.07^{A}$ & $0.56 \pm 0.04^{A}$ & $0.45 \pm 0.06^{\mathrm{B}}$ & $0.55 \pm 0.06^{A}$ \\
\hline & Day 5 & $0.56 \pm 0.06^{A}$ & $0.56 \pm 0.08^{\mathrm{A}}$ & $0.48 \pm 0.07^{\mathrm{A}, \mathrm{B}}$ & $0.53 \pm 0.08^{A}$ \\
\hline \multirow{3}{*}{ WOB } & Day 1 & $0.73 \pm 0.03^{\mathrm{A}}$ & $0.69 \pm 0.06^{\mathrm{A}}$ & $0.69 \pm 0.07^{A}$ & $0.68 \pm 0.06^{A}$ \\
\hline & Day 3 & $0.71 \pm 0.05^{A}$ & $0.69 \pm 0.06^{A}$ & $0.66 \pm 0.1^{A}$ & $0.67 \pm 0.08^{A}$ \\
\hline & Day 5 & $0.67 \pm 0.06^{A}$ & $0.68 \pm 0.07^{\mathrm{A}}$ & $0.63 \pm 0.08^{A}$ & $0.67 \pm 0.07^{A}$ \\
\hline \multirow{3}{*}{$\begin{array}{l}\text { ALH } \\
(\mu \mathrm{m})\end{array}$} & Day 1 & $1.9 \pm 0.3^{A}$ & $2.0 \pm 0.3^{A}$ & $2.0 \pm 0.4^{\mathrm{A}}$ & $2.0 \pm 0.2^{A}$ \\
\hline & Day 3 & $2.0 \pm 0.3^{A}$ & $2.1 \pm 0.4^{\mathrm{A}}$ & $2.4 \pm 0.4^{\mathrm{A}}$ & $2.1 \pm 0.3^{A}$ \\
\hline & Day 5 & $1.9 \pm 0.2^{\mathrm{A}}$ & $2.1 \pm 0.3^{A}$ & $2.2 \pm 0.3^{A}$ & $1.9 \pm 0.4^{\mathrm{A}}$ \\
\hline \multirow{3}{*}{$\begin{array}{l}\text { BCF } \\
(\mathrm{Hz})\end{array}$} & Day 1 & $35.9 \pm 2.3^{A}$ & $37.1 \pm 2.1^{A}$ & $36.9 \pm 2.3^{\mathrm{A}}$ & $34.3 \pm 2.0^{\mathrm{A}}$ \\
\hline & Day 3 & $37.8 \pm 1.4^{\mathrm{A}}$ & $38.3 \pm 3.8^{\mathrm{A}}$ & $36.6 \pm 3.5^{A}$ & $31.5 \pm 4.5^{\mathrm{A}}$ \\
\hline & Day 5 & $34.3 \pm 4.1^{\mathrm{A}}$ & $37.9 \pm 2.7^{\mathrm{A}}$ & $37.8 \pm 3.0^{A}$ & $31.3 \pm 4.0^{\mathrm{A}}$ \\
\hline
\end{tabular}


Supplement table 3 Spearman correlation coefficients for ATP content and energy charge measured at storage temperature and after 15 minute incubation at $38^{\circ} \mathrm{C}$.with parameters for samples incubated at $38^{\circ} \mathrm{C}$. Data from both extenders and all days of storage were combined for a given storage temperature $(n=42)$.

\begin{tabular}{|c|c|c|c|c|c|c|c|c|c|c|c|c|c|}
\hline & & & & & & & At $38^{\circ}$ & & & & & & \\
\hline & & $\begin{array}{c}\text { Total } \\
\text { motility } \\
{[\%]}\end{array}$ & $\begin{array}{c}\text { Progressive } \\
\text { motility } \\
{[\%]}\end{array}$ & $\begin{array}{l}\text { VAP } \\
{[\mu \mathrm{m} / \mathrm{s}]}\end{array}$ & $\begin{array}{c}\mathrm{VCL} \\
{[\mu \mathrm{m} / \mathrm{s}]}\end{array}$ & $\begin{array}{c}\mathrm{VSL} \\
{[\mu \mathrm{m} / \mathrm{s}]}\end{array}$ & STR & LIN & WOB & $\begin{array}{l}\mathrm{ALH} \\
{[\mu \mathrm{m}]}\end{array}$ & $\begin{array}{l}\mathrm{BCF} \\
{[\mathrm{Hz}]}\end{array}$ & $\begin{array}{c}\text { Live, hMMP } \\
(\%)\end{array}$ & $\begin{array}{c}\text { PI \& PNA- } \\
\text { FITC neg. } \\
\quad[\%]\end{array}$ \\
\hline $\begin{array}{l}\text { O } \\
\text { in }\end{array}$ & $\begin{array}{c}\text { ATP } \\
\left(\mathrm{pmol} / 10^{5} \text { sperm) }\right.\end{array}$ & $0.53 * * *$ & $0.54 * * *$ & $\begin{array}{c}0.42 \\
* *\end{array}$ & $\begin{array}{c}0.43 \\
* *\end{array}$ & $\begin{array}{c}0.34 \\
* *\end{array}$ & -0.11 & $\begin{array}{c}-0.33 \\
*\end{array}$ & -0.20 & $0.49 * *$ & $0.37 *$ & $0.33 *$ & $0.55 * *$ \\
\hline を & Energy charge & $0.53 * * *$ & $0.45 * *$ & 0.17 & 0.21 & 0.16 & -0.17 & $\begin{array}{c}-0.34 \\
*\end{array}$ & -0.21 & 0.21 & $\begin{array}{c}0.41 \\
* *\end{array}$ & $0.56 * * *$ & $0.54 * *$ \\
\hline O & $\begin{array}{c}\text { ATP } \\
\left(\mathrm{pmol} / 10^{5} \text { sperm }\right)\end{array}$ & 0.15 & 0.20 & 0.02 & -0.19 & 0.22 & $\begin{array}{c}0.42 \\
* *\end{array}$ & 0.10 & 0.27 & 0.04 & -0.22 & 0.12 & 0.10 \\
\hline 莫 & Energy charge & 0.29 & $0.42 * *$ & -0.22 & -0.27 & -0.02 & $0.32 *$ & 0.10 & 0.16 & -0.19 & 0.08 & $0.42 * *$ & 0.29 \\
\hline $\begin{array}{l}0 \\
\stackrel{2}{N}\end{array}$ & $\begin{array}{c}\text { ATP } \\
\left(\mathrm{pmol} / 10^{5} \text { sperm }\right)\end{array}$ & $-\mathbf{0 . 3 7} * *$ & -0.24 & 0.18 & $\mathbf{0 . 3 3} *$ & 0.13 & 0.01 & -0.29 & -0.20 & $0.46 * *$ & -0.03 & -0.06 & 0.05 \\
\hline $\begin{array}{l}\text { O } \\
\stackrel{\circ}{\circ}\end{array}$ & $\begin{array}{c}\text { ATP } \\
\left(\mathrm{pmol} / 10^{5} \text { sperm }\right)\end{array}$ & 0.02 & 0.07 & 0.15 & 0.26 & 0.05 & -0.10 & -0.15 & -0.01 & $\begin{array}{l}\mathbf{0 . 5 7} \\
* * * *\end{array}$ & 0.02 & -0.24 & -0.02 \\
\hline 走 & Energy charge & $0.46 * *$ & $0.32 * *$ & -0.01 & 0.05 & -0.04 & -0.17 & -0.08 & -0.10 & 0.05 & 0.04 & $0.34 *$ & 0.29 \\
\hline
\end{tabular}




$$
{ }^{*} \mathrm{P}<0.05
$$

${ }^{* *} \mathrm{P}<0.01$

*** $P<0.001$

$\mathrm{VAP}=$ average path velocity

STR $=$ straightness

$\mathrm{ALH}=$ amplitude of lateral head-displacement energy charge

Live, $\mathrm{hMMP}=$ sperm with high mitochondrial transmembrane potential

\author{
VSL $=$ straight-line velocity \\ WOB $=$ wobble \\ $\mathrm{BCF}=$ beat cross frequency $\quad \mathrm{EC}=$ \\ ATP = adenosine triphosphate
}




\section{Chemicals}

Substances

Adenylate kinase

ATP assay mix

ATP assay mix dilution buffer

ATP standard

BSA (fraction V)

$\mathrm{CaCl}_{2}$

DMSO

EGTA

Formaldehyde $37 \%$

FITC-PNA

Fluo-4/AM

Gentamycinsulfat

$D(+)$-Glucose-monohydrate

$\mathrm{HCl}$

HEPES

$\mathrm{KCl}$

$\mathrm{KH}_{2} \mathrm{PO}_{4}$

$\mathrm{Na}$-(DL)-lactate $60 \%(\mathrm{w} / \mathrm{w})$

$\mathrm{MgSO}_{4}{ }^{\star} 7 \mathrm{H}_{2} \mathrm{O}$

tri-Natriumcitrat-dihydrate

$\mathrm{NaCl}$

$\mathrm{NaOH}$

Percoll®

Pyruvate kinase
Source

Sigma-Aldrich, Steinheim

Sigma-Aldrich, Steinheim

Sigma-Aldrich, Steinheim

Sigma-Aldrich, Steinheim

Sigma-Aldrich, Steinheim

Serva, Heidelberg

Roth, Karlsruhe

Roth, Karlsruhe

Roth, Karlsruhe

Axxora, Lörrach

Invitrogen, Oregon

Serva, Heidelberg

Merck, Darmstadt

Merck, Darmstadt

AppliChem, Darmstadt

Merck, Darmstadt

Merck, Darmstadt

Sigma-Aldrich, Steinheim

Sigma-Aldrich, Steinheim

Merck, Darmstadt

AppliChem, Darmstadt

Merck, Darmstadt

GE Healthcare, München

Sigma-Aldrich, Steinheim
Article number

M 3003

FL-AAM

FL-AAB

FL-AAS

A3803

15585

6643

3054

4979

VC-FL-1071

F14201

22185

104074

09057

A106

104939

105108

L1375

M5921

106448

A4661

106462

17-0891

P 1506 


\section{Equipment}

Counting chamber Thoma "neu"

Votex, Reax top

Flow cytometer "Galaxy"

pH-meter, Multiplex 3000/pMX

Freezing point osmometer (osmomat 030)

Water bath

Typ 1013

WNB 745

Slides

Cover slip

Leja chamber 4-chamber slide

Phase contract microscope

Semen bottle with cap

Semen collection bag, US-bag

Semen collection cup

Variable Single Chanel pipet

$0.5-10 \mu l$

$2.0-20 \mu l$

$10-100 \mu l$

$100-1000 \mu l$

Pipette tips $(10 \mu l)$

P Pipette tips (100 and $1000 \mu \mathrm{l})$

Parafilm
Fa. Jürgens, Hannover

Fa. Heidolph, Schwabach

Partec GmbH. Münster

Fa. WTW, Weilheim

Fa. Gonotec, Berlin

Fa. GFL, Burgwedel

Fa. Memmert, Schwabach

IDL GmbH\&Co. KG, Nidderau

IDL GmbH\&Co. KG, Nidderau

Leja Products B.V., Nieuw-Vennep, The Netherlands

Fa. Zeiss, Jena

Fa. Minitüb GmbH\&Co KG, Tiefenbach

Fa. Minitüb GmbH\&Co KG, Tiefenbach

Fa. Minitüb GmbH\&Co KG, Tiefenbach

Eppendort AG, Hamburg

Biozym Scientific $\mathrm{GmbH}$, Hessich

Oldendorf

Landgraf Laborsysteme $\mathrm{GmbH}$, Langenhagen

Landgraf Laborsysteme $\mathrm{GmbH}$, 


\section{Langenhagen}

Centrifugation, Megafuge 2.0 R

Reactor tube $(3.5 \mathrm{ml})$

Laboratory weigh (PT12)

Laboratory weigh (ACL-80.4)

multi-channel pipette, Biohit eLine E 1000

Thermomixer 5436

96 well microtiter plate

Tecan GENios Pro plate reader
Fa. Hareaus, Hanau

Fa. Sarstedt, Nürnbrecht

Sartorius AG, Göttingen

Sartorius AG, Göttingen

Biohit $\mathrm{GmbH}$, Rosbach

Eppendorf, Hamburg

Greiner Bio-One, Frickenhausen

Tecan Group Ltd., Männedorf, 


\section{Summary}

\section{Nguyen Thu Quynh (2015)}

\section{Energy metabolism during long-term storage and subsequent thermal stress in liquid preserved boar spermatozoa}

Boar spermatozoa are susceptible to cold shock and therefore are stored between 16 and $18^{\circ} \mathrm{C}$ before use in artificial insemination. Storage of extended semen alters essential sperm function which may affect fertility of sows. The aim of the present thesis was to examine the impact of hypothermic storage and subsequent thermal stress on sperm quality and energy metabolism in liquid-preserved boar semen. In addition, it was investigated whether deficiencies in the energy metabolism are causative for impaired sperm function of stored semen.

In the first study (Chapter 1), a revised protocol for efficient ATP extraction of diluted boar spermatozoa was established which allows a highly repeatable measurement of adenine nucleotides and adenylate energy charge (AEC) by the luciferin-luciferase reaction. Boar semen samples $(n=6)$ diluted in Beltsville Thawing Solution (BTS) were incubated with phosphatase inhibitor cocktail at room temperature or on ice. Boiling for ATP extraction with or without boiling buffer, centrifugation, and subsequent ATP assessment from the supernatant was done either directly after the inhibition step in fresh semen samples or after frozen-storage of subsamples at $20^{\circ} \mathrm{C}$. Both, inhibition on ice and the use of a boiling buffer, increased the amount of extracted ATP $(P<0.05)$. Combination of both steps resulted in the highest efficiency of ATP extraction. In fresh samples, measured ATP concentration was approximately tenfold higher when both steps were combined $(P<0.05)$. Freezing had no impact on ATP concentration compared to freshly analyzed samples when phosphatase inhibition was done on ice and a boiling buffer was used ( $p>0.05)$. ATP content of fresh and frozen samples correlated best for this treatment $(r=0.83$; $p<0.05)$. AEC levels in fresh (0.9) and extended (0.7) spermatozoa were on high level indicating an active energy status in viable cells. The observed positive correlation between ATP $(r=0.9, P<0.001) /$ AEC levels $(r=0.7, P<0.001)$ and the proportion of membrane intact spermatozoa as determined by flow cytometry using Propidium iodide (PI)/FITC-PNA staining emphasize that cell viability must be 
considered for interpretation of energetic data. Increased membrane permeability induced by storage of extended boar semen at $5^{\circ} \mathrm{C}$ lead to higher $(P<0.05)$ levels of AMP in the extracellular medium whereas no adenine nucleotides were measured in the seminal plasma of fresh semen samples. Overall, a revised protocol for efficient and highly repeatable ATP extraction was developed which allows storage of samples at $-20^{\circ} \mathrm{C}$ prior to the luciferin-luciferase reaction without affecting ATP content and AEC. This protocol was then used for Studies 2 and 3 of the present thesis.

In the second study (Chapter 2), the impact of a long-term storage at $+17^{\circ} \mathrm{C}$ and subsequent thermal stress on the cellular ATP level and AEC of extended boar spermatozoa was investigated. Metabolic energy data were related to mitochondrial membrane potential (MMP) of live sperm as assessed by flow cytometry using the JC-1/PI assay and to sperm kinematics evaluated by computer-assisted semen analysis (CASA). Ejaculates of seven boars were diluted in BTS, cooled to $17^{\circ} \mathrm{C}$ and stored for 24 h (day 1), 72 h (day 3), 120 h (day 5), and 168 h (day 7). At each time, samples were analyzed before and after 15, 30,60,120, and 180 min incubation at $38^{\circ} \mathrm{C}$. During storage at $17^{\circ} \mathrm{C}$, ATP content (day of collection (= day 0$): 454 \mathrm{pmol} / 10^{5}$ sperm, day 5: $398 \mathrm{pmol} / 10^{5}$ sperm) and AEC (day 0: $0.78 \mathrm{pmol} / 10^{5}$ sperm, day 5: $0.71 \mathrm{pmol} / 10^{5}$ sperm) remained stable (P>0.05). ATP levels and AEC of spermatozoa during incubation at $38^{\circ} \mathrm{C}$ were significantly affected by storage length and incubation time $(P<0.05)$. ATP content and total motility of sperm declined moderately and earliest after 60 min incubation $(P<0.05)$ while the percentage of live sperm with high MMP remained high (> $80 \%$ ) throughout semen storage, but decreased dramatically already after $30 \mathrm{~min}$ of incubation at $38^{\circ} \mathrm{C}(\mathrm{P}<0.05)$. Concomitantly with the decrease of MMP, motility patterns based on curvolinear velocity, linearity and lateral head displacement changed from an activated to a steady state pattern. ATP values of samples stored at $17^{\circ} \mathrm{C}$ decreased during incubation for $15 \mathrm{~min}$ at $38^{\circ} \mathrm{C}(\mathrm{P}<0.05)$. With ongoing storage time the relative difference between ATP levels before and after incubation increased (day 0:7.1, day 5: $24.2 \mathrm{pmol} / 10^{5}$ sperm, $\left.\mathrm{P}<0.05\right)$ indicating an increasing relative expense of ATP to regain a functional (motile) state during re-warming. Total motility correlated moderately with the ATP content $(r=0.48, P<0.05)$ and low to moderate to \% live sperm with high MMP $(r=0.38, P<0.05)$. 
The results demonstrate that energy reserves in liquid preserved boar spermatozoa remain stable during prolonged storage at $17^{\circ} \mathrm{C}$, though the contribution of oxidative phosphorylation in mitochondria seems to be rapid and only short-term compared to glycolysis. The transitory increase in ATP levels yield by mitochondrial activity may modulate wave patterns and trajectories of motile sperm. Moreover, the storageassociated increase of the ATP expense of energy for reactivation of motility indicates that ATP dependent cell functions become increasingly vulnerable during semen storage.

The aim of the third study (Chapter 3) was to investigate whether maintenance of ATP levels and energy charge are dependent on the storage temperature and storage time during liquid preservation of boar spermatozoa. The relationship to mitochondrial activity, motility and viability of spermatozoa after re-warming of spermatozoa was monitored. Moreover, it was tested whether stabilisation of membrane integrity and motility at low storage temperature by the use of a coldshock protective extender is associated with a stable energy metabolism. Split ejaculates from seven boars were diluted with standard extender BTS and protective extender Androstar® Plus (Minitüb GmbH, Tiefenbach), cooled down to 25, 17, 10 and $5^{\circ} \mathrm{C}$ and stored up to $120 \mathrm{~h}$. After $24 \mathrm{~h}, 72 \mathrm{~h}$ and $120 \mathrm{~h}$ preserved samples were checked for motility (CASA) and integrity of plasma and acrosomal membranes (PI and FITC-PNA/PI staining), MMP (JC1/ PI assay), ATP and energy charge (luciferinluciferase assay). Motility and membrane status were significantly influenced by storage length, storage temperature and extender $(P<0.05)$. Neither ATP levels, nor energy charge or motility differed for samples stored at $17^{\circ} \mathrm{C}$ or $25^{\circ} \mathrm{C}$. Hypothermic storage at $10^{\circ} \mathrm{C}$ and $5^{\circ} \mathrm{C}$, respectively, lead to a storage-length related decrease of both intracellular ATP levels and AEC and to a concomitant appearance of adenine nucleotides in the extender medium. The percentage of live sperm with high MMP decreased with lower storage temperatures $(P<0.05)$. Storage temperature and extender had a significant influence $(\mathrm{P}<0.05)$ on ATP content and energy charge of preserved spermatozoa whereas storage time did not reveal an influence. The energy charge obtained in Androstar Plus samples at $5^{\circ} \mathrm{C}$ and $10^{\circ} \mathrm{C}$ storage was significantly higher than that in samples diluted in BTS, but dropped below 0.6 in both extenders indicating a deficient energy metabolic state. These results indicate a pronounced temperature sensitivity of sperm energy metabolism when sperm are 
exposed to cooling stress. The extent of it can be modified by extender media. Cooling induced rearrangement of membrane lipids increase permeability and leads to a loss of adenine nucleotides alongside with other solutes. Presumably, low motility in chilled boar spermatozoa cannot simply be attributed to a lack of energy substrates but also to irreversible failure in utilization of ATP and disruption of motility regulating cellular processes. Contrary to common expectation, an elevated cell activity during long-term storage at $25^{\circ} \mathrm{C}$ does not lead to a lack of energy and metabolic exhaustion of sperm.

In conclusion, using a revised validated ATP assay protocol novel information on the influence of storage temperature and length on the energy metabolism in liquid preserved boar spermatozoa was obtained. The energy status of spermatozoa is maintained on a high level during long-term storage between 17 and $25^{\circ} \mathrm{C}$ and subsequent thermal stress, and consequently is not limiting cell function. Oxidative phosphorylation in mitochondria is not decisive for the maintenance of energy status and motility of thermically stressed boar spermatozoa after long-term storage in vitro. In spermatozoa exposed to long-term cooling stress at 10 and $5^{\circ} \mathrm{C}$ loss of ATP and energy charge may contribute to irreversible failure of cell function, ultimately leading to reduced fertility. 


\section{Acknowledgement}

First of all I would like to express my gratitude thankfulness to Prof. Dr. Dr. h.c. Wolfgang Holtz and Prof. Dr. Matthias Gaully for accepting me as doctoral candidates at Division of Livestock Production Science, Department of Animal Science, Göttingen University.

I am deeply grateful to Prof. Dr. Dagmar Waberski and Dr. Heiko Henning for giving me honour to do my $\mathrm{PhD}$ research at Reproduction Medical Units of Clinic, University of Veterinary Medicine Hannover (Tiho/ Tierärztliche Hochschule Hannover). I am highly appreciate their excellent supervision, close follow up, guidance, beneficial discussion and unlimited assistance, especially their efforts in thoroughly correcting my thesis.

Furthermore, I am grateful to JProf. Dr. Marion Piechotta and her lab at Clinic for Cattle, University of Veterinary Medicine Hannover for giving me opportunity working in their friendly and supportive laboratory.

Special thanks to the Association for Bioeconomy Research (FBF e.V.,Bonn, Germany) and Lotus- Eramus Mundus Action 2 Project for financial support.

Moreover, I am thankful to Ulrike Wallner, doctoral students and colleagues from Reproduction Medical Units of Clinic for their excellent help in the lab, always friendly and collegiate working atmosphere.

Finally, my deepest appreciation goes to my beloved family specially my children Leon and Noel. 
